\title{
Reorganisation of postural control in spinal cord injured persons
}

Citation for published version (APA):

Seelen, H. A. M. (1997). Reorganisation of postural control in spinal cord injured persons. [Doctoral Thesis, Maastricht University]. Universiteit Maastricht. https://doi.org/10.26481/dis.19971127hs

Document status and date:

Published: 01/01/1997

DOI:

10.26481/dis.19971127hs

Document Version:

Publisher's PDF, also known as Version of record

\section{Please check the document version of this publication:}

- A submitted manuscript is the version of the article upon submission and before peer-review. There can be important differences between the submitted version and the official published version of record.

People interested in the research are advised to contact the author for the final version of the publication, or visit the DOI to the publisher's website.

- The final author version and the galley proof are versions of the publication after peer review.

- The final published version features the final layout of the paper including the volume, issue and page numbers.

Link to publication

\footnotetext{
General rights rights.

- You may freely distribute the URL identifying the publication in the public portal. please follow below link for the End User Agreement:

www.umlib.nl/taverne-license

Take down policy

If you believe that this document breaches copyright please contact us at:

repository@maastrichtuniversity.nl

providing details and we will investigate your claim.
}

Copyright and moral rights for the publications made accessible in the public portal are retained by the authors and/or other copyright owners and it is a condition of accessing publications that users recognise and abide by the legal requirements associated with these

- Users may download and print one copy of any publication from the public portal for the purpose of private study or research.

- You may not further distribute the material or use it for any profit-making activity or commercial gain

If the publication is distributed under the terms of Article $25 \mathrm{fa}$ of the Dutch Copyright Act, indicated by the "Taverne" license above, 


\section{Reorganisation of postural control in spinal cord injured persons}


Seelen, Henricus Alexander Maria /

Reorganisation of postural control in spinal cord injured persons

Copyright (c) 1997 by H.A.M. Seelen

ISBN 90-9011021-6

Cover design: Datawyse Maastricht

Printed by: Datawyse Maastricht / Krips Repro Meppel 


\title{
Reorganisation of postural control in spinal cord injured persons
}

\author{
PROEFSCHRIFT
}

ter verkrijging van de graad van doctor aan de

Universiteit Maastricht, op gezag van de Rector Magnificus, Prof. Mr. M.J. Cohen, volgens het besluit van het College van Decanen, in het openbaar te verdedigen op donderdag 27 november 1997 om 16.00 uur

door

Henricus Alexander Maria Seelen 


\section{Promotores:"}

Prof. dr. A. Huson

Prof. dr. F. Spaans

\section{Co-promotor:}

Dr. J.J.M.E. Adam

\section{Beoordelingscommissie:}

Prof. dr. H. Kuipers (voorzitter)

Prof. dr. Th.W. Mulder (Katholieke Universiteit Nijmegen)

Prof. dr. R.H. Rozendal (Vrije Universiteit Amsterdam)

Prof. dr. J. Troost

Dr. ir. H.C.W. de Vet

Prol. dr. J. Drukker, Dr. J.P.H. Reulen, Drs. C. Pons en Mw. drs. Y.J.M. Potten hebben een belangrijke bijdrage aan de totstandkoming van dit proefschrift geleverd. 
Aan mijn ouders 
Contents 
Chapter 1 General introduction

Introduction $\quad 2$

Spinal cord injury 2

Incidence and prevalence of spinal cord injury 4

Rehabilitation of spinal cord injured patients: A general overview

Scope of this thesis

References

Chapter 2 Control of posture and movement: Literature review and research design

Introduction

Postural control: Definitions

Feedback and feedforward in postural control and movement

Previous postural control research

Postural adjustments during stance

External postural support during sitting $\quad 14$

Control of posture during sitting $\quad 16$

Alternative postural control in SCI subjects $\quad 18$

Biomechanical and neuromuscular considerations $\quad 18$

Motor control considerations 25

Present research $\quad 28$

Research aims and questions addressed 28

Overall research design and instrumentation 28

References

$\begin{array}{lll}\text { Chapter } 3 & \text { Impaired balance control in paraplegic subjects } & 39\end{array}$

Summary $\quad 40$

Introduction $\quad 40$

Methods $\quad 42$

Experiment $1 \quad 42$

Subjects $\quad 42$

Task and apparatus $\quad 43$

Data analysis $\quad 46$

Experiment 2

Subjects $\quad 46$

Task and apparatus $\quad 46$

Data analysis $\quad 48$

Results 51

Experiment 1

Experiment $2 \quad 56$

Experiment 1 and $2 \quad 58$ 
Discussion

References

Chapter 4 Development of new muscle synergies in postural control in spinal cord injured subjects

Summary

Introduction

64

Methods

65

Subjects

65

Task and apparatus

68

Data analysis

Results

Error analysis

Postural changes

Muscle activity

Within-group EMG results concerning graded $\mathrm{CP}$

displacements per session

Within-group EMG changes across the rehabilitation phase

Between-group differences across the rehabilitation phase

Discussion

References

Chapter 5 Motor preparation in postural control in seated spinal cord injured people

Summary

Introduction

Methods

86

Experiment 1

86

Subjects

86

Task and apparatus

88

Data analysis

89

Experiment 2

89

Subjects

89

Task and apparatus

89

Data analysis

Results

Experiment 1

Experiment 2

94

Discussion

References 
Chapter 6 Postural motor programming in paraplegic patients during rehabilitation

Summary

104

Introduction

104

Methods

106

Subjects

106

Experiment 1: task and apparatus 108

Experiment 2: task and apparatus

Data analysis of experiment 1 and 2

Results

Experiment 1

Error analysis

RT performance

Experiment 2

Error analysis

Overall RT performance

Precue benefit

Balance perturbation influence

Discussion

References

\section{Chapter 7 General discussion}

A concept of alternative postural control

Efficiency of alternative postural muscle use

Regaining of postural control during rehabilitation

Post clinical period

Some methodological issues

EMG normalisation

Average EMG values and muscle synergies

General conclusions

Future directions

References

Summary

Samenvatting

Doel en vraagstelling

Gehanteerd werkplan en onderzoeksdesign

Resultaten en discussie

Transwersale onderzoeksfase

Longitudinale onderzoeksfase 
List of abbreviations

Dankwoord

About the author 
1

General introduction 


\section{Introduction}

One of the more elementary sensorimotor functions that is lost in spinal cord injured ( $\mathrm{SCI}$ ) subjects concerns the maintenance of posture and balance. In this thesis postural control in subjects suffering from a complete thoracic SCI has been investigated. Experimental evidence from several research domains is combined into a theoretical framework of alternative control of posture in SCI subjects.

\section{Spinal cord injury}

An acute and complete severing of the spinal cord leads to instantaneous loss of voluntary control of movement, loss of sensation and disregulation of the viscera regulated by the autonomous nervous system in those parts that are innervated from spinal segments caudal to the lesion site. Among the most frequent causes for SCI are (a) acute spinal traumata, often involving fractures of the vertebrae after car and motor accidents, diving accidents, sports accidents or falls and (b) non-traumatic processes like thrombosis and embolisms, spinal haemorrhage, infections, local carcinogenic growths, spina bifida or spinal degeneration. The loss of voluntary control of movement is caused by the disruption of the descending tracts like the lateral and ventral corticospinal tracts, the pontine and medullary reticulospinal tracts, the medial and lateral vestibulospinal tracts and the rubrospinal tract. Disruption of the ascending spinal tracts like the anterior and lateral spinothalamic tracts, the gracile and cuneate fascicles and the spinocerebellar tract leads to loss of sensation and proprioception.

In an initial, post-traumatic phase of spinal shock all spinal reflexes are absent. After some time these reflexes gradually return in different intensities. Spasticity may develop as a consequence of disinhibition of spinal reflex activity. This disinhibition is caused by the interruption of the cerebrospinal pathways. The extent of the sensorimotor function loss in SCI patients depends on the neurological lesion level and the completeness of the lesion. The neurological lesion level associated with loss of voluntary muscle function is clinically assessed through the testing of so-called 'key muscles', each of which is clinically associated with a specific myelum segment [3]. An overview of these key muscles is given in table 1.1. The Frankel scale, a five point, nominal scale presented in table 1.2 , is commonly used in Anglo-Saxon literature to quantify the paralysis in SCI patients. A scale that is frequently used to assess muscle weakness is the MRC scale [11, 12] presented in table 1.3 . 
Table 1.1. Key muscles used in clinical practice to assess the neurologion level of motor function loss in spinal cord injured subjects:
Myelum segment
Key muscle
Cl-3
neck muscles, m. trapezius pars descendens
$\mathrm{CA}$ diaphragm, m. deltoideus
$\mathrm{C5}$ m. biceps brachii
C6 mm. extensores carpi radialis
C7
m. triceps brachii
$\mathrm{C} 8$
$\mathrm{m}$. flexor digitorum
$\mathrm{T} 1$ intrinsic hand muscles
$\mathrm{T} 2-\mathrm{T} 12$ intercostal muscles
T7-LA 1 abdominal muscles
L2
m. iliopsoas, adductor muscles
L3
m. quadriceps femoris
L4
$m$. tibialis anterior
L5
m. tibialis posterior, $m$. extensor hallucis longus
SI
$m$. gastrocnemicus, $m$. soleus, $m$. flexor hallucis
$\mathrm{S} 2$
$m$. flexor digitorum
$\mathrm{S} 2-\mathrm{S} 4$
bladder and bowel

(Adapted from Beckers et al., 1992.)

Table 1.2. Frankel scale for the classification of paralysis levels in spinal cord injury.
A Complete:
No motor activity or sensation below the segmental level
B. Sensory only: indicated.
C Motor useless: There is some motor activity present below the lesion
Some sensation is present below the segmental level indicated, but no motor activity is present. level, but it is of no practical use to the patient.
D Motor useful: There is useful motor activity present below the lesion level.
E Recovery: The patient is free of neurologic symptoms. He has no muscle weakness or sensory function loss. 
Table 1.3. MRC scale for the evaluation of muscle strength.

$\begin{array}{ll}\text { Score } & \text { Muscle strength } \\ 1 & \text { A trace of contraction is discernible. } \\ 2 & \text { Active movement with gravity eliminated is possible. } \\ 3 & \text { Active movement against gravity is possible. } \\ 4 & \text { Active movement against gravity and resistance is possible. } \\ 5 & \text { Normal strength. }\end{array}$

(Adapted from Olsen, 1990.)

Sensory loss in SCI subjects is classified according to the dermatomes [14]. The International Standards for Neurological and Functional Classification of Spinal Cord Injury (ISCSCI-92), which was revised by the American Spinal Injury Association (ASIA) in 1992, is a more recent set of standard methods of assessing both neurological and functional status of a patient with SCI [2].

The disruption of autonomous regulation in SCI may cause circulatory control problems, thermoregulation problems and disturb the redistribution of blood during exercise causing changes in physiological responses to exercise [10]. Also bladder and bowel control problems occur [16]. Among the (secondary) physical problems that may accompany SCI are pressure ulcers $[8,9]$, contractures [3], heterotopic ossifications [5, 17], cardiovascular disease [10] and pulmonary problems. Frequently pain in $\mathrm{SCI}$ is reported. Often hyperalgesia is present in the dermatomes at the same level as the spinal cord lesion [7].

\section{Incidence and prevalence of spinal cord injury}

Accurate incidence figures on $\mathrm{SCI}$ in the Netherlands are not available. In a recent study, based on data concerning admission of SCI patients to a rehabilitation centre, Schönherr and co-workers [15] estimated the incidence rate of SCI to be 16 per million per year. It should be noted, however, that not all $\mathrm{SCl}$ patients are referred to a rehabilitation clinic after hospitalisation [13]. Post [13] reports an estimated incidence of SCI in the Netherlands of 24.2 per million, also taking into account those $\mathrm{SCI}$ patients that are not referred to a rehabilitation clinic. Incidence figures on SCI may differ considerably from country to country. For example, a recent American Healthcare Cost and Utilization Project (HCUP-3) by the Agency for Health Care Policy and Research of the US Department of Health and Human Services [1], presenting more accurate estimates than the studies in the Dutch community, showed that 11,443 patients were principally diagnosed with spinal cord injury in the USA in 1992. Combining these data with the (extrapolated) data 
on the US population in 1992 of the US Department of Commerce, Department of the Census, an incidence figure of 45.0 per million for 1992 can be calculated.

The SCI population consists, for an important part, of young people. According to Vorsteveld [18] and Bedbrook [4] the life expectancy of a paraplegic young adult is only marginally reduced, compared to the average of age-matched, non-sensorimotor impaired persons, whereas the life expectancy of a tetraplegic patient is reduced 5 to 10 years. Earlier estimates by DeVito and co-workers [6] reported a reduction in life expectancy, for example, of a 20 to 30 years old complete paraplegic male to be approximately 15 years and approximately 26 years for a complete tetraplegic, young male. Exact prevalence figures of $\mathrm{SCl}$ in the Netherlands are not available. The prevalence of SCl subjects in the USA is estimated at approximately 768.3 per million, based on data from 1994 (Source: (a) National Institute of Neurological Disorders and Stroke; (b) US Department of Commerce, Department of the Census).

\section{Rehabilitation of spinal cord injured patients: A general overview}

The rehabilitation of the SCI patient involves a multidisciplinary approach. Next to the rehabilitation physician a SCI rehabilitation team consists of one or more physiotherapists, occupational therapists, nursing staff, social workers and psychologists. In the rehabilitation process of a SCI patient generally several phases can be discerned: a stabilisation phase, a primary mobilisation phase, a functional training phase and a social reintegration phase. Both rehabilitation approach and functional outcome depend on the level of the SCI, the subsequent function loss and residual capacities/potential of a patient. Since this thesis concerns research in paraplegic patients, an overview of the training aspects of these patients will be given.

In the initial post-injury phase rehabilitation treatment is focused on stabilisation of the condition of the SCI patient and on prevention of complications. In this initial rehabilitation phase the fixation and stabilisation of the fractured spine, the management of autonomous functions, the prevention of complications regarding ventilation, bladder and bowel function and the prevention of pressure ulcers and contractures take a high priority. Pyschosocial councelling is started. The initial rehabilitation treatment is essential for the outcome of the subsequent rehabilitation phases.

After the aforementioned phase, when the spine is stabilised, spinal loading is gradually increased as part of a primary mobilisation phase. The speed with which verticalisation of the patient can take place also depends on (a) the length of time the patient has been in a prone or supine lying position and (b) the state of the autonomous function regulation. Orthostatic hypotension may occur in SCI patients especially in the early post-traumatic phases. Depending on the cause of the injury paraplegic patients may wear a spinal brace to stabilise the spine during the early 
rehabilitation period. Physical therapy encompasses training of (joint) mobility and muscle strength as prerequistes for functional training. Throughout the whole rehabilitation period efforts are made to reduce spasticity.

The main goal in the functional training phase is for the patient to try to regain independence in activities of daily living (ADL). At the start of this phase attention is focused on regaining mobility in bed, rolling, control over sitting balance and posture. A wheelchair, adapted to fit the needs and anthropometry of the patient, is provided. Transfers from bed to (wheel-) chair and vice-versa, from chair to chair, from chair to lloor and back, etc are trained. Meanwhile, during this phase separate mobility training and muscle strength exercise continue. Items of self-care, like personal hygiene, bowel and bladder care, mobility and dressing are also addressed. Wheelchair use is trained in a wide variety of environmental circumstances, both indoor and outdoor. At the level of physical fitness the functional ADL-training also improves mobility, muscle strength, co-ordination and physical (and psychological) endurance.

Towards the end of the clinical rehabilitation additional attention is focused on the pexiod after clinical discharge. Preparations are made for social reintegration, adaptations in the domestic environment, possible re-entry in a professional career, specialised transport facilities, additional medical and non-medical care etc.

An in-depth overview of the rehabilitation of spinal cord injured subjects is given by Beckers et al. [3], Bedbrook [4] and Somers [16].

\section{Scope of this thesis}

Although the importance of an adequate control of sitting posture in SCI subjects is generally acknowledged in rehabilitation, only little systematic research has been performed to elucidate the ways in which control of sitting posture adapts to the altered sensorimotor conditions in SCI. Aim of this thesis has been to investigate reorganisation of postural control in SCI patients during and after their clinical rehabilitation. Results from this study may serve as a basis for therapy efficacy research.

Most of the chapters of this thesis are based on experimental work which has been reported in a number of papers. In chapter 2 an outline of previous research concerning postural control is presented, which may serve as an overture in answering questions related to impaired postural control in sitting SCI subjects. Also, phenomena of alternative postural control in SCI subjects are discussed. Several issues in the field of biomechanics, netrophysiology and motor control, addressed in the current line of research, are presented. Finally, the main aim of the present research, the overall research design and the methods used in the investigation of postural control in sitting SCI subjects are addressed.

In chapter 3 a kinematic concept of alternative postural muscle use in subjects suffering from a complete thoracic SCI is investigated both at 
neuromuscular level and biomechanical level. The involvement of both postural and phasic muscles in the control of sitting posture during standardised upper extremity task performance is investigated experimentally. A comparison is made between groups of low and high thoracic SCI subjects and non-SCl subjects. All SCI subjects participating in the experiments reported in chapter 3 had completed their clinical rehabilitation program at least one year. They were thought to have acquired a new and stable pattern of postural muscle use. Chapter 3 also reports the results of an additional experiment in which pelvic movement in non-SCI subjects has been investigated.

In chapter 4 a longitudinal study aimed at investigating the development of new patterns of postural muscle use and sitting balance control in patients with a complete thoracic SCI during their active clinical rehabilitation program is reported. Changes in muscle use and postural performance during this period are described in low and high thoracic SCI patients.

In chapter 5 motor programming in sitting balance control is investigated in three groups, i.e. in high thoracic SCI, low thoracic SCI and non-SCI subjects. Postural control in SCI subjects implies the presence of motor programs that are adjusted to the new physical circumstances. The effects of the level of sensorimotor impairment on the ability to program movements which involve a high amount of balance control are studied using a precue choice reaction time (RT) paradigm.

In chapter 6 the time course of the re-organisation of postural motor programming in low and high thoracic SCI patients during their clinical rehabilitation is investigated. RT performance in conditions in which postural perturbation was immanent, is reported.

In the final chapter the integration of the findings of all studies is presented and is discussed against the background of the proposed concept of alternative postural control in SCI subjects. Some methodological issues are discussed and several recommendations for future research, both basic and applied, are put forward.

\section{References}

1. Agency for Health Care Policy and Research of the US Department of Health and Human Services: Healthcare Costs and Utilization Project 1988-1994 (HCUP-3): pocket guides national statistics by principle diagnosis HCUP-3: Nationwide Inpatient Sample for 1992 Hospital Inpatient Stays, 1992.

2. American Spinal Injury Association (ASIA): Reference manual for the international standards for neurological and functional classification of spinal cord injury. American Spinal Cord Injury Association \ Uniform Data System for Medical Rehabilitation, Chicago, 1994.

3. Beckers DML, Buck MJL Pons C: /The Rehabilitation of spinal cord injured patients/. De revalidatie van dwarsiaesieparienten. In Dutch. Uitgeversmaatschappij de Tijdstroom, Lochem, 1992. 
4. Bedbrook GM: The care and management of spinal cord injuries. Springer Veriag, New York, 1981 .

5. Colachis SC. Clinchot DM: The association between deep venous thrombosis and heterotopic ossification in patients with acute traumatic spinal cord injury. Paraplegia $31.507-512,1993$.

6. DeVito MJ, Fne PR, Maertz HM et al.: Prevalence of spinal cord injury: A reestimation employing life table techniques. Arch Neurol 37:707-708, 1980.

7. Donovan WH, Dimitrijevic MR, Dahm $L$ et al.: Neurophysiologic approaches to chronic pain following spinal cord injury. Paraplegia 20:135-146, 1982.

8. Ferguson-Pell MW, Hurwitz DE, Burn TG. Masiello $R$ : Remote monitoring of wheelchair sitting behaviour. In: Pressure sores: clinical practice and scientific approach, ed by Bader DL, MacMillan Press, London, pp 261-273, 1990.

9. Goossens RHM: Biomechanics of body support: A study of load distribution, shear, decubitus risk and form of the spine. Thesis. Copy Print 2000, Enschede, 1994.

10. Hopman MTE: Paraplegia and exercise. A study of cardiowascular behaviour during arm exercise in persons with paraplegia. Thesis. University of Nijmegen, Nijmegen, 1993.

II. Medical Research Council (MRC): Aids to the examination of the peripheral nerwous system. Her Majesty's Stationary Office, London, 1976.

12. Olsen TS: Arm and leg paresis as outcome predictors in stroke rehabilitation. Stroke 21(2):247.251, 1990 .

13. Post MWM: Living with spinal cord injury. Thesis. Drukkerij Elinkwijk BV, Utrecht, pp $1-117,1997$.

14. Rowland LP: Clinical syndromes of the spinal cord and brain stem. In: Principles of neural science, ed by Kandel ER, Schwartz JH, Jessell TM, Prentice-Hall International Inc., London, pp $711-730,1997$.

15. Schönherr MC, Groothoff JW, Mulder GA, Eisma WH: Rehabilitation of patients with spinal cord lesions in the Netherlands: an epidemiological study. Spinal Cord 34:679-683, 1996.

16. Somers MF: Spinal cord injury. Functional rehabilitation. Appleton \& Lange, Norwalk, pp 299-312, 1992.

17. Stauffer ES: The rehabilitation of the patient with neurologic dysfunction as a result of cervical trauma. In: The adult spine: principles and practice, ed by Frymoyer, Raven Press Lid, New York, pp 1131-1141, 1991.

18. Vorsteveld JHC: [Spinal Cord Injury. In: Basic Course in Rehabilitation Medicine "Problems in Spinal Cord Injury"] Het dwarslaesiebeeld. In: Basiscursus Revalidatiegeneeskunde "Dwarstaesie problematiek", In Dutch, ed by Vorsteveld JHC, Het Roessingh, Uniwarsiteit Twente, Enschede, Chapter 1, 1995. 


\section{2}

\section{Control of posture and movement Literature review and present research}




\section{Introduction}

\section{Postural control: Definitions}

During activities of daily living posture needs to be adjusted constantly in order to meet the requirements of the ongoing movements and to prevent loss of balance or equilibrium. In the field of mechanics equilibrium is defined as a state in which the resultant of all forces $(\Sigma F)$ and the resultant of all moments ( $L M)$ acting upon a system are zero. In this approach equilibrium is viewed as being static. In biological systems like the human sensorimotor system, however, the dynamic nature of equilibrium is apparent, necessitating a form of continuous control. The purpose of control mechanisms in general is (a) to maintain stability in a system by either restoring a disturbed equilibrium to its previous state, or modify the system state to attain a new equilibrium, and (b) to facilitate non-equilibrious, transient actions or movements when going from one state of equilibrium to a new one [71]. Sensorybased motor co-ordination serves the purpose of (a) stabilising the whole body with respect to external forces like gravity, (b) stabilising body segments adjacent to each other and (c) facilitate (voluntary) movement. This triple function expresses the complexity that is inherent in motor co-ordination processes. It is also an indication of the dynamic, time-dependent and task-related nature of posture. Postural control refers to the ability of a person to maintain both equilibrium and posture against perturbing internal and external influences. Massion and co-workers $[89,90]$, in line with many other authors $[14,84,85]$, define equilibrium as "the stabilisation of the body as a whole with respect to the supporting surfaces" which, in static conditions, "occurs only when the projection on the ground of the centre of gravity (CG) is placed within the supporting area (...)". Posture, on the other hand, is defined as the position of body segments relative to each other at a given time [51, 89]. Both the maintenance of equilibrium and posture are dynamic processes, which should be evaluated in the context of the momentary tasks that are required.

Varying definitions of the term 'perturbation' (of posture and equilibrium) exist in literature. Some authors exclusively use the term 'perturbation' in conjunction with externally induced changes in equilibrium and posture $[48,64,85]$. Others use the term "perturbation' also to indicate changes in equilibrium and posture caused by internal factors like arm movements $[28,30,31,41,42,89]$. Perturbation can also be interpreted as being associated with a loss of balance or equilibrium rather than a change in the actual equilibrious state of the sensorimotor system. In an attempt to avoid semantic ambiguity, in the present thesis 'perturbation' is used as referring to both internal and external actions causing changes in the momentary state of equilibrium and posture which do not necessarily lead to loss of balance. 


\section{Feedback and feedforward in postural control and movement}

Control of posture relies on two types of mechanisms. Feedback mechanisms elicit actions in response to disturbances of posture, whereas feedforward mechanisms elicit anticipatory actions prior to postural disturbances.

Three types of sensory feedback govern the co-ordination of postural. responses: (a) vestibular, (b) somatosensory and (c) visual feedback. The utriculus and sacculus provide information on the absolute position of the head in space as well as linear acceleration of the head in any direction. The semicircular canals provide information on the rotational acceleration of the head [74]. Somatosensory information consists of exterocepsis, i.e. cutaneous tactile information, thermal information and pain sensation, and proprioceptive information from muscle spindles, Golgi tendon organs and several types of joint receptors. Vestibular reflexes and proprioceptive neck reflexes are involved in positioning the head relative to the force of gravity and the alignment of the rest of the body. Vestibular input is mediated through the vestibular nuclei and the medial and lateral vestibulospinal tracts onto the motor neurons of the axial and limb muscles. Vestibular input is also directed towards the reticular formation which connects to the spinal motor neurons of the axial back muscles through the pontine and medullary reticulospinal tracts [52]. The influence of this input on activation of postural muscle responses during stance has been demonstrated by Keshner et al. $[77,78]$. At the spinal level myotatic reflexes are involved in postural control by keeping the length of (postural) muscles within narrow margins. The visual system provides information about the environment, but also about the orientation of the body. The optic flow field specifies the movement of the head relative to the environment $[80,81]$.

Several studies have provided evidence for the assumption that the position of the $\mathrm{CG}$ relative to the ground acts as a reference for equilibrium control in static and in dynamic conditions for example during postural perturbation $[23,28,38,39,54$, $67,90,144]$. Two modes of detection of changes in the position of the CG are proposed by Massion. The first mode of equilibrium control is associated with relatively slow continuous feedback loops based on proprioceptive, visual and labyrinthine information. The second mode is associated with a limited number of specific, network based postural muscle patterns governed by cliscontinuous feedback loops acting on faster, phasic perturbations demanding faster muscular responses. The latter was also postulated by Nashner and co-workers $[102,104]$. Other experiments, however, have shown that one can learn to utilise references different from the $\mathrm{CG}$. Pozzo et al. [114], for example, suggested that head stabilisation could act as a reference frame for balance control during locomotion. Forssberg et al. [48] provided evidence for the assumption that somatosensory signals induced by rotation of the pelvis during sitting are essential triggers for central pattern generatiors eliciting specific postural adjustments.

One of the problems of studying postural control in complex, real world conditions during movement, is the fact that the movement itself also causes alterations in posture and equilibrium thus interacting with the postural control 
phenomena studied. Anticipatory postural adjustments (APA), i.e. postural adaptations prior to disruption or perturbation of current posture and equilibrium by focal movement, meant to prevent loss of balance, are based on feedforward. The main focus of APA research is on stance. Some of these investigations will be discussed in the next section.

\section{Previous postural control research}

\section{Postural adjustments during stance}

Control of posture is essential for the execution of activities of daily living, skilled movement and task performance in general. In the past decades research concerning postural control, mainly focused on upright stance, has been carried out extensively in a wide variety of (experimental) conditions. Especially feedforward based anticipatory actions to counteract oncoming equilibrium perturbation have interested scientists studying biomechanical and neuromuscular phenomena in normal posture and equilibrium control and pathological mechanisms in balance maintenance. Belenkii et al. [17] were among the first to investigate phenomena of movement anticipation. Using surface electromyography (EMG), they focused on the relationship between latency periods between activity of the deltoid muscle during volluntary arm movement and the activation of trunk and leg muscles during stance. They found quite stable patterns of trunk and leg muscle activation prior to voluntary arm movements which they attributed to (anticipatory) equilibrium control. Bouisset and colleagues, investigating the association between posture and equilibrium on the one hand and motor pre-programming phenomena associated with APA on the other hand, showed that postural activity is synergetically organised $[28,30,42,107]$ as was hypothesised by Nashner [102, 103]. In line with Friedli et al. [49, 50], they argued that APA's oppose or compensate perturbations of the equilibrium elicited by voluntary movements prior to these perturbations and that APA's are part of a central motor program [28-30].

A frequently cited experiment in APA research has been performed by Brown and Frank [31], who investigated temporal activation of postural adjustments in standing subjects. Their aim was to explore whether APA"s and focal, task-related movements are controlled either by one or by several different processes of preparation. They measured reaction time (RT) performance as well as postural and focal muscle activation during manipulation of a mechanical device, i.e. a stiff handle. In their two-choice RT experiment precues informing the participant of different probabilities (true/not true) of actions were given informing the subject on the nature of one of two antagonistic movements, i.e. push or pull. Both movements would necessitate different kinds of preparation during stance. It was expected that precues with high probabilities would lead to a higher degree of preparation and subsequently to faster movement responses which should be detected in terms of EMG onsets. Results revealed that, although all (six) subjects showed postural muscle activation 
prior to onset of focal muscle activity, only three (out of six) subjects showed an increase in reaction times as response probability decreased. These three subjects were all generally slow responders. Latency measures were not influenced by precue information in the other subjects who were generally responding fast. The authors reasoned that subjects in both groups adopted different movement strategies, whereby the fast movers chose to ignore precue information. Furthermore, they concluded that APA and activation of focal muscles seem to be triggered by separate motor commands. However, some methodological flaws can be detected in the study of Brown and Frank. They used a rather small group of participants $(n=6)$ which they sub-divided into two groups of three subjects, depending on the speed of response subjects displayed. This small sample size is too low for the parametrical statistical tests they used. Secondly, their determination of EMG onset seerns rather vague. Also the influence of the signal filters on the postural-focal latency period was not addressed by the authors.

Horak et al. [64, 65] and MacPherson et al. [83] found evidence for the assumption that a limited set of central programs govern muscle activation strategies anticipatory to postural perturbation during stance. These strategies are influenced by momentary support-surface conditions, initial stance position and prior experience. Their concept of central programs embraces the need to reduce the degrees of freedom in postural control and additionally offers an explanation for the flexibility of the (anticipatory) postural control mechanism. Their concept is in opposition to the theory Nashner et al. [102, 103] proposed earlier, postulating the existence of a fixed or limited repertoire of postural muscle synergies.

Horak and co-workers [66] studied possible redundancy of feedback information in postural control in patients with pathological absence of either vestibular or somatosensory information. They found that lack of each of these types of information gave rise to different environment-dependent postural movement strategies during stance. Somatosensory loss led to an increased hip strategy for postural correction, in contrast to vestibular loss which led to a reduced hip strategy and a normal ankle strategy during stance. Manchester et al. [86] investigated the influence of deterioration of vision, vestibular functions and somatosensory information integration in postural control in elderly. They found that unlike in young adults, balance control was less in conditions of reduced vision and somatosensation in elderly. Wolfson et al. [139] found similar evidence linking deterioration of sensory feedback in elderly to reduced postural stability capacity. In contrast, Teasdale et al. [135] found no unequivocal evidence for such age related changes in postural sway in conditions of reduced vision. When, additionally to the reduction of vision, somatosensory input was manipulated by changing the solidity of the support surface, postural sway increased more in elderly than in young adults. Dietz [37] gave an extensive literature review on the involvement of the proprioceptive, vestibular and visual system in postural control during stance and in locomotion. A review of postural dynamics and balance control assessment during stance is given by Johansson et al. [71], Oddsson [110] and Winter et al. [138]. 


\section{External postural support during sitting}

Many studies involving sitting posture typically focus on ergonomics and seating, i.e. the adaptation of chair support interrelating with (a) anthropometric measures [69], (b) (bio)mechanical stress and stability [4-10, 19, 20, 33, 92, 123, 126, $127]$ (c) pressure distribution and shear forces $[2,15,43,47,55,56,63,82,112,141]$, (d) neuromuscular activity $[3-7,9,10,12,13,68,70,99,111,132]$, (e) work related conditions $[35,46,57,58,124,125,137]$, (f) sitting comfort $[34,60]$ or a combination of these areas $[123,131,142]$.

Many authors consider the extensive work of Andersson, Örtengren and coworkers $[4-7,9,10,13]$ as a classical example of sitting posture research. Their work has resulted in a large spin-off in kinesiological, ergonomical and paramedical research and literature. Andersson's group investigated paravertebral erector spinae activity and psoas muscle activity in both healthy subjects $[4-7,9,10]$ and paraplegic patients [6] during sitting in a variety of seating conditions. In their studies they used both surface EMG and needle EMG in conjunction with lumbar intervertebral disc pressure monitoring. The influence of different means of body support during supported sitting was compared with several standing positions and unsupported sitting conditions, among which were relaxed sitting with posterior pelvic tilt and straight sitting with anterior pelvic tilt and lumbar lordlosis. In their research they used different chairs, i.e. an office chair, a wheelchair, a car seat and an experimental chair. Their results showed a decrease in back muscle activity in healthy subjects with increasing backrest inclination, whereas alterations in lumbar support, thoracic support, seat inclination and seat height led only to minor changes in back muscle activity. In unsupported sitting highest back muscle activity was recorded in the thoracic region, whereas in the lumbar and cervical regions EMG activity was less. From their work they concluded that reproducibility of posture in unsupported sitting and standing was rather low. This was in contrast to supported sitting when a subject was seated in an experimental chair which could be configured in terms of sitting height, seat and backrest inclination and position of lumbar and thoracic support. EMG activity was found to be very much the same in all the different muscle regions of the back muscles over all supported sitting positions. In both supported and unsupported sitting conditions the subject's arms were kept hanging relaxed. When comparing erector spinae activity in the non-spinal cord injured subjects and the two (!) spinal cord injured ( $\mathrm{SCl}$ ) subjects, with a complete traumatic lesion of the spinal cord at level T12, during task performance while sitting in a wheelchair, they found only minor differences between the subjects [6].

Bendix investigated different chair concepts by manipulating seat inclination $[19,20]$ and seat height $[18,21]$. They showed that the lumbar angle increased when the seat was forward inclined. As to muscle activity of the erector spinae they found no significant differences between either the various forward inclinations of the seat or the seat heights used in their experiments. The influence of lumbar support in car seats on paraspinal muscle strain and possible causes for low back pain was 
investigated in real-world conditions by Hosea et al. [68], thereby extending the experiment of Andersson and colleagues [10]. Johanson [70] investigated myoelectric activity of the oblique abdominal muscles, the lumbar and thoracic erector spinae and also anteroposterior pelvic tilt in several supported and unsupported sitting positions. Also sitting balance was manipulated mechanically using a tiltable board on which the subjects sat. She found specific muscle activation patterns depending on the position of the pelvis, in agreement with findings of Andersson, showing the importance of pelvic movement in so-called "functional sitting".

Nwaobi and co-workers $[108,109]$ investigated whether tonic lumbar erector spinae muscle activity in spastic cerebral palsy children changed as a function of seat adaptation. One aim of their work was to identify a chair configuration in which activity of the erector spinae (ES) muscle would be low in these children. It was argued that position of the head, neck and body play an important role in controlling extensor muscle activity. From their experimental work they concluded that tonic activity of the iliocostalis lumborum muscle was higher in cerebral palsy patients when the whole chair was inclined $30^{\circ}$ as opposed to a $0^{\circ}$ inclination position. Similar to the work of Nwaobi, the research performed by Myhr [99] in part dealt with the identification of seating parameters that influence functional sitting in children with cerebral palsy. She found that head control and control of posture in cerebral palsy children was enhanced and pathological movement was reduced when the projection of the CG of the upper body was anterior to the ischial tuberosities. Furthermore, she developed and methodologically tested clinically applicable means, like for example the Sitting Assessment Scale (SAS), to evaluate postural control and functional performance in different sitting positions in children with cerebral palsy. The SAS is a four-point nominal rating scale with which head control, foot control, arm and hand control can be rated in various sitting positions. The rating is done by an observer. The findings of Nwaobi and Myhr are in contrast to the results Andersson and co-workers [4] reported in healthy subjects, whereby both seat and backrest inclination resulted in a reduction of back muscle activity.

Schoberth [123] also stressed what he called "dynamic sitting". He extensively described various sitting postures from an anatomical and biomechanical perspective, as well as possible pathology related to sitting. Dynamic sitting is referred to as the continuous positional changes during sitting. It expresses both the functional characteristic of sitting, i.e. the interaction between sitting posture and (daily) task performance, as well as the time related aspect of sitting, i.e. the postural changes over time. According to Schoberth these changes are associated with pressure (re-) distribution in time, prevention of continuous obstruction of local tissue perfusion, prevention of localised muscle fatigue and pain caused by persisting static strain and also with vigilance strategies during monotonous task performance. Chaffin and Andersson more recently gave an in-depth overview of research literature on biomechanical aspects of sitting and other work related postures [33]. 


\section{Control of posture during sitting}

In contrast to the aforementioned investigations in which the main research interest was focused on chair manipulation, research concerning the pathophysiological factors limiting postural control during sitting, and more specifically phenomena of (partial) restoration and reorganisation of postural control in patients suffering from central nervous deficits like $\mathrm{SCI}$ and stroke, has been carried out less frequently. Generally, two different research domains can be identified. The first domain encompasses the clinical assessment of functional therapy outcome in patients. The second domain addresses the more basic biomechanical, neurophysiological and motor control mechanisms that govern (impaired) postural control during sitting.

An extensive literature review revealed a lack of means to objectively quantify sitting posture and (impaired) postural control. Some of the clinically used assessment scales feature small subsections in which (sitting) posture is briefly addressed. Sandin and Smith [120] showed that the functional rehabilitation outcome, measured using the Barthel Index, in stroke patients with initially good sitting balance was better than in stroke patients with initially poorer sitting balance control. Nichols et al. [106] evaluated the reliability of sitting balance measures collected during force platform use in healthy subjects and in hemiparetic post-stroke patients. In a longitudinal substudy they also investigated whether force platform data could describe changes in sitting balance performance in hemiparetic patients. They compared these data with functional outcome parameters of the Functional Independence Measure (FIM). Testretest reliability was found to be very good, whereby intraclass correlation coefficient (ICC) values ranged from 0.86 for symmelrical sitting to 0.96 for leaning forward, Whereas all FIM scores indicated a change in functional status of the hemiparetic patients, the force platform data only showed a significant change over time for the forward lean condition.

Concerning the more basic postural research domain, Moore and co-workers $[95,96]$ investigated the possible occurrence of anticipatory postural adjustments (APA) prior to reaching movements during sitting in healthy subjects. They found no unequivocal evidence for APA during their experiments, in contrast to the many APA studies carried out in standing subjects as reported in the literature. The relatively large base of support, which enhances stabillity, seems to reduce the necessity for APA during sitting. Forssberg and Hirschfeld [48] investigated muscle activation patterns and kinematics during several forms of external perturbation, i.e. forward translation or legs-up rotation in sitting healthy adults. They argued that the postural responses they observed during sitting were mainly triggered by somatosensory signals associated with backward pelvic rotation rather than vestibular information, although some smaller differences in muscle responses could have been associated with information from the head and body parts other than the pelvis. Do and co-workers [41] showed that in paraplegics upper extremity task performance was less than in non-SCI subjects. Mean velocity of the voluntary movement was lower in SCI subjects, resulting in less postural disturbance and fewer postural adjustments as 
indicated by their force plate and surface EMG data. Muscle activity in the residual muscles of the trunk and the shoulder girdle differed both in temporal aspects as well as in amplitude as opposed to non-SCI subjects. The authors concluded that paraplegics adopt alternative postural strategies to counteract balance perturbation during task execution. However, they performed their investigation only in a very select group of SCI subjects, i.e. subjects with a complete $\mathrm{T} 4$ lesion, reducing the possibility to generalise their findings towards the overall paraplegic population. Another matter of discussion regarding their work is the fact that, analogous to the experiments of Andersson et al. [5], the participants were asked to shift a weight with their right hand, thus combining postural and strenuous focal muscle activity. This unilateral weight shifting most certainly will have caused asymmetrical muscle activation and asymmetrical loading of the spine, as was reported by Andersson. Both aspects make the interpretation of the EMG data with respect to postural control strategies adopted by the participants more difficult.

From clinical experience it has been known that (high thoracic) SCI subjects try to compensate the loss of postural muscle activity by using non-postural muscles. Some of these findings have been confirmed by Seelen and Vuuman [128] who recorded surface EMG of the latissimus dorsi (LD) and the ascending part of the trapezius (TPA) during systematic perturbation of sitting posture in subjects suffering from a complete thoracic SCI (T2-T12) as well as a matched group of non-SCI subjects, using submaximal active reaching movements. Activity patterns of these muscles differed significantly both in time and in magnitude between SCI and nonSCI participants. These findings both corroborated conclusions drawn by Do, Bouisset and Moynot [41] and generalised their findings to the larger population of SCI subjects with a lesion between level T2 and T12. This alternative postural muscle use in SCI subjects seems to be in contrast to general textbook descriptions on the function of specific muscles in healthy subjects, whereby the LD is used in endorotation, retroflection and adduction of the humerus and both retraction and depression of the shoulder. The TPA is associated with retraction, depression and lateral rotation of the scapula.

Additionally to the biomechanical and neuromuscular findings Seelen and Vuurman [128] addressed the issue of possible impaired central motor programming. Results from their experiments revealed that $\mathrm{SCl}$ subjects who had completed rehabilitation reacted slower both in general conditions as well as in more specific conditions where precued movement information regarding reaching direction was given. It was argued that both motor programming and program loading concerning upper extremity reaching movements may have been impaired due to the discrepancies between the required (compensatory) motor control parameters and the impaired postural motor system. A point to be made, however, is that in these experiments they did not further stratify their thoracic SCI group into subgroups of different levels of SCI. Notwithstanding this (relative) SCI group heterogeneity concerning sensorimotor impairments, clear differences were found between the experimental groups of SCI and non-SCI subjects, regarding central motor 
programming and postural and equilibrium control reflected in different patterns of muscle involvement.

\section{Alternative postural control in SCI subjects}

Although impaired sitting posture can be assisted more easily using external devices than e.g. stance and gait, patients with a $\mathrm{SCI}$ in the low cervical to lumbar region are still extensively trained in maintaining sitting balance as prerequisite for their training of $\mathrm{ADL}$ during rehabilitation [16]. Although some restoration of lost functions may occur, physical training during rehabilitation is mainly focused on compensation of function loss, using residual functions. This seemingly obvious and simple rehabilitation approach, however, holds a broad complex of adaptive biomechanical and neurophysiological mechanisms of which our understanding is yet limited. It leads to a wide variety of questions, some of which are addressed in this thesis.

\section{Biomechanical and neuromuscular considerations}

During quiet unsupported sitting non-SCI subjects can maintain equilibrium, or balance, as long as the projection of the centre of gravity (CGpr) is kept within the base of support, clelimited by the buttocks, the thighs and the supporting feet. Chari and Kirby $[32,79]$, investigating the influence of the legs in maintaining sitting balance in dynamic situations during forward reaching movements, found that thigh (and foot) support permitted larger forward excursions of the CGpr in bealthy subjects.

In non-SCI subjects pelvic movement may vary actively during sitting, depending on the task being executed at a given moment. The relative contribution of upper leg muscles, the gluteal muscles, the tensor fasciae latae, the abdominal muscles and the erector spinae muscle to this pelvic tilt during passive and active sitting and during dynamic task performance conditions has been investigated in seated non-SCI subjects by Reinders and Risamasu [115]. An example of muscle activation patterns of the aforementioned muscles, illustrating muscle use during anteroposterior pelvic tilt in a healthy sitting person who performed a bimanual forward reaching movement, is given in figure 2.1 .

Snijders et al. [129, 130] found that during sitting the activity of the oblique abdominal muscles changed as a function of leg position. They also found that activity of the abdominal muscles was higher during sitting, compared to the supine position, but lower compared to stance. They concluded that the oblique abdominal muscles assist in the stabilisation of the lower part of the spine and the sacroiliac joints during unsupported sitting and standing. The role of the iliopsoas muscle in stabilising the lumbar spine has been investigated by Nachemson [100, 101], Keagy et al. [73] and Andersson et al. [11, 12]. 
Stability of the pelvis and the lower part of the spine is low in thoracic SCI subjects, due to the lack of control over the aforementioned leg and pelvic muscles. However, some form of stability is provided by passive liganentous and tendinous tissue as well as the bony parts of the legs and pelvis, which is ursed in therapeutio training conditions to facilitate unsupported sitting in SCI subjects [16]. In many cases additional external support (e.g. the backrest or lumbar support) is necessary to maintain equilibrium and posture during sitting. Problems in actively maintaining sitting balance and posture in SCI subjects are further reflected in the reduced extent to which they can shift the CGpr. One of the main questions regarding the reorganisation of postural control in SCI subjects concerns the biomechanical and neurophysiological mechanisms governing this reorganisation.

Figure 2.1. Example of activation patterns of several leg, pelvic and trunk muscles during anteroposterior pelvic movement in a healthy subject (Rectified EMG recordings.)

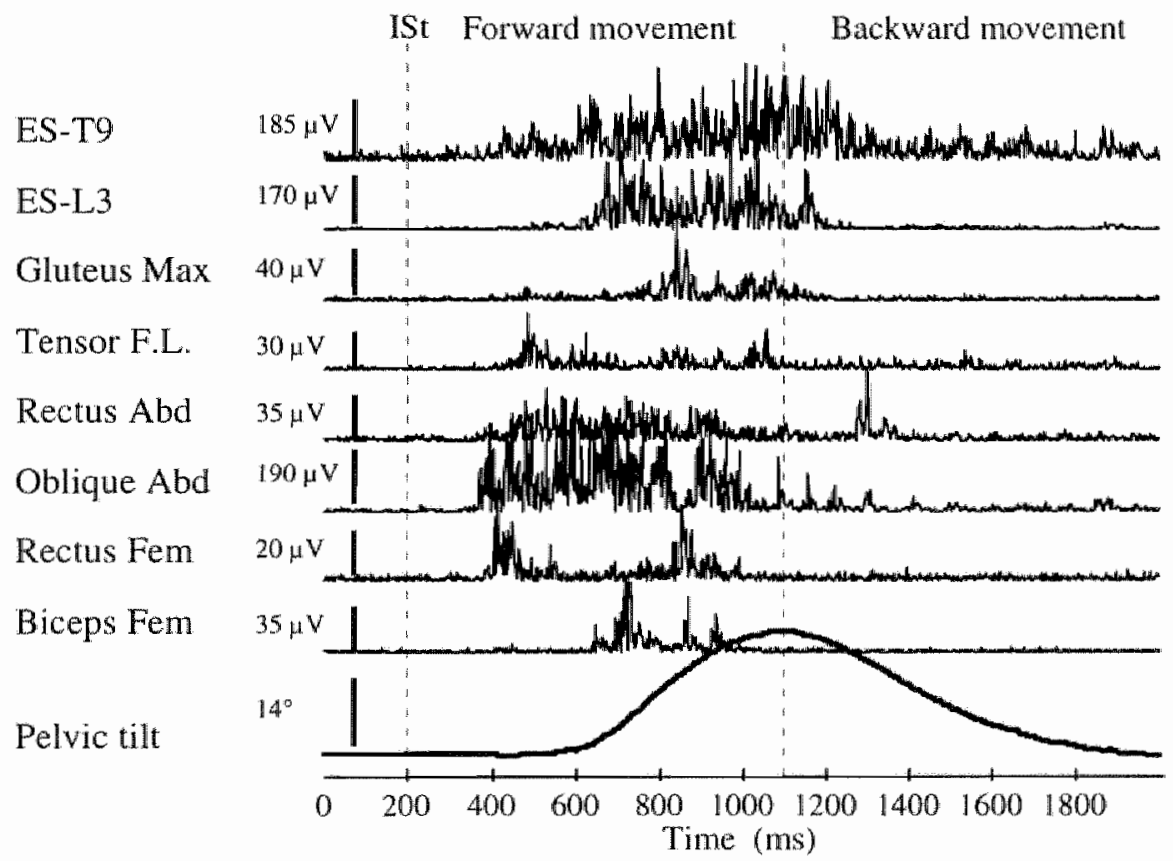

ISt $=$ imperative stimulus; $E S-T 9=m$. erector spinae at level T9; ES-L $3=\mathrm{m}$. erector spinae at level L3; Gluteus $M a x=m$. gluteus maximus; Tensor F.L. $=m$. tensor fasciae latae; Rectus $A b d=m$. rectus abdominis; Oblique $\mathrm{Abd}=\mathrm{m}$. abliquus abdominis; Rectus Fem, = m. rectus femoris; Biceps Fem $=m$. biceps femoris.

(EMG data adapted from Reinders \& Risamasu, 1995.) 
As to active postural muscle control, one biomechanically very simple concept is that seated thoracic SCI subjects stabilise the trunk relative to the base of support, i.e. (externally) the seat and as such (internally) the stabilised pelvis and the adjacent part of the lumbar spine, by using the LD and TPA (figure 2.2) while fixating the shoulder girdle.

Figure 2.2. M. latissimus dorsi and $\mathrm{m}$. trapezius pars ascendens.

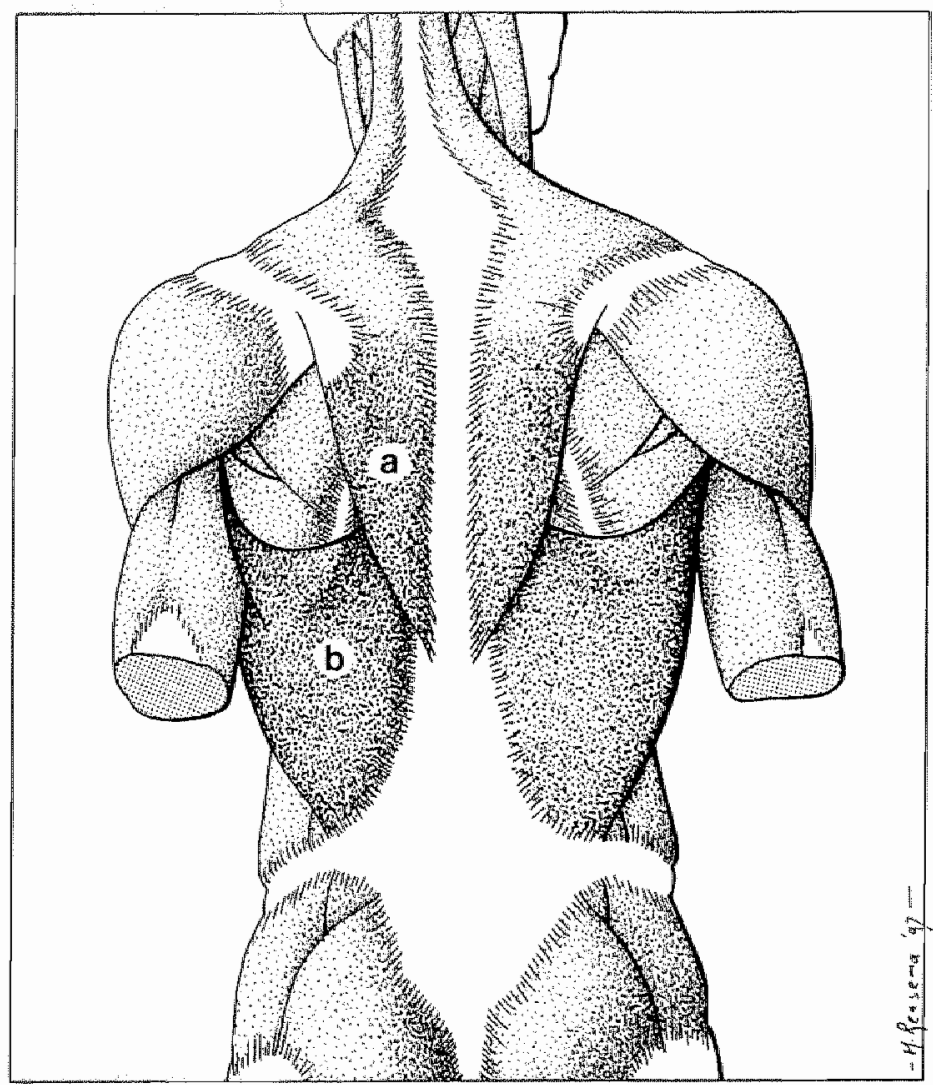

$\mathrm{a}=\mathrm{m}$. trapezius pars ascendens; $\mathrm{b}=\mathrm{m}$. latissimus dorsi.

(Drawing by H. Rensema, 1997.)

Both the LD and the TPA may have a biomechanically favourable position in that they originate from the lumbar-pelvic region, i.e. from the spinous processes T7-T12, the posterior parts of the 9 th to 12 th rib, the thoracolumbar fascia and the posterior part of the iliac crest (LD) and spinous processes T6-T12 (TPA) and insert at 
craniolateral positions in the region of the shoulder girdle, i.e. the crest of the lesser tubercle of the humerus (LD) and the spine of the scapula (TPA). Also they have an innervation level cranial to the thoracic spinal segments permitting them to be active in thoracic SCI patients.

An inverted pendulum concept, similar to the concept proposed by Gurfinkel et al. [59] in their work on postural sway and balance control during stance and by Hayes [61], could be applied to the (erect) sitting posture of thoracic SCl subjects. Crisco et al. [36] describe the muscular Euler column model. This biomechanical model consists of a vertical bar representing a bony segment, connected to a fixed base via a joint. Ligaments crossing the joint are represented by a torsional spring. Spring elements, representing muscles originating from the base and inserting at the vertical bony segment, are arranged around the vertical bar like guy ropes stabilising the mast on a ship (see figure 2.3). This concept is similar to the schematic representation of the back muscles proposed by Benninghoff and Goerttler [22]. In reality muscle tension is not constant, but slowly oscillating within narrow margins, based on feedback control.

Figure 2.3. Muscular Euler column. (Two dimensional representation.)

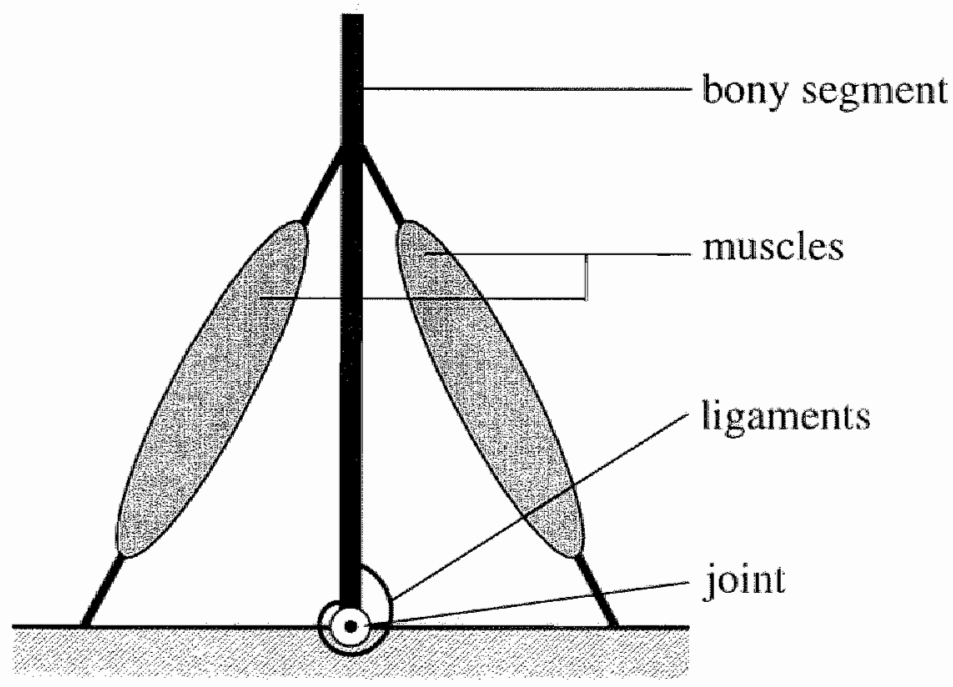

(Adapted from Crisco et al., 1990.)

Similarly, Bergmark [24] presented a simple biomechanical model of the lower part of the spine (see figure 2.4) in which the ribcage and lumbar spine were modelled as one stiff element pivoting around one point on the sacrum which was considered part 
of the rigid base: The global erector spinae muscle and other local muscles are represented as pairs of single springs.

Figure 2.4. Simple three dimensional biomechanical model of the lower part of the spine. (posterior view.)

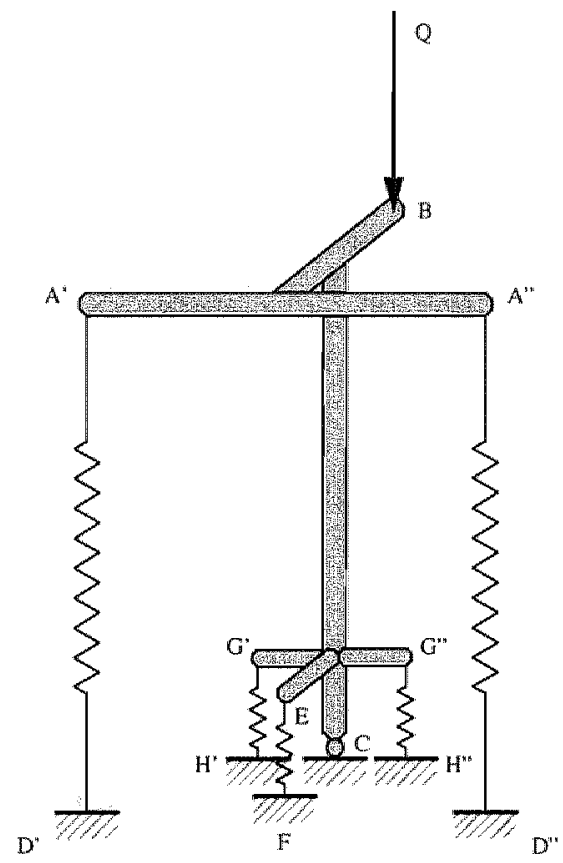

$Q=$ vertical load; $A^{\prime} A^{\prime \prime} B=$ ribcage; $G^{\prime} G^{\prime \prime} C=$ lumbar spine; $C=$ joint; $A^{\prime} D^{\prime} / A^{\prime \prime} D^{\prime \prime}=$ erector spinae muscle; $G^{\prime} H^{\prime} / G^{\prime \prime} H^{\prime} / E F=$ local muscles;

(Adapted from Bergmark, 1989.)

A version of the muscular Euler column concept, in which the LD and TPA are implemented as possible stabilisers of the trunk, is given in figure 2.5 . 
Figure 2.5. Posterior view of the muscular Euler columi concept holding the m. latissimus dorsi and the $\mathrm{m}$. trapezius pars ascendens. (Two dimensional representation.)

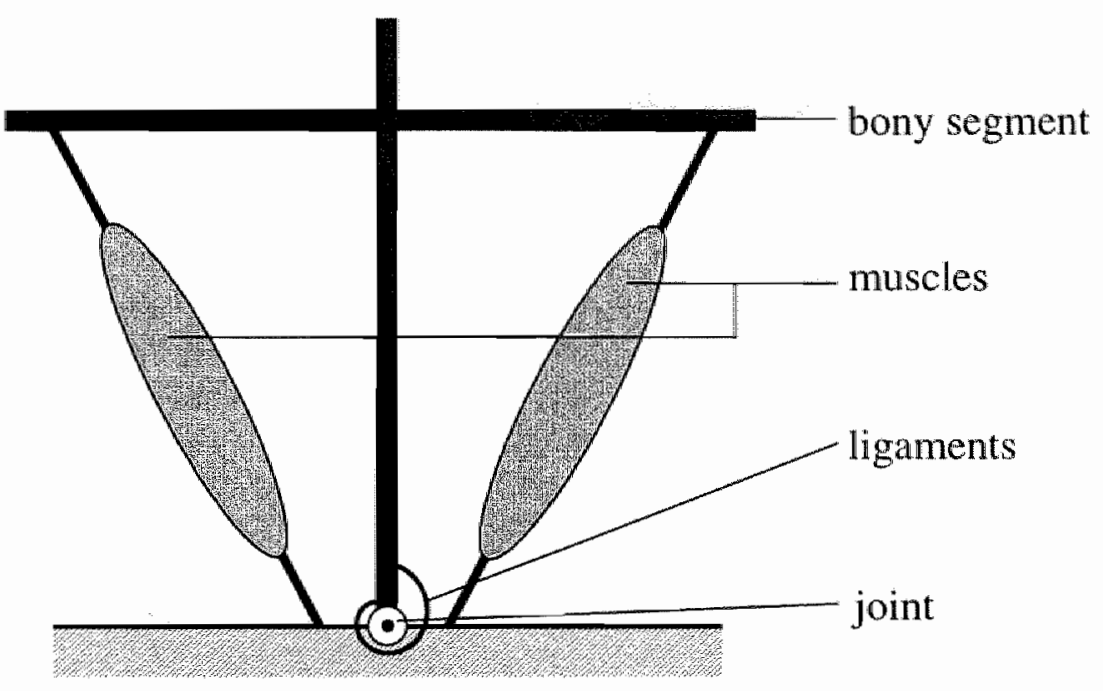

One drawback of this class of models, however, is that they do not take into account the multisegment nature of the body (in the present case the spinal column, trunk and shoulder girdle), thus ignoring the necessity for co-ordination of stabilising (muscle) actions between (sub-)segments, as was pointed out by e.g. Massion et al. [89, 90]. Zajac and Winters [143] in their review on the evolution of models of musculoskeletal movement systems, however, state that such simplifications are justified when the understanding of the system or task to be executed is low. The idea of the multilink. architecture of posture and movement control is currently widely applied [24, 26]. An example of a multilink lumbar spine model, used to study the stability problems of the spine, proposed by Bergmark, is given in figure 2.6. The passive structures between the stacked passive structures or vertebrae are represented by torsional springs. The erector spinae muscle is represented by a spring. The pelvis is considered part of the rigid base. 
Figure 2.6. Mululink model of the lower part of the spine.

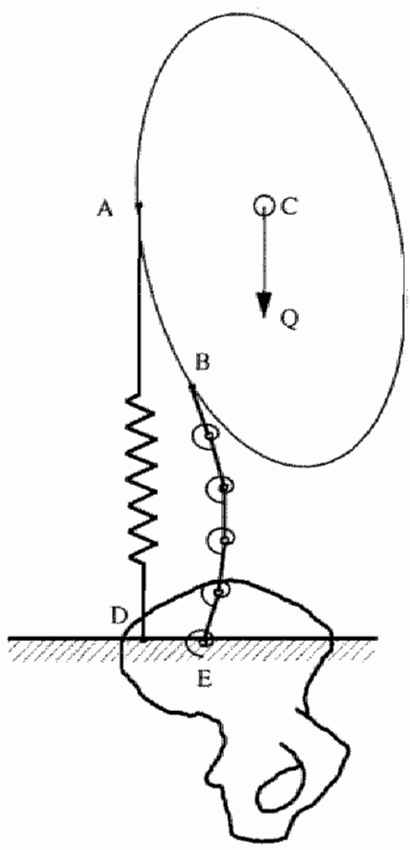

$\mathrm{AD}=$ erector spinae muscle; $\mathrm{ABC}=$ stiff rib cage; $\mathrm{BE}=$ lumbar spine; $\mathrm{C}=$ centre of gravity of the upper body; $\mathrm{Q}=$ vertical load;

(Adapted from Bergmark, 1989.)

However, one of the problems in the multilink concept concerns the redundancy problem, i.e. the many ways in which multilink systems can be operated and controlled to produce the same output, i.e. movement. This redundancy problem has already extensively been described by Bernstein [25] and his followers.

The concept of stabilisation of the spine during sitting in thoracic SCI subjects using the LD and TPA would postulate that, in order to prevent mere phasic activity of these muscles, i.e. retraction and depression of the scapulae and movement of the humerus, counteracting forces should be generated either passively, caused by e.g. gravity during kyphotic sitting, or actively using muscles still controllable in a agonist-antagonistic coactivation strategy. In effect the shoulder girdle should be stabilised with respect to the spine. Additionally, in such a postural stability concept, it would be necessary that the pelvis and the lower part of the spine are stabilised in order to act as a punctum fixum. 
Another issue in control of sitting posture is the upward displacement of the $\mathrm{CG}$ in SCI subjects, due to the extensive muscle atrophy and subsequent weight loss in the lower part of the body and the possible increase of muscle mass in the shoulder and arm regions through physical training. This phenomenon was addressed by Duval-Beaupere and Robain [45]. Such a CG shift in cranial direction may further reduce postural stability of SCI subjects during sitting, especially in view of the loss of sensorimotor function necessary to act (in anticipation) upon CGpr displacements and postural perturbations.

\section{Motor control considerations}

Contemporary motor control theories propose several stages in the processing of information in order to control motor actions. Sternberg [134] proposed a stimulusresponse paradigm in which different, successive stages were serially organised. McClelland's cascade model [91] encompassed a 'continuous flow" of information from one stage to the next. Miller $[93,94]$ described an information processing model in which stages were partially overlapping. Although different authors may use slightly different names or subclassifications, the main stages typically involve (a) stimulus identification, (b) stimulus-response translation or response selection and (c) response programming (figure 2.7 ) [113, 122].

Figure 2.7. Information processing stages in stimulus-response paradigm.

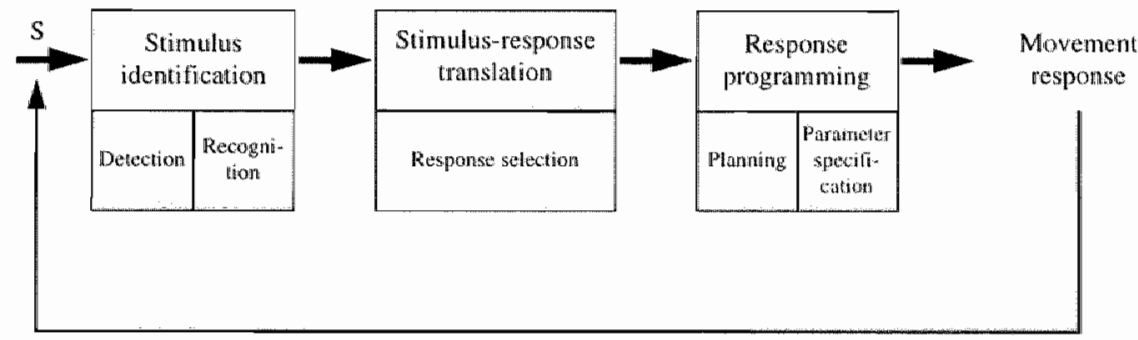

Feedback

$S=$ stimulus

The stimulus identification phase comprises of two substages: a slimulus detection phase associated with input selection and a recognition phase in which the main characteristics of a stimulus are extracted based upon knowledge recalled from memory. Stimulus-response translation is thought to encompass the selection among a limited set of abstract programming rules or so-called prototypical representations of a task rather than selection from a pool of more or less rigidly and predefined motor programs [97, 116]. The latter can not explain the occurrence of new movement patterns, nor the versatility in movement strategies, associated with the many degrees 
of freedom. In the response programming phase a final motor program is elaborated starting from a conceptual, abstract level $[76,133]$. Several authors have hypothesised the existence of response programming substages. Spijkers et al. [133] postulated a parameter specification phase in which the necessary motor control parameters are computed and a motor adjustment stage in which the appropriate parameters are adjusted as to intensity to fit the specific environmental requirements. Rosenbaum [119] and Mulder [97] define the response programming substages as (a) selecting or planning ordered sequences of movement instructions and (b) selecting and adding abstract motor variables to the program that is selected. Massaro and Cowan [87] gave an in-depth overview of different information processing models used in psychology.

Another, ecological, approach to the study of perception and action has initially been advocated by Gibson [53]. Alhough sharing many similarities with the information processing theories, the ecological approach, or co-ordination dynamics [75] negates the necessity for mental representations or coding, algorithmic processes and cognitive processing stages such as a response translation stage [1, 121]. Instead, a more direct link between perception and motor action is assumed. Unlike the information processing approach, the co-ordination dynamics paradigm postulates motor control to be a self-organising mechanism in which the constraining of the many degrees of freedom to reduce co-ordination requirements is accomplished through so-called co-ordinative structures or functional synergies acting as a single unit $[75,136]$. Elements of these co-ordinative structures do not necessarily have to be linked anatomically [27].

In thoracic SCI subjects both exterocepsis and propriocepsis are impaired, as well as the motor system, which inevitably leads to impairments in feedback control loops necessary for adequate postural control. Impairments in the motor system seriously affect feedforward control in anticipatory actions focused on maintaining equilibrium and posture as well as sequencing of muscle activation during movement.

Because of the SCI existing postural muscle synergies are impeded. To regain adequate control over (sitting) posture and balance, new co-ordinated muscular activity or synergies must develop which are adapted to the new situation. This implies the occurrence of a central reorganisation process in motor control in $\mathrm{SCI}$ subjects. Although some restoration of function may occur over time $[40,72,140]$ rehabilitation of $\mathrm{SCl}$ patients is mainly focused on the (partial) compensation of function loss [16], thus directly addressing the aforementioned central reorganisation. Neither this central reorganisation nor its causal relation to the (pathological) changes in the systems state have been studied extensively [98]. Thus the general question arises what effect $\mathrm{SCI}$ has on mechanisms in the control of posture and how the process of reorganisation of motor control manifests itself in SCI patients.

Seelen and Vuurman [128] investigated postural control in sitting thoracic SCI subjects who had completed their rehabilitation program at least one year earlier and in non-SCI subjects. The subjects had to perform submaximal reaching movements presented as a visual precue choice reaction time (RT) task, following the precue paradigm proposed by Rosenbaum [117-119]. One of the assumptions was that the 
lack of balance control would interfere with the manual task performance and would lead to longer RT's as opposed to the performance in non-SCI subjects. It was also hypothesised that paraplegic persons, although extensively retrained, still suffer from impairments concerning motor preparation prior to selective, goal-directed upper extremity movements. Indeed, investigators were able to demonstrate that the SCIsubjects were generally slower in processing information for a motor response involving postural changes in contrast to non-SCI subjects. Their data also indicated that thoracic SCI subjects were also less able to take advantage of precued information as to reaching direction in a precue choice reaction time task indicated by a significant group versus precue interaction (see figure 2.8 ).

Figure 2.8. Mean reaction time and $99 \%$ confidence interval of the mean during precued and non-precued reaching conditions for thoracic SCl subjects $(\mathrm{n}=15)$ and non-SCI subjects $(n=15)$.

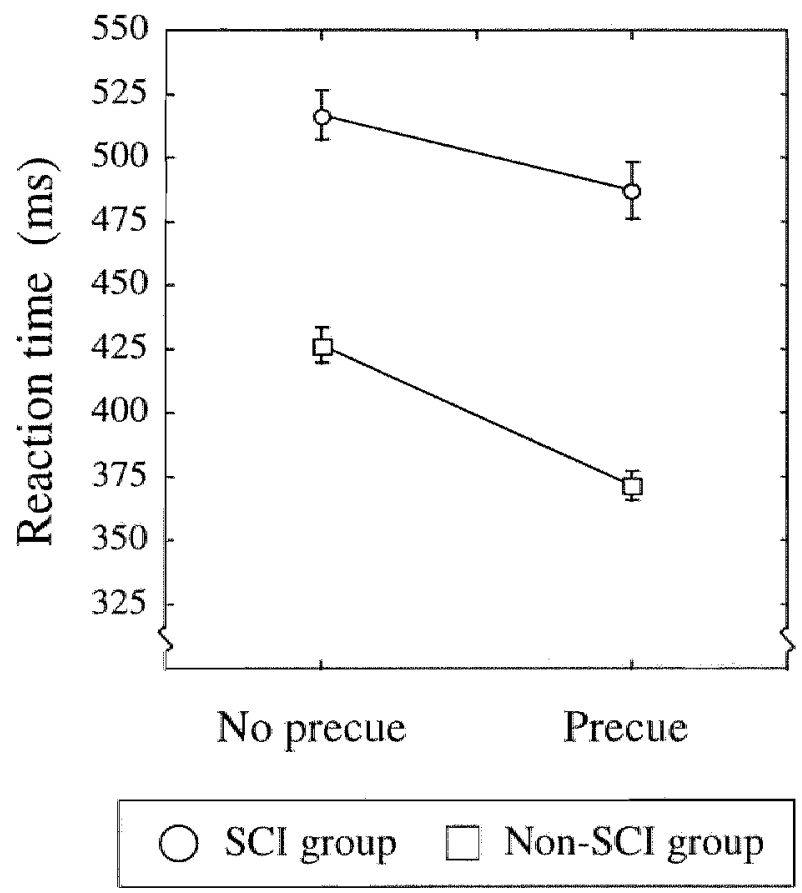

Data are pooled for reaching distance conditions.

(Adapted from Seelen \& Vuurman, 1991.)

The findings by Seelen and Vuurman [128] led to a number of additional questions concerning changes in central processes responsible for postural motor performance in 
$\mathrm{SCI}$ people. Since postural control is a prerequisite for task performance in activities of daily living (ADL), one question was to what extent different levels of impairment in the sensorimotor system would affect RT performance in postural control in $\mathrm{SCI}$ subjects. Another question of interest concerned the time course the hypothesised reorganisation of postural control takes with respect to the clinical rehabilitation period. This, again, gave rise to a series of experiments reported in the current thesis.

\section{Present research}

\section{Research aim and questions addressed}

The main aim of the present research has been to gain insight in the mechanisms that govern reorganisation of postural control in people suffering from a complete thoracic SCI. Impaired postural co-ordination and control of sitting balance during manual task performance have been examined in SCI patients during and after their active clinical rehabilitation period. The investigations have been focused on (a) the effects a thoracic SCI has on sitting stability during manual task performance, (b) changes in postural muscle use and (c) central motor control processes. A biomechanical and neuromuscular concept of alternative postural muscle use has been verified in a number of experiments. Four main research questions have been posed:

1. How and to what extent can persons suffering from a complete thoracic SCI compensate the loss of erector spinae muscle function in their attempt to control sitting posture during manual task performance? (Chapter 3)

2. To what extent does postural motor programming in thoracic SCI subjects differ from non-SCI subjects? (Chapter 5)

3. To what extent do new patterns of alternative postural muscle use develop in thoracic SCI patients during their clinical rehabilitation? (Chapter 4)

4. To what extent do postural motor programming processes adapt in thoracic $\mathrm{SCl}$ patients during their clinical rehabilitation? (Chapter 6)

\section{Overall research design and instrumentation}

The present research has been carried out in three phases. In the first phase several instruments have been developed for objective quantification of postural control in both SCI and non-SCI subjects. First a set of standardised tasks with which sitting posture could be systematically perturbed, was developed. In view of the research questions mentioned above, these tasks had to meet several requirements. For example, both $\mathrm{SCI}$ and non-SCI subjects should be able to perform the same tasks. The tasks should elicit changes in posture and sitting balance. Task reproducibility should be high. Additionally, tasks should be open to experimental manipulation in the domain of biomechanics, neuromuscular performance and motor programming. The main task used in the present research involved reaching movements over four different submaximal reaching distances, thus introducing graded postural perturbations. Reaching was performed bimanually in the parasagittal plane. 
Maintauning sitting balance was expected to become more difficult as reaching distance increased, especially in SCI subjects.

Patterns of (alternative) postural muscle responses during task execution were quantified using surface EMG equipment (K_Lab MF-118/SPA-12, K_Lab, Amsterdam, Neth.) featuring 12 EMG channels. Active electrodes, pre-amplifying the EMG signal on-site (signal amplification 100; input impedance $>500 \mathrm{M} \Omega$; CMRR $>110 \mathrm{~dB}$; noise referred to input $\angle 2 \mu \mathrm{V}$; inter-electrode distance $2.3 \mathrm{~cm}$ ), were used in conjunction with $\mathrm{Ag}-\mathrm{AgCL}$ disposable electrodes with a contact area of $1 \mathrm{~cm}^{2}$ (Graphics Control Co, Buffalo, NY). Also a multi-adaptable chair (THZ Engineering, Eys, Neth.) was designed, that could be adjusted to the anthropometry of each participant in the study. Seat depth, seat inclination, armrest position and height, footrest inclination and height as well as backrest inclination of the chair could be altered. A force plate (Biovec-1000, AMTI, Watertown, MA) was mounted underneath the chair. From the force plate signals 'centre of pressure' (CP) displacement, used as an indicator for postural changes during sitting, and parameters associated with body acceleration were calculated. In order to quantify three dimensional pelvic movement during task execution (chapter 3) an infrared camera system (PRIMAS, Delft Motion Analysis, Delft, Neth.) with four cameras was used. Retroreflective markers were placed on bony landmarks of the low thoracic and lumbar spine, the pelvis and the femur.

Apart from the aforementioned kinematic aspects also possible differences in motor preparation, associated with postural control, between $\mathrm{SCI}$ and non-SCI subjects have been studied, using a 'precue choice reaction time' paradigm put forward by Rosenbaum $[118,119]$. Software for this RT research has been developed. Timing of all experiments was performed using a PCL830 timer/counter card (Advantech Co., Taiwan).

A computer driven, multi-channel data-acquisition and processing system (MUCAPS, iRv, Hoensbroek, Neth.) has been developed, integrating and synchronising all systems mentioned above. MUCAPS consists of both software and hardware. Signal A/D-conversion was performed by a 16 channel (single-ended) DT2824-PGL card (Data Translations, Marlboro, III) with a maximum A/D throughput frequency of $50 \mathrm{KHz}$. Continuous data storage on hard disc during prolonged periods of time was made possible using so-called 'double buffered DMA' (Direct Memory Access).

In a number of pilot studies the reproducibility of postural perturbation during task performance was evaluated. An example of the reproducibility of $\mathrm{CP}$ displacement in high and low thoracic SCI subjects as well as in non-SCI subjects is presented in figure 2.9 . 
Figure 2.9. Examples of anteroposterior $\mathrm{CP}$ displacement during task performance.

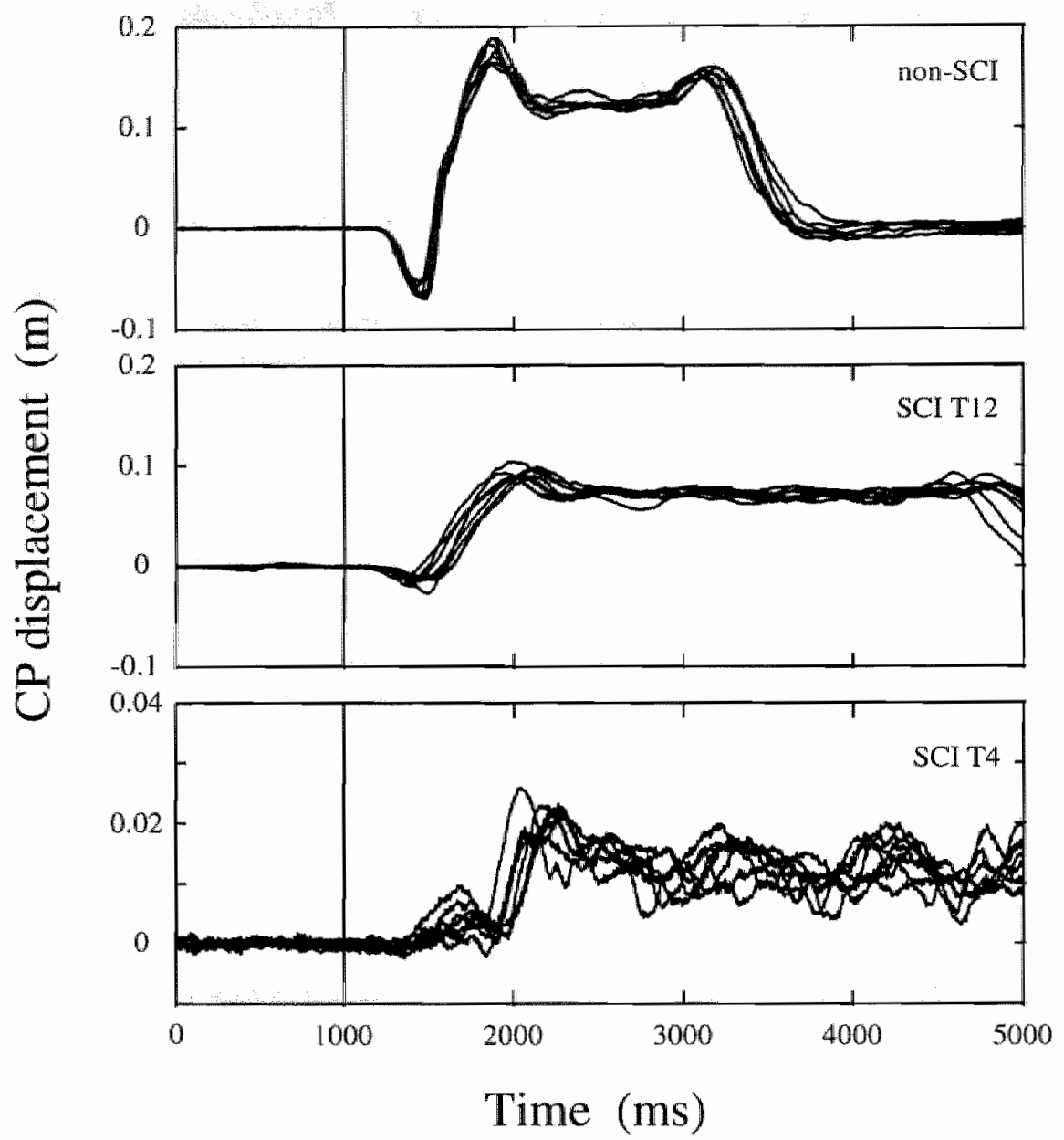

Multiple trials are displayed for all three participants.

$\mathrm{CP}=$ centre of pressure; $\mathrm{SCI}=$ spinal cord injury.

In the second phase of the study an answer was sought to research question 1 and 2 formulated above. In this phase a transversal group study was carried out involving two groups of complete thoracic SCI subjects, stratified for lesion levels between spinal segment $\mathrm{T} 2$ and $\mathrm{T} 8$ or $\mathrm{T} 9$ and $\mathrm{T} 12$, who had completed their active rehabilitation and a group of non-SCI subjects. It was hypothesised that the differences in sensorimotor impairment (and in residual sensorimotor potential) 
associated with the different levels of SCI would lead to the development of different strategies in postural muscle use and to changes in motor programming and movement anticipation prior to functional postural perturbation. It was assumed that in $\mathrm{SCl}$ patients who had already completed their active rehabilitation program for some years a consistent pattern of alternative muscle use in control of posture and equilibrium would be more clearly present in contrast to SCI patients who were still undergoing therapy. The non-SCI group acted as a reference group for the two SCI groups in this transversal study.

In this second research phase several experiments were carried out. First a baseline RT experiment was performed. It was aimed at investigating whether groups differed as to simple visual perception and simple, non-balance perturbing upper extremity tasks, which might obscure possible differences in postural motor programming between groups.

In the next experiment a bimanual forward reaching task resulting in systematic sitting balance perturbation was presented to the participants. The subjects sat in the multi-adaptable chair. They were instructed, via a monitor, to reach towards button pairs placed at 15,30,75 and $90 \%$ of their individual maximum reaching distance in anterior direction. The task was presented as a visual precue choice $\mathbb{R}^{T} T$ task. RT"s were measured to investigate possible differences in motor programming phenomena in impaired balance control due to different levels of SCI. One assumption was that postural motor programming would take longer in thoracic $\mathrm{SCl}$ subjects, since they would have to use muscles that do not have a primary postural function to control sitting posture. Furthermore, it was assumed that the level of sensorimotor impairment in SCI would also lead to different strategies in postural control and to differences in RT performance between high and low thoracic SCI subjects. To investigate possible differences in balance restoration phenomena between groups surface EMG was recorded in several muscles assumed to be inwolved in maintaining and restoring sitting posture. Centre of pressure displacement and anteroposterior directed forces, associated with acceleration of body mass, were recorded to give insight in the magnitude of changes in sitting posture.

In a final experiment during the second research phase, three-dimensional pelvic motion during task performance in non-SCl subjects was evaluated, in order to further specify the origin of typical posturographic findings in the non-SCl subject group. The purpose of this set of three experiments was to establish final functional outcome level concerning control of posture, maintenance of sitting balance, alternative postural muscle use and task performance in SCI subjects relative to nonSCI people.

In the third, longitudinal research phase an answer to research question 3 and 4 was sought. In this third phase patients with a complete thoracic SCI, who were admitted to the spinal cord injury unit of the Hoensbroeck Rehabilitation Centre, participated. At several, predetermined stages in their clinical rehabilitation process they were tested on their ability to maintain posture and equilibrium during manual task performance. At each of these stages the aforementioned baseline RT experiment 
and the experiment involving the bimanual forward reaching task were held. The purpose of this longitudinal study was to investigate the time course of the reorganisation of postural control during clinical rehabilitation. Having gained such insight, i.e. being able to objectively describe the development of alternative postural muscle use, the next step would be to investigate if a causal relationship between a specific therapy intervention and a typical development of alternative postural muscle use can be identified.

\section{References}

1. Adam J, Paas FGWC, Buekers MJ, Wuyts U, Spijkers WAC, Wallmeyer P: Perceptionaction coupling in choice reaction time tasks. Hum Mov Sci 15:511-519, 1996.

2. Allen $V$, Ryan DW, Murray A: Potential for bed sores due to high pressures: influence of body sites, body position, and mattress design. Br J Clin Pract 47(4):195-197, 1993.

3. Andersson GBJ: Posture and compressive spine loading: intradiscal pressures, trunk myoelectric activities, intra-abdominal pressures, and biochemical analyses. Ergonomics $28: 91-93,1985$

4. Andersson BJG, Jonsson B, Ötengren R: Myoelectric actiwity in individual lumbar erector spinae muscles in sitting. A study with surface and wire electrodes. Scand I Rehab Med. suppl 3:91-108, 1974a.

5. Andersson BJG, Örtengren R: Lumbar disc pressure and myoelectric back muscle activity during sitting: II. Studies on an office chair. Scand J Rehab Med 6:115-121, 1974b.

6. Andersson BJG, Ötengren R: Lumbar disc pressure and myoelectric back muscle activity durng sitting: III. Studies on wheelchair. Scand J Rehab Med 6:122-127, 1974c.

7. Andersson BJG, Örtengren R: Myoelectric back muscle activity during sitting. Scan I Rehab Med, suppl 3:73-90, 1974d.

8. Andersson BJG, Ortengren R, Schultz A: Analysis and measurement of the loads on the lumbar spine during work at a table. $J$ Biomech $13: 513-520,1980$.

9. Andersson BJG, Örtengren R, Nachemson A, Elfström G: Lumbar dise pressure and myoelectric back muscle activity during sitting: I. Studies on an experimental chair. Scand J Rehab Med 6:104-114, 1974e.

10. Andersson BJG, Ortengren $\mathrm{R}$, Nachemson A, Elfström G: Lumbar dise pressure and myoelectric back muscle activity during sitting: IV. Studies on a car driver"s seat. Scand J Rehab Med 6:128-133, 1974r.

11. Andersson E, Grundström $\mathrm{H}$, Oddsson L, Thorstensson A: Psoas and iliacus muscles act in concert or selectively during natural movements in man. In: Proceedings of the XIII ISB Congress, Perth 1991, pp 254-255, 1991.

12. Andersson E, Oddsson L, Grundström H, Thorstensson A: The role of the psoas and iliacus muscles for stability and movement of the lumbar spine, pelvis and hip. Scand $J$ Med Sci Sports 5:10-16, 1995.

13. Andersson GBJ, Ötiengren $\mathrm{R}$, Nachemson $\mathrm{AL}$, Elfström $\mathrm{G}$, Broman $\mathrm{H}$ : The sitting posture: an electromyographic and discometric study. Orthop Clin North Am 6:105-120, 1975.

14. Andersson GBJ, Winters JM: Role of Muscle in postural tasks: Spinal loading and postural stability. In: Multiple muscle systems, ed by Winters JM, Woo SLY, Springer-Verlag, New York, pp 377-395, 1990.

15. Buder DL, Hawken MB: Ischial pressure distribution under the seated person. In: Pressure sores: dinical practice and scientific approach, ed by Bader DL, MacMillan Press, London, pp 223-233, 1990. 
16. Beckers DML, Buck MJ, Pons C: The rehabilitation of spinal cond injured patients/. De revalidatie van dwarslaesiepatienten. In Dutich. Uitgeversmatschappij de Tijdstroom, Lochem, 1992.

17. Belenkii VY, Gurfinkel VS, Pal'tsev YI: Elements of control of voluntary movements. Biofizika 12(1): 135-141, 1967.

18. Bendix T: A seated trunk posture at various seat inclinations, seat heights and table heights. Hunan Factors 26:695-703, 1984.

19. Bendix T, Biering-Sorensen F: Posture of the trunk when sitting on forward inclining seats. Scand J Rehab Med 15:197-203, 1983.

20. Bendix T, Jessen F, Krohn L: Biomechanics of forward-reaching movements while sitting on fixed forward- or backward-inclining or tiltable seats. Spine 13:193-196, 1988.

21. Bendix $T$, Winkel J, Jessen $F$ : Comparison of office chairs with fixed forwards and backwards inclining or tiltable seats. Eur I Appl Physiol 54:378-385, 1985.

22. Benninghoff $\mathrm{A}$, Goenttler $\mathrm{H}$ : Lehrbuch der Anotomie des Menschen: Erster Band: Algemeinet Anatomie und Bewegungsapparat. In German. Urban \& Schwarzenberg, München, 1964.

23. Berger W, Discher $M$, Trippel M, Ibrahim IK, Dietz V: Developmental aspects of stance regulation, compensation and adaptation. Exp Brain Res 90(3);610-619, 1992.

24. Bergmark A: Stability of the lumbar spine Acra Orthop Scand 60, suppl. 230, 1-54, 1989.

25. Bernstein N: Coordination and regulation of movements. Pergamon Press, New York, 1967.

26. Bogduk N, Twomey LT: Clinical anatomy of the lumbar spine. Churchill Livingstone, New York, 1987.

27. Bootsma RJ, Beek PJ: [Co-ordination and control of gross motor skills]. Coördinatie en controle van groot-motorische vaardigheden. In Dutch. In: [Human movement]. Menselijke motoriek, ed by Keuss, ten Hoopen, Mannaerts, Swets \& Zeitlinger B.V., Amsterdam, pp 29. $42,1988$.

28. Bouisset $S$ : [Relationship between postural support and intentionall movement: biomechanical approach] Relation entre support postural et mouvement intentionnel: approche biomecanique. In French. Arch Int Physiol Biochem Biophys 99(5):A77-92, 1991.

29. Bouisset S, Zattara M: A sequence of postural movements precedes voluntary movement. Neurosci Lett 22:263-270, 1981.

30. Bouisset S, Zattara M: Biomechanical study of the programming of anticipatory postural adjustments associated with voluntary movement. $J$ Biomech 20:735-742, 1987.

31. Brown JE, Frank JS: Influence of event anticipation on postural actions accompanying voluntary movement. Exp Brain Res 67:645-650, 1987.

32. Chari VR, Kirby RL: Lower limb influence on sitting balance while reaching forward. Arch Phys Med Rehabil 67:730-733, 1986.

33. Chaffin DB, Andersson GBJ: Occupational Biomechanics. J Wiley and Sons, New York, 1991 .

34. Corlett EN, Bishop RP: A technique for assessing postural discomfort. Engonomics 19:175$182,1976$.

35. Corlett $\mathrm{N}$, Wilson J, Manemica I: The ergonomics of working postures: Models, methods and cases. Taylor \& Francis, London, 1986.

36. Crisco JJ, Panjabi MM: Postural biomechanical stability and gross muscular architecture in the spine. In: Multiple muscle systems, ed by Winters JM, Woo SLY, Springer-Verlag, New York, pp 438-450, 1990.

37. Dietz V: Human neuronal control of antomatic functional movements: interaction between central programs and afferent input. Physiol Rev 72(1):33-69, 1992.

38. Dietz V, Horstmann GA. Berger $W$ : Significance of proprioceptive mechanisms in the regulation of stance. Prog Brain Res 80:419-423, 1989. 
39. Dietz $V$, Trippel $M$, Bbrahim $K$, Berger $W$ : Human stance on a sinusoidally translating platform: balance control by feedforward and feedback mechanisms. Exp Brain Res $93(2): 352-362,1993$.

40. Dimitrijevic MR, Hsu CY, Mckay WB: Neurophysiological assessment of spinal cord and head injury. I Neurotrauna 9 , suppl 1:293-300, 1992.

41. Do MC, Bouisset $S$, Moynot $C$ : Are paraplegics handicapped in the execution of a manual task? Ergonomics 28:1363-1375, 1985.

42. Do MC, Nouillot $\mathrm{P}$, Bouisset $\mathrm{S}$ : Is balance or posture at the end of a voluntary movement programmed? Neurosci Lett 130(1):9-11, 1991.

43. Drummond DS, Narechania RG, Rosenthal AN, Breed AL, Lange TA, Drummond DK: A study of pressture distributions measured during balanced and unbalanced sitting. I Bone Joint Surg Am 64:1034-1039, 1982.

44. Dufosse $\mathrm{M}$, Massion J: Posturo-kinetic interactions: modeling and modes of control In: Tutorials in motor behavior $/ 1$, ed by Stelmach GE, Requin J, Elsevier Science Publishers, Amsterdam, pp 125-155, 1992.

45. Duval-Beaupere G, Robain G: Upward displacement of the centre of gravity in paraplegic patients. Paraplegia 29:309-317, 1991.

46. Eklund JAE, Corlett EN, Johnson F: A method for measuring the load imposed on the back of a sitting person. Ergonomics 26:1063-1076, 1983.

47. Ferguson-Pell MW, Hurwitz DE, Burn TG, Masiello R: Remote monitoring of wheelchair sitting behaviour. In: Pressure sores: clinical practice and scientific approach "ed by Bader DL, MacMilian Press, London, pp 261-273. 1990.

48. Forssberg $\mathrm{H}$, Hirschfeld $\mathrm{H}$ : Postural adjustments in siting humans following external perturbations: muscle activity and kinematics. Exp Brain Res 97:515-527, 1994.

49. Friedli WG, Cohen L, Hallett M, Stanhope S, Simon SR: Postural adjustments associated with rapid voluntary arm movements. II. Biomechanical analysis. J Neurol Neurosurg Psychiatry 51:232-243, 1988.

50. Firiedli WG, Hallet M, Simon SR: Postural adjustments associated with rapid voluntary arm movements I. Electronyographic data. I Neurol Neurosurg Psychiarry 47:61 1-622, 1984.

51. Gahéry Y, Massion J: Co-ordination between posture and movement. TINS 4:199-202, 1981.

52. Ghez C: Posture. In: Principles of neural Science, ed by Kandel ER, Schwartz JH, Jessel TM, Prentice HallInternational Inc., London, pp. 596-607, 1997.

53. Gibson J: The ecological approach to visual perception. Houghton Mifflin, Boston, 1979.

54. Gollhofer A, Horstmann GA, Berger W, Dietz $V$ : Compensation of translational and rotational perturbations in human posture: stabilization of the centre of gravity. Neurosci Lett $105,73-78,1989$.

55. Goossens RH, Snijders CJ, Hoek van Dijke GA, den Ouden AH: A new instrument for the measurenent of forces on beds and seats. J Biomed Eng 15(5):409-412, 1993

56. Goossens RHM: Biomechanics of bady support: A study of load distribution, shear. decubisus risk and form of the spine. Thesis. Copy Print 2000, Enschede, 1994.

57. Grieco A: Sitting posture: an old problem and a new one. Ergonomics 29(3):345-362, 1986.

58. de Groot JP: Electromyographic analysis of a postural sorting task. Ergonomics 30:1079$1088,1987$.

59. Gurfinkel VS, Osovets SM: Dynamics of equilibrium of the vertical posture in man. Biofizika $17: 478-485,1972$.

60. Hagberg M, Sundelin G: Discomfort and load on the upper trapezius muscle when operating a wordprocessor. Ergonomics 29:1637-1645, 1986.

61. Hayes $\mathbb{K C}$ : Biomechanics of postural control. Exerc Sport Sci Rev 10:363-391, 1982.

62. Henry FM, Rogers DE: Increased response latency for complicated movements and a "nemory drum" theory of neuromotor reaction. Reseanch Quarterly 31:448-458, 1960. 
63. Hobson DA: Comparative effects of posture on pressure and shear at the body seat interface. J Rehabil Res Dev 29(4):21-31, 1992.

64. Horak FB, Diener HC, Nashner LM: lnfluence of central set on thuman postural responses. $J$ Neurophysiol 62(4):841-853, 1989.

65. Horak FB, Nashner LM: Central programming of postural movements: adaptation to altered support-surface confugurations. I Neurophysiol 55(6):1369u1381, 1986.

66. Horak FB, Nashner LM, Diener HC: Postural strategies associated with somatosetisory and vestibular lass. Exp Brain Res 82(1):167-177, 1990.

67. Horstmann GA, Dietz V: A basic posture control mechanism: the stabilization of the centre of gravity. Electroencephalogr Clin Neurophysial 76:165-176, 1990.

68. Hosea TM, Simon SR, Delatizky J, Wong MA, Hsieh CC: Myoelectric Analysis of the paraspinal musculature in relation to automobile driving. Spine 11(9):929-936, 1986.

69. ICE, Institute for Consumer Ergonomics: Seated anthropometry: the problems involved in a large scale survey of disabled and elderly people. Ergonomics 24:831 845, 1981.

70. Johanson ME: Electromyographic investigation of trunk control in the sitting position. In: Electrophysiological Kinesiology, ed by Wallinga W, Boon HBK, de Vries J. Elsevier Science Publishers, Amsterdam, pp 463-466, 1988.

71. Johansson R, Magnusson M: Human postural dynamics. Crit Rev Bioned Eng 18:413-437, 1991.

72. Kakulas A: The applied neurobiology of human spinal cord injury: a review. Paraplegia $26: 371-379,1988$.

73. Keagy RD, Brumlik J, Bergan JJ: Direct electromyography of the psoas major muscle in man. J Bone Joint Surg 48A:1377-1382, 1966.

74. Kelly JP: The sense of balance. In: Principles of neural science, Third edn, ed by Kandel $\mathbb{E R}$, Schwartz JH., Jessell TM, Prentice-Hall International Ine., London, pp 500-529, 1997.

75. Kelso JAS: Relative timing in brain and behavior: Some observations about the generalized motor program and self-organized coordination dynamics. Hum Mov Sci 16:453-460, 1997.

76. Kerr B: Task factors that influence selection and preparation of voluntary movements. In: Information processing in motor control and leaming, ed by Stelmach GE, Academic Press, New York, pp 55-69, 1978.

77. Keshner EA, Allum JHJ, Pfaltz CR: Postural coactivation and adaptation in the sway stabilizing responses of normals and patients with bilateral vestibular deficit. Exp Brain Res $69: 77-92,1987$.

78. Keshner $\mathbb{E A}$, Woollacott $\mathrm{MH}$, Debu B: Neck trunk and limb muscle responses during postural perturbations in humans. Exp Brain Res 71:455-466, 1988.

79. Kirby RL, Chari VR: Prostheses and the forward reach of sitting lower-limb amputees. Arch Phys Med Rehabil 71:125-127, 1990.

80. Lee DN, Lishman JR: Visual proprioceptive control of stance. J Hum Mov Sci 1:87-95, 1975.

81. Lee DN, Lishman JR: Vision - The most efficient souce of proprioceptive information for balance control. Aggressologie 18,A:83-94, 1977.

82. Levine SP, Kett RL, Ferguson-Pell M: Tissue shape and deformation versus pressure as a characterization of the seating interface. Assist Technol 2:93-99, 1990.

83. Macpherson JM, Horak FB, Dunbar DC, Dow RS: Stance dependence of automatic postural adjustments in humans. Exp Brain Res 78(3):557-566, 1989.

84. Maki BE: Selection of perturbation parameters for identification of the posture-control system in man. Med Biol Eng Comp 24:561-568, 1986.

85. Maki BE, Holliday PJ, Fernie GR: A posture control model and balance test for the prediction of relative postural stability. IEEE Trans Biomed Eng 34:797-810, 1987.

86. Manchester D, Woollacott $M$, Zederbauer-Hylton $N$, Marin $O$ : Visual, vestibular and somatosensory contributions to balance control in the older adult. J Gerontol 44:M118-127. 1989 
87. Massaro DW, Cowan N: Information processing models: Microscopes of the mind. Anmu Rev Psychol 44:383-425, 1993.

88. Massion J: Postural changes accompanying voluntary movements. Normal and pathological aspects. Hum Neurobiol 2:261-267, 1984 .

89. Massion J: Movement; posture and equilibritum: interaction and coordination. Progr Neurobiol 38:35-56, 1992 .

90. Massion J, Dufosse M: Coordination between posture and movement: Why and how? NIPS 3:88-93, 1988.

91. McClelland JL: On the time relations between mental processes: a framework for analyzing processes in cascade. Psychol Rev 86:287-330, 1979.

92. McClenaghan BA: Sitting stability of selected subjects with cerebral palsy. Clin Biomech 4:213-216, 1989.

93. Miller $J$ : Discrete and continuous models of human information processing: theoretical distinctions and empirical results. Acta Psychol 67:191-257, 1988.

94. Miller J: Discreteness and continuity in models of human intormation processing. Acta Psychol 74:297-318, 1990.

95. Moore S, Brunt D: Effects of trunk support and target distance on postural adjustments prior to a rapid reaching task by seated subjects. Arch Phys Med Rehabil 72:638-641, 1991.

96. Moore S, Brunt D, Nesbitt ML, Juarez T: Investigation of evidence for anticipatory postural adjustments in seated subjects who performed a reaching task. Phys Ther 72(5):335-343, 1992.

97. Mulder T: A process-oriented model of human motor behavior: Towards a theory-based rehabilitation approach. Phys Ther 7\|(2):157-164, 1991.

98. Mulder $\mathrm{T}$, Geurts A: The reorganization of motor control. In: Proceedings of the workshop: CAMARC, experience and new programs. Rome, November $29-30$, ed by Leo T, pp 43-55, 1990.

99. Myhr U: On factors of importance for sitting in children with cerebral palsy. Thesis. Luled. I-Tryck/Grafiska Huset, 1994.

100. Nachennson A: Electromyographic studies on the vertebral portion of the psoas muscle. Acta Orthop Scand 37:177-190, 1966.

101. Nachemson A: The possible importance of the psoas muscle for stabilization of the lumbar spine. Acta Orthop Scand 39:47-57, 1968.

102. Nashner LM: Fixed patterns of rapid postural-responses among leg muscles during stance. Exp Brain Res 30:13-24, 1977.

103. Nashner LM: Organisation and programming of motor activity during posture control in reflex control of posture and movement. Prog Broin Res 50:177-184, 1980.

104. Nashner LM, McCollum G: The organization of human postural movements: A formal basis and experimental synthesis. Behav Brain Sci 8:135-172, 1985.

105. Nashner LM, Shupert CL, Horak FB, Black FO: Organization of posture controls: an analysis of sensory and mechanical constraints. Prog Brain Res 80:411-418, 1989.

106. Nichols DS, Miller L, Colby LA, Pease WS: Sitting balance: Its relation to function in individuals with hemiparesis. Arch Phys Med Rehabil 77:865-869, 1996.

107. Nouillot $P$, Bouisset $S$, Do MC: Do fast voluntary movements necessitate anticipatory posturai adjustments even if equilibrium is unstable? Neurosci Leth 147(1):1-4, 1992 .

108. Nwabi OM: Effects of body orientation in space on tonic muscle activity of patients with cerebral palsy. Dev Med Child Nearol 28:41-44, 1986.

109. Nwatobi OM, Brubaker CE, Cusick B, Sussman MD: Electromyographic investigation of extensor activity in cerebral-palsied children in different seating positions. Dev Med Child Neurol 25:175-183,1983.

110. Oddsson LIE: Control of voluntary trunk movements in man. Thesis. Acta Physiol Scand 140, Suppl 595. 1990. 
11. Ortengren $\mathbb{R}$, Andersson GBJ: Electromyographic studies of unun muscles with special reference to the functional anatomy of the lumbar spine. Spine $2(1): 44-52,1977$.

112. Peterson MJ, Adkins HY: Measurement and redistribution of excessive pressures during wheelchair sitting. Phys Ther 62(7):990-994, 1982.

113. Proctor RW, Reeve TG, van Zandt $T$ : Salient-features coding in response selection. Im: Tutorials in motor behavior II, ed by Stelmach GE, Requin J, Elsevier Science Publishers, Amsterdam, pp 727-741, 1992.

114. Pozzo T, Berthoz A, Lefort L: Head stabilization during various locomotor tasks in humans. Exp Brain Res 82:97-106, 1990.

115. Reinders N, Risamasu A: [Postural muscle activity and pelvic position during sitting.] Postarale spieractiviteit en bekkenpositie in zit. In Dutch. MSc thesis. University Maastricht, Institute for Rehabilitation Research, Maastricht/Hoensbroek, 1995.

116. Requin J: Towards a psychobiology of preparation of action. In: Tutorials in motor behavior, ed by Stelmach GE, Requin J, North-Holland Publishing Company, Amsterdam, pp 373-398, 1985 .

117. Rosenbaum DA: Human movement initiation: specification of arm, direction and extent. $J$ Exp Psychol Gen 109:444-474, 1980.

118. Rosenbaum DA: The movement precueing technigue: Assumptions, applications and extensions. In: Memory and control of action, ed by Magill RA, North-Holland Publishing Company, Amsterdam, pp 231-274, 1983.

119. Rosenbaum DA: Motor programming; a review and scheduling theory. In: Motor behavior: programming, control and acquisition, ed by Heuer H, Kleinbeck U, Schmidt KM, Springer Verlag, Berlin, pp 1-33, 1985.

120. Sandin KJ, Smith BS: The measure of balance in sitting in stroke rehabilitation prognosis. Stroke 21:82-86, 1990 .

121. Schmidt RA: Motor and action perspectives on motor behaviour. In: Complex movement behaviour: The motor-action controversy, ed by Meijer $O G_{\text {, Roth }} \mathbb{K}$, Elsevier Science Publishers B.V., Amsterdam, pp 3-44, 1988.

122. Schmidt RA: Motor control and learning. Human Kinetics Publishers, Champaign, pp 75-98, 1988.

123. Schoberth H: Orthopädie des Sitzens. In German. Springer-Verlag, Berlin, 1989.

124. Schülldt K, Ekholm J, Harms-Ringdahl K, Németh G, Arborelius UP: Effects of sitting work posture on static neck and shoulder muscle activity. Ergonomics 29:1525-1537, 1986.

125. Schüldt $K$ : On neck muscle activity and load reduction in sitting postures. An electromyographic and biomechanical study with applications in ergonomics and rehabilitation. Scand J Rehab Med, Suppl 19:1-19, 1988.

126. Schultz AB, Andersson GBJ: Analysis of loads on the lumbar spine. Spine 6(1):76-82, 1981.

127. Schultz $A$, Andersson $G$, Örtengren $R$, Haderspeck $K$, Nachemson $A$ : Loads on the lumbar spine. J Bone Joint Surg 64A:713-720, 1982.

128. Seelen HAM, Vuurman EFPM: Compensatory muscle activity for sitting posture during upper extremity task performance in paraplegic patients. Scan J Rehab Med 23:89-96, 1991.

129. Snijders CJ, Bakker MP, Vleeming A, Stoeckart R, Stam HJ: Oblique abdominal muscle activity in standing and in sitting on hard and soft seats. Clin Biomech 10(2):73-78, 1995a.

130. Snijders CJ, Slagter AH, van Strik R, Vleeming A, Stoeckart R, Stam HJ: Why leg crossing? The influence of common postures on abdominal muscle activity. Spine 20(18):1989-1993, 1995b.

131. Sochaniwskyj A, Koheil R, Bablich K, Milner M, Lotio, W: Dynamic monitoring of sitting posture for children with spastic cerebral palsy. Clin Biomech 6:161-167, 1991.

132. Soderberg GL, Blanco MK, Casentino TL, Kurdelmeier KA: An EMG analysis of posterior trunk muscles during flat and anteriorly inclined sitting. Hum Factors 28:483-491, 1986. 
133. Spijkers WAC, Watter A: Response processing stages in choice reactions. Acta $P_{s y c h o l}$ $58: 191-204,1985$.

134. Stemberg $\$$ : The discovery of processing stages: extensions of Donder's method. In: Attention and performance $I_{4}$ ed by Koster WG, North-Holland Publishing Company, Amsterdam, pp 276-315, 1969 .

135. Teastale $\mathrm{N}$, Stelmach GE, Brennig A: Postural sway characteristics of the elderly under hormal and altered visual and support surface conditions. J Gerontol 46:B238-B244, 1991.

136. Turvey MT, shaw RA, Mace W: Issues in the theory of action: degrees of freedom, coordinative structures and coalitions. In: Attention and performance VII, ed by Requin JE, Eribaum, Hillsdale, pp 557-595, 1978.

137. de Watl M, wan Riel MPIM, Snijders Cl: The effect on sitting posture of a desk with a $10^{\circ}$ inclination for reading and writing. Ergonomics 34:575-584, 1991.

138. Winter DA, Pata AE, Frank IS: Assessment of balance control in humans. Medical progress through Technology 16:31-51, 1990.

139. Wolfson L., Whipple R, Derby CA, Amerman P. Murphy T, Tobin JN, Nashner L: A dynamic posturography study of balance in healthy ellderly. Neurology $42(11) 2069-2075$, 1992.

140. Young W: Neurophysiotogy of spinal cord injury. In: Spinal trauma, ed by Errico TJ, Baner RD, Waugh T, JB Lippincott Company, Philadelphia, pp 377-414, 1991.

141. Zacharkow D: Wheetchair poseure and pressure sores. $\mathrm{CC}$ Thomas Publisher, Springfield, 1984.

142. Zacharkow D: Posture, sitting, standing, chair design and exercise. CC Thomas Publisher, Springfield, 1988.

143. Zajac FE, Winters JM: Modeling musculoskeletal movement systems: Ioint and body segmental dynamics, musculoskeletal Actuation, and Neuromuscular Control. In: Multiple muscle systems, ed by Winters JM, Woo SLY, Springer-Verlag, New York, pp 121-148, 1990.

144. Zattara M, Bouisset S: Posturo-kinetic organisation during the early phase of voluntary upper limb movement. I Normal subjects. J Neurol Neurosurg Psychiatry 51:956-965, 1988. 


\section{Impaired balance control in paraplegic subjects}

H.A.M. Seelen ${ }^{1}$, Y.J.M. Potten ${ }^{1,2}$, A. Huson ${ }^{3}$, F. Spaans ${ }^{4}$, J.P.H. Reulen ${ }^{4}$

Institute for Rehabilitation Research, Hoensbroek, the Netherlands

University Maastricht, Department of Anatomy and Embryology, Maastricht, the Netherlands

University Maastricht, Department of Movement Sciences, Maastricht, the Netherlands

* University Hospital Maastricht, Department of Clinical Neurophysiology, Maastricht, the Netherlands

Reprinted from Journal of Electromyography and Kinesiology, Vol. 7(2), Seelen HAM, Potten YJM, Huson A, Spaans F, Reulen JPH: Reorganisation of postural control in spinal cord injured persons, pp. 149-160, Copyright 1997, with kind permission from Elsevier Science Ltd, The Boulevard, Langford Lane, Kidlington 0X5 $1 \mathrm{~GB}, \mathrm{UK}$. 


\section{Summary}

Postural muscle use during sitting balance control in persons with a complete thoracic spinal cord injury (SCI) was studied. It was hypothesised that these subjects use non-postural muscles like the latissimus dorsi (LD) and the ascending part of the trapezius (TPA) to restore sitting balance, whereas non-SCI subjects primarily use their erector spinae (ES). This adaptive postural strategy in SCI subjects presupposes stabilising effects of the scapular protractors, like the pectoralis major (PM) and the serratus anterior (SA), on the shoulder girdle. Sitting balance was perturbed systematically in three groups of either low thoracic SCI, high thoracic SCI or non-SCI participants. Centre of pressure changes and activity of the LD, TPA, PM, SA, ES and oblique abdominal muscles during task execution were measured. Since non-SCI subjects differ from SCI subjects in their ability to tilt their pelvis during sitting, also the correlation between pelvic movement and postural changes during task execution was investigated. Results indicate that high thoracic SCI subjects use their LD, TPA, PM, SA and high thoracic part of the ES more in situations of similarly perturbed sitting balance than non-SCI subjects. Differences are smaller in the low thoracic SCI group. A kinematic concept combining alternative postural muscle activity and altered movement in thoracic SCI subjects is discussed.

\section{Introduction}

Human movement in general involves complex processes at perceptive, cognitive and motor levels. In healthy, non-sensorimotor impaired, people maintaining sitting balance is a highly automated process which demands little attention. In people suffering from spinal cord injury (SCI) this automatism is impaired. New patterns of postural control, involving parts of the sensorimotor system still intact, have to be acquired by the SCI patient during rehabilitation. This implies compensation of loss of function and reduction of disabilities rather than restoration of function. Although a great amount of clinical experience about therapy outcome has been acquired, many of the mechanisms by which movement therapy might influence or enhance reorganisation of motor control and more specifically postural control in e.g. SCl patients are still largely unknown (6). Postural control in this paper refers to the ability of a person to maintain both equilibrium and posture against perturbing internal and external influences. Massion and co-workers $[10,11]$, in line with many other authors $[5,9]$, define equilibrium as "the stabilisation of the body as a whole with respect to the supporting surfaces", which, in static conditions, "occurs only when the projection on the ground of the centre of gravity is placed within the supporting area" $[10,11]$. Posture on the other 
hand is defined as the position of body segments relative to each other at a given time.

Many studies about sitting focus on the adaptation of seat support interrelating with biomechanical and neuromuscular stress $[1-5,7,12,14,15,18 \rrbracket$. Research into (impaired) postural control in seated subjects has been carried out less frequently. Several studies have shown that SCI subjects with e.g. high thoracic spinal cord lesions compensate for the loss of postural muscle activity by using nonpostura] muscles $[8,16]$. However, one may wonder which biomechanical and neurophysiological mechanisms underlie this phenomenon in seated $\mathrm{SCI}$ subjects. One, widely held, view is that seated thoracic SCI subjects stabilise the trunk and the spine relative to a punctum fixum as near as possible to the base of support, i.e. (externally) the seat and as such (internally) the pelvis and the adjacent part of the spine, by using the latissimus dorsi (LD) and the ascending part of the trapezius (TPA) while fixating the shoulder girdle. The anatomical position and cervical innervation of the LD, with its insertion in the thoraco-lumbar region, and the TPA, with its insertion on the low thoracic vertebral spinous processes, seem to be both biomechanically and neurologically favourable to this concept. This in contrast to the rhomboidei and the levator scapulae which do not have the aforementioned biomechanically favourable position to stabillise the spine in thoracic SCI subjects. This concept would imply that, in order to prevent mere retraction of the scapulae by LD and TPA activity, forces protracting the scapulae should be generated either passively, caused by e.g. gravity during kyphotic sitting, or actively using muscles still controllable like the pectoralis major (PM) and serratus anterior (SA). It would also mean that the pelvis and the lumbar spine should be stabilised in order to act as a punctum fixum. Because of their innervation level the oblique abdominal (OA) muscles may be paretic or paralytic in SCI subjects. If part of the $O A$ can be actively controlled it could be used in a synergetic muscle pattern together with the PM and the SA and serve as an antagonist of the ES-LD-TPA synergy to stabilise the trunk relative to the base of support.

In view of the proposed concept of alternative postural muscle use and altered movement in thoracic SCI subjects, several questions can be posed. Firstly, to what extent is sitting balance control impaired in SCI subjects? Secondly, does increased activity of the LD and TPA occur in thoracic SCI subjects during sitting balance restoration after balance perturbation? Thirdly, does increased PM and SA activity occur simultaneously with both restoration of sitting balance and increased LD and TPA activity in thoracic SCI subjects? An experiment aimed at investigating alternative postural muscle use in $\mathrm{SCl}$ subjects has been carried out (experiment 1). Evidence substantiating the aforementioned concept will be presented, which may both corroborate and extend earlier findings by Seelen and Vuurman [16] and Do et al. [8].

Intricately related to the differences in postural motor control, gross kinematic differences occur between seated thoracic SCI and non-SCI subjects, especially in pelvic tilt, spinal movement and reduced upper body movement during 
task execution. Data from a first experiment gave rise to a fourth question, i.e.: How does pelvic movement and movement of the lower part of the spine correlate with sitting balance control? The link between postural changes and antero-posterior pelvic movement, recorded during the initial stage of a balance perturbing reaching movement, was examined in an additional experiment (experiment 2).

\section{Methods}

\section{Experiment 1}

\section{Subjects}

In a first experiment 15 non-SCI subjects (N-group), 15 subjects with a complete low thoracic SCI at spinal level T9 - T12 (L-group) and 15 subjects with a complete high thoracic SCI at spinal level T2 - T8 (H-group) participated. SCI subjects had completed their active rehabilitation process at least 1 year before. No secondary pathology was present in any of the subjects. Groups were matched for age, sex, weight, height, left or right handedness (Table 3.1) and educational level.

Table 3.1. Group composition.

\begin{tabular}{lllll}
\hline & & N-group & L-group & H-group \\
& & & 15 & 15 \\
\multirow{2}{*}{ age (year) } & mean (s.d.) & $34.8(10)$ & $36.8(10)$ & $34.3(8)$ \\
& range & $22-56$ & $26-55$ & $24-51$ \\
weight $(\mathrm{kg})$ & $\begin{array}{l}\text { mean (s.d.) } \\
\text { range }\end{array}$ & $73.9(8)$ & $69.6(13)$ & $73.4(13)$ \\
& & $53.7-88.9$ & $45.7-91.8$ & $49.3-102.6$ \\
height $(\mathrm{m})$ & $\begin{array}{l}\text { mean (s.d.) } \\
\text { range }\end{array}$ & $1.78(0.06)$ & $1.78(0.11)$ & $1.81(0.11)$ \\
& & $1.68-1.86$ & $1.53-1.98$ & $1.58-2.00$ \\
sex & $\mathrm{M} / \mathrm{F}$ & $14 / 1$ & $14 / 1$ & $13 / 2$ \\
handedness & left $/$ right & $1 / 14$ & $1 / 14$ & $\mathbb{1} / 14$ \\
\hline
\end{tabular}

$\mathrm{N}$-group $=$ non-SCI group; L-group $=$ low thoracic SCI group; H-group $=$ high thoracic $\mathrm{SCI}$ group; $\mathrm{M}=$ male; $\mathrm{F}=$ female. 
The levels of spinal cord injury of subjects from the $\mathrm{L}$ - and the $\mathrm{H}$-group are given in Table 3.2.

Table 3.2. Levels of complete spinal cord lesion of subjects in the $\mathrm{L}-$ and the H-group.

high SCI (H-group) low SCl (L-group)

\begin{tabular}{cccccccccccc} 
& $\mathrm{T} 2$ & $\mathrm{~T} 3$ & $\mathrm{~T} 4$ & $\mathrm{~T} 5$ & $\mathrm{~T} 6$ & $\mathrm{~T} 7$ & $\mathrm{~T} 8$ & $\mathrm{~T} 9$ & $\mathrm{~T} 10$ & $\mathrm{~T} 11$ & $\mathrm{~T} 12$ \\
$\mathrm{n}$ & 1 & 0 & 4 & 3 & 2 & 3 & 2 & 1 & 5 & 3 & 6 \\
\hline
\end{tabular}

Informed consent was obtained from all participants prior to the beginning of this study. All experimental protocols in this study were approved by the local medical ethical committee.

\section{Task and apparatus}

Subjects were seated behind a table in a multi-adaptable chair fixed on an AMTI force platform (Biovec-1000, AMTI, Watertown, Mass.). All subjects of all groups sat in this chair during the experiments. Tilt angle of the chair was $0^{\circ}$, reclination angle was $10^{\circ}$. Arm rests were not used by the participants. Leg rests were at a $10^{\circ}$ angle relative to the frontal plane. Height of the foot supports and seat depth were adjusted for individual anthropometrical measures in line with the work of Zacharkow [20]. Tabletop was approx. $3 \mathrm{~cm}$ above elbow height. The initial posture, which was equivalent for all subjects, was dictated by the chair configuration. One, rectangular, central start button (SB) (dimensions: $1.5 \times 2.3 \mathrm{~cm}$ ) was placed on the table about $25 \mathrm{~cm}$ in front of the seated subject. Also eight round peripheral target buttons were placed on the table in two rows of four, in parasagittal direction. These target button pairs were placed at locations marking $15 \%, 30 \%$, $75 \%$ and $90 \%$ of the individual unsupported maximal reaching distance of the participant (conditions A, B, C and D) as is depicted in figure 3.1. This meant that, although absolute button distance could vary between subjects and between groups because of e.g. anthropometrical differences between subjects or differences in postural control between groups, relative button distance was kept constant for all subjects for all groups. Distance between target buttons in the left and right row was $15 \mathrm{~cm}$. Target button diameter was $1.5 \mathrm{~cm}$. Positive contact force for all buttons was about $2 \mathrm{~N}$.

Maximal reaching distance in the sagittal plane, which the participant was able to cover without manual support on the table, was measured. Subjects were asked to perform multiple bimanual reaching movements in the sagittal plane towards the target button pairs placed at $15 \%, 30 \%, 75 \%$ or $90 \%$ of their individual maximal reaching distance, introducing graded systematical sitting balance 
Figure 3.1. Arrangement as used in experiment 1.

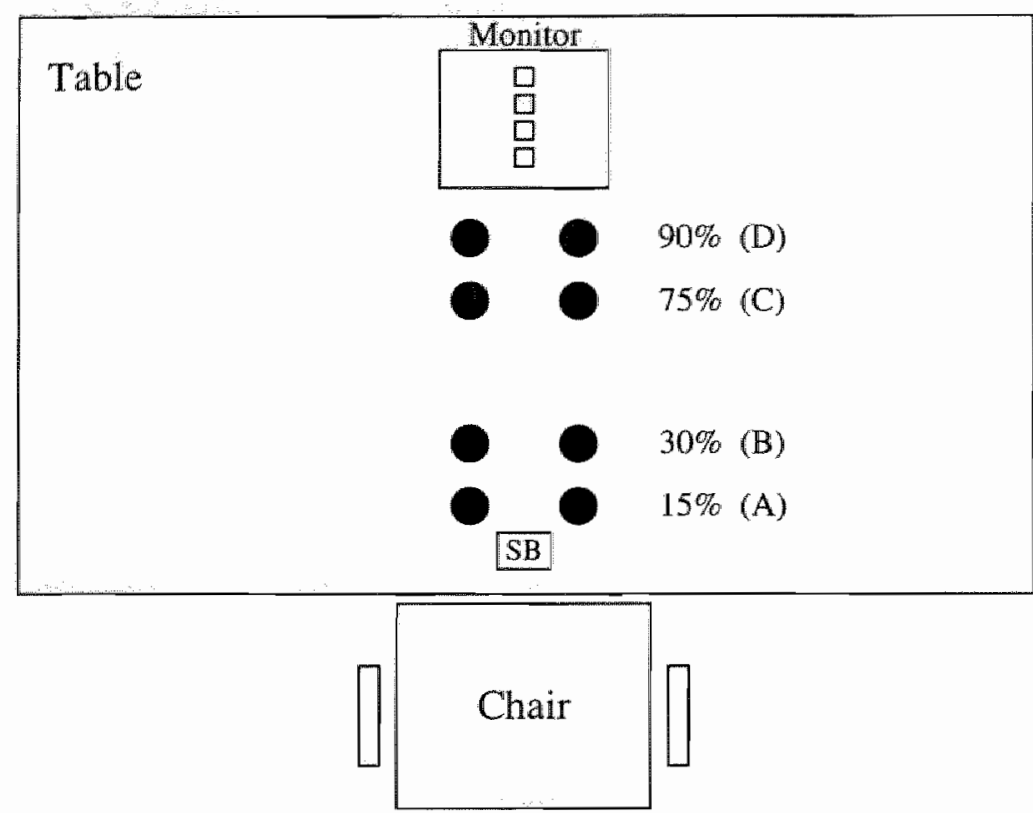

$\mathrm{SB}=$ start button; $\mathrm{A}, \mathrm{B} \times \mathrm{C}$ and $\mathrm{D}=$ peripheral button pairs at different (relative) reaching distances.

perturbation in all subjects. The movement included arm displacement and possible trunk displacement in antero-posterior direction. The 90\% reaching distance was chosen to avoid complete balance loss in SCI subjects during task performance. A clear distinction was made between relatively easy coverable reaching distances of $15 \%$ and $30 \%$ on the one hand and $75 \%$ and $90 \%$ on the other hand which were thought to be more difficult to cover by SCI subjects. During initial sitting position the proximally placed start button (SB) was lightly pressed. Information as to reaching distance was presented as a visual choice reaction lime task on a personal computer (Compaq deskpro 386sx, Compaq Computer Co., Houston. Texas). Timing of the task was performed using a PCL830 timer/counter board (Advantech Co, Taiwan). A standard 14 inch VGA monitor was located at a distance of approximately $1.25 \mathrm{~m}$ in front of the subject. On the monitor one centrally located row of four squares that spatially corresponded to the four pairs of target buttons was displayed during the experiment. The subject had to start each trial by holding down the SB with both hands. After $3250 \mathrm{~ms}$ a visual warning signal (WS) was presented as small open squares within the original squares already present on the screen. An imperative stimulus (ISt) (i.e. a "sign) was displayed in one of the 
four small squares after $750 \mathrm{~ms}$ relative to the WS-onset. The ISt indicated the location of the button pair the subject had to reach to. When the ISt appeared the subject had to release the SB and move both hands as fast as possible towards the correct button pair. Peripheral buttons were to be pressed 5 times, causing a prolonged period in which maintaining sitting balance was thought to be more difficult, especially in SCI-subjects. Subsequently the subject had to move back to his initial sitting position as fast as possible and press SB again. The experiment consisted of two series of 64 trials each. Each of the four reaching distances was presented 16 times in random order per series. The intertrial interval was at least $3 \mathrm{~s}$. Each series lasted approx. 12 minutes. To avoid fatigue a resting period of at least 4 minutes was introduced between series. Written instructions regarding the task and the reaching movement were given at the start of the experiment. Six to eight training trials were given in advance to familiarise the subject with the task.

During task execution force platform signals were recorded. Simultaneously bilateral EMG activity from the latissimus dorsi (LD), the ascending part of the trapezius trapezius (TPA), the serratus anterior (SA), the sternocostal head of the pectoralis major (PM), the oblique abdominal muscles $(\mathrm{OA})$ and the erector spinae (ES) at level L3, T9 and T3 was recorded (K_Lab MF-118 and SPA-12, K_Lab, Amsterdam, Neth.) using $\mathrm{Ag}-\mathrm{AgCl}$ disposable electrodes with an $1 \mathrm{~cm}^{2}$ contact surface (Graphic Controls Corp., Buffalo, NY). Inter-electrode distance was $2.3 \mathrm{~cm}$. All pairs of electrodes were placed in the direction of the fibres of the different muscles. Position of the ES electrodes was $2.5 \mathrm{~cm}$ lateral to the spinous processes. LD electrodes were placed $3.5 \mathrm{~cm}$ caudo-lateral to the inferior angle of the scapula. TPA and OA electrodes were placed on the bulkiest part of the muscle belly. SA electrodes were placed on the muscle part originating from the fifth rib anterior to the LD muscle. PM electrodes were placed in the middle of the cranial part of the sternocostal head. A grounding electrode was attached to the lower leg. Reaction time (RT), movement times (MT) and button status were also recorded on a separate event channel. On a second Compaq $386 \mathrm{sx}$ computer signals were A/D-converted and stored using 16 single ended channels on a DT2824 PGL data-acquisition board (Data Translations, Marlboro, Mass.) and MUCAPS software (Institute for Rehabilitation Research, Hoensbroek, Neth.). Sample frequency was $500 \mathrm{~Hz}$. Sample time was $5 \mathrm{~s}$, starting $250 \mathrm{~ms}$ before the WS onset. Because of the limited number of channels on the data-acquisition board the task series of 64 trials was executed twice, in a counterbalanced design. During one task series one event signal, six force platform signals and eight EMG signals from the bilateral ES-L3, ES-T9, ES-T3 and SA were recorded. During the second task series, again, one event signal, six force platform signals were recorded as well as eight EMG signals from the bilateral OA, PM, LD and TPA. The task series order was random. At the end of the experiment data were stored on magnetic computer tape (Tape Shuttle 1000, Shuttle Technology LTD, India). Activities of both computers were synchronised by the PCL 830 board. 


\section{Data analysis}

Signals were analysed off-line using MATLAB software (The Math Works Inc., Natick, Mass.). Statistical analyses were performed using SPSS (SPSS Inc., Chicago, 111.). From the force plate signals centre of pressure (CP) displacement during task performance was calculated. According to Winter [19] the $\mathrm{CP}$, i.e. the location of the vertical ground reaction vector from the force plate, can be viewed as the neuromuscular response to imbalances of the body's centre of gravity [19]. Maximum CP displacement (CPmax) and mean rectified EMG values per trial, for all groups, for all reaching conditions, were calculated over a period in which maintaining sitting balance was more difficult, i.e. around final button release (Ty) of the target buttons (period $Y$ ), as is depicted in figure 3.2. Period $Y$ was delimited by $\mathrm{Ty} \pm 0.2 * \mathrm{MT}_{3} . \mathrm{MT}_{3}$ was the phase between final peripheral button release and renewed $\mathrm{SB}$ contact in which restoration of sitting posture to the initial position occurred. $\mathrm{MT}_{1}$ was the period between $\mathrm{SB}$ release and peripheral button press which corresponded to the time needed for forward reaching. $\mathrm{MT}_{2}$ was a time period between first contact with the peripheral button and final peripheral button release in which a prolonged forward reaching position was maintained by the subject (See also figure 3.2). Between-group differences in EMG and CPmax were tested subsequently using two-way MANOVA's (factors: group and reaching distance) and additional multiple comparison techniques combined with the Bonferroni approach. Since SCI subjects can not reach as far as non-SCI subjects during sitting, two main types of data comparison were used. First, conditions in which relative reaching distance between groups was the same, were analysed (i.e. conditions of $15,30,75$ and $90 \%$ of the maximal reaching distance). Secondly, conditions in which absolute reaching distance between groups was equivalent, were evaluated (i.e. D, C and B conditions for the $\mathrm{H}-, \mathrm{L}-$, and $\mathrm{N}$-group respectively).

\section{Experiment 2}

\section{Subjects}

In the second experiment, aimed at investigating the relation between pelvic and spinal movement and CP displacement during the initial stage of a bimanual submaximal reaching during sitting, 3 male and 7 female non-SCl subjects (mean age 21.6 , sd 1.6) participated.

\section{Task and apparatus}

Subjects sat in the same chair as was used in experiment 1 . However, the backrest and armrests were removed. Via a visual simple reaction time task participants were instructed to perform bimanual reaching movements towards one pair of buttons placed at $90 \%$ of their maximal reaching distance in the sagittal plane. In contrast to experiment 1 , in which phases of graded balance perturbation were of interest, the primary phase of interest in experiment 2 was at movement 
Figure 3.2. Example of signals recorded during task execution.
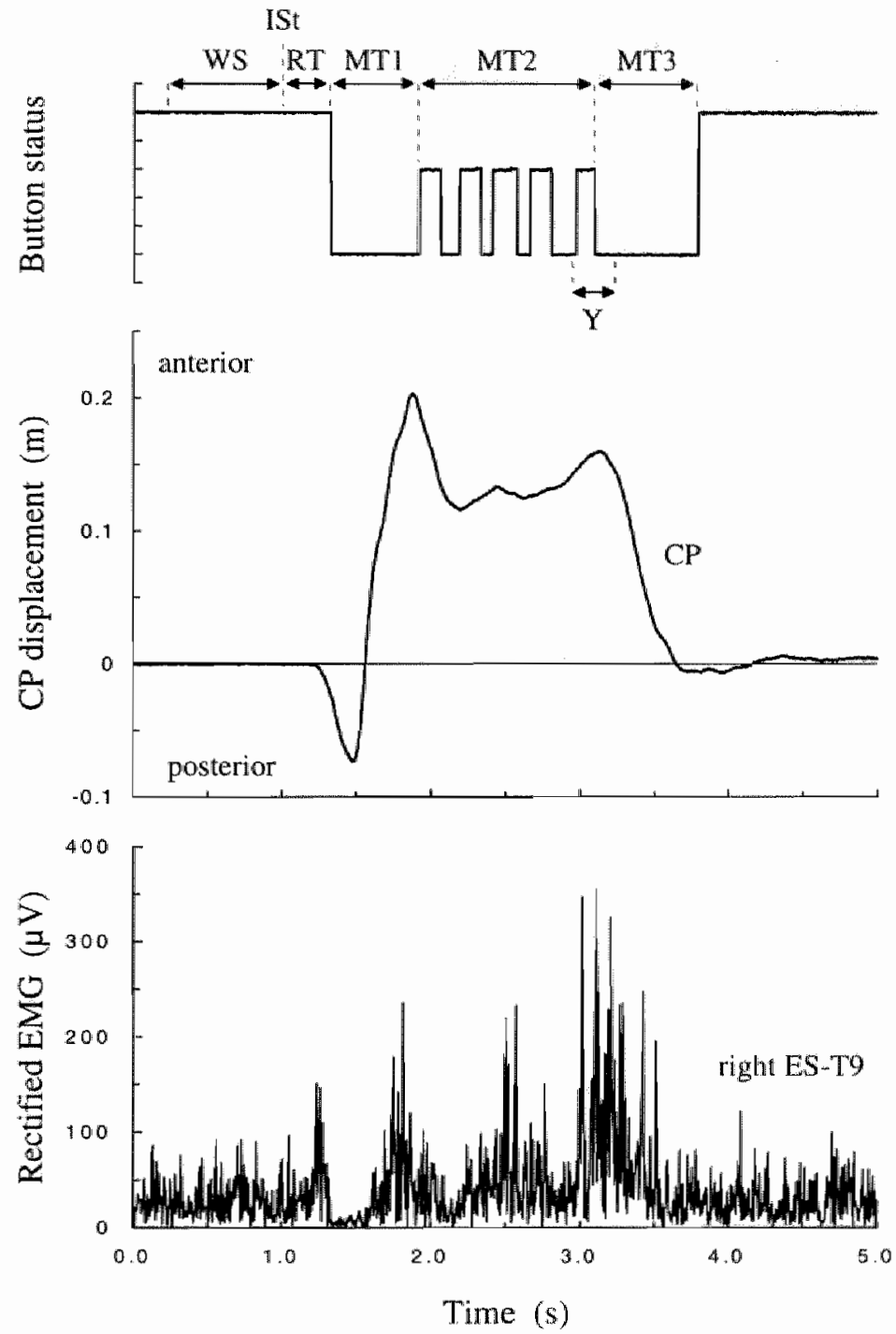

WS = warning signal; $I S t=$ imperative stimulus; $C P=$ centre of pressure; $R T=$ reaction time; $M T_{1}$ $=$ mowement time between central button release and peripheral button press (i.e. forward reaching time); $\mathrm{MT}_{2}=$ time between first contact with peripheral button and final peripheral button release (i.e. prolonged period of forward reachning position); $\mathrm{MT}_{3}=$ time between final peripherial button release and renewed central button contact (i.e. time for restoration of sitting posture to the initial position); $\mathrm{ES}-\mathrm{T} 9=$ erector spinae muscle at level $\mathrm{T} 9 ; \mathrm{Y}=$ period around final target button release. 
onset. Therefore subjects were instructed to press peripheral buttons only once instead of five times. Display of information on the screen was similar to experiment 1 . One square that spatially corresponded to the pair of peripheral buttons on the table was displayed during the experiment. The subject had to start each trial by holding down the centrally placed SB with both hands. After $3250 \mathrm{~ms}$ a visual warning signal (WS) was presented for a period between 1000 and $3000 \mathrm{~ms}$ in order to avoid anticipation. The WS was presented as a small open square within the original square already present on the screen. An imperative stimulus (ISt) (i.e. a "E" sign) was displayed within the small square of the WS immediately after the WS, instructing the subject to reach towards the peripheral pair of buttons with both hands as fast as possible. After pressing the peripheral button pair the subject had to move back to his initial siltting position as fast as possible and press SB again. The intertrial interval was at least $3 \mathrm{~s}$. Procedures as to written instruction and pre-test training of the task were similar to experiment 1. Per subject eight trials were recorded.

Force platform signals were recorded. Also reaction time (RT), movement time (MT) and button status were recorded. The same force platform equipment was used as in experiment 1 . Sample time was $5 \mathrm{~s}$, starting $250 \mathrm{~ms}$ before the onset of the WS. Sample frequency was $500 \mathrm{~Hz}$. Intertrial interval was at least $3 \mathrm{~s}$. Simultaneously with task execution three dimensional (3D) movements of the pelvis and the lumbar and lower thoracic spine were recorded with an infrared camera system PRIMAS (Delft Motion Analysis, Delft, Neth.) using 4 cameras. Cameras were positioned in a semi circle, lateral and posterior to the seated subject. Camera position was at greater trochanter height at approximately $1.8 \mathrm{~m}$ distance to the pelvis. Retroreflective camera markers, $2.5 \mathrm{~cm}$ in diameter, were placed on anatomical landmarks of the femur (lateral femoral epicondyle (LFE) and greater trochanter (GT)), the pelvis (anterior superior iliac spine (ASIS) and posterior superior iliac spine (PSIS)) and the lower part of the spine (spinous processes L3, L1, T11, T9). Sample time was $7 \mathrm{~s}$, sample frequency was $100 \mathrm{~Hz}$. One image frame, displaying all markers, was recorded per $10 \mathrm{~ms}$. The 3D signals were electronically synchronised to the force platform signals. Before the experiment, the position of the camera system was calibrated. The size of the 3D measuring volume was about $1 \times 1 \times 1 \mathrm{~m}$. Camera inaccuracy for this measuring volume was less than $1 / 2000 \mathrm{~m}$.

\section{Data analysis}

The position of the camera markers was calculated using PRIMASYS software (Delft Motion Analysis, Delft, Neth.). Spatial displacement of the markers on the spine, the pelvis, the GT's and LFE's was calculated. An example of spatial marker displacement during the phase in which forward reaching towards the peripheral buttons occurred, is given in figure 3.3. 
Figure 3.3. Lateral view of marker displacement during forward reaching.

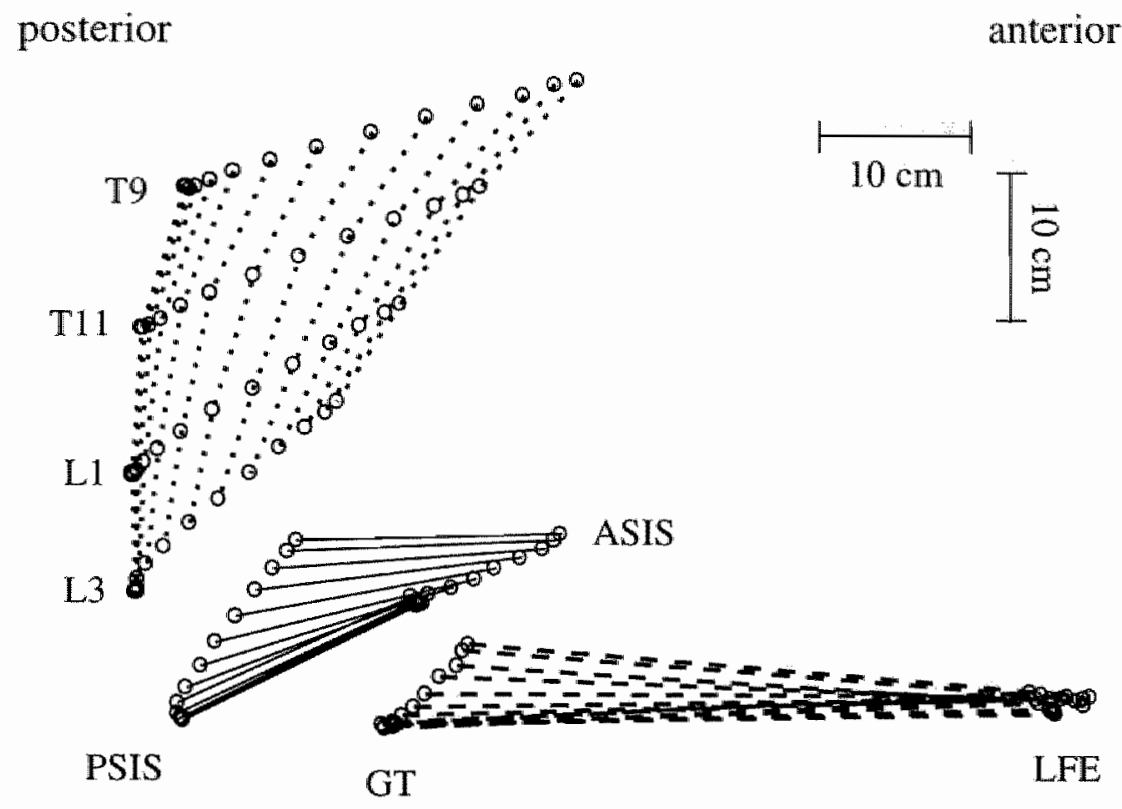

Here a non-SCI subject reached towards peripheral buttons placed and $90 \%$ of his maximal reaching distance in the medio-sagittal plane. For clarity reasons only the spinal markers and right pelvic and right leg markers are displayed at a frame rate of 1:5 (i.e. $20 \mathrm{~Hz}$ ). Time interval of the movement shown here started at $t=0 \mathrm{~s}$ and ended when the peripheral button was pressed. L3, L1, $\mathrm{T} 11$ and $\mathrm{T} 9=$ markers on the spine; PSIS = posterior superior iliac spine marker; $\mathrm{ASIS}=$ anterior superior iliac spine; GT = greater trochanter; $L F E=$ lateral femoral epicondyle.

From the real world co-ordinates of the bilateral ASIS and PSIS markers a unit vector (UVc) system, per image frame, was calculated for the pelvis (figure 3.4). The first UVc $(\mathrm{z})$ was parallel to the line through both ASIS. The second UVc $(\mathrm{x})$ was perpendicular to the first UVc and its work line crossed through the midpoint between both PSIS. The third UVc (y) was perpendicular to both the first and second UVc. The second and third UVc defined the sagittal plane of the pelvis. The changes of the angle of the third UVc in the sagittal plane corresponded to the relative antero-posterior pelvic tilt during task performance. 
Figure 3.4. Defined unit vector system of the pelvis.
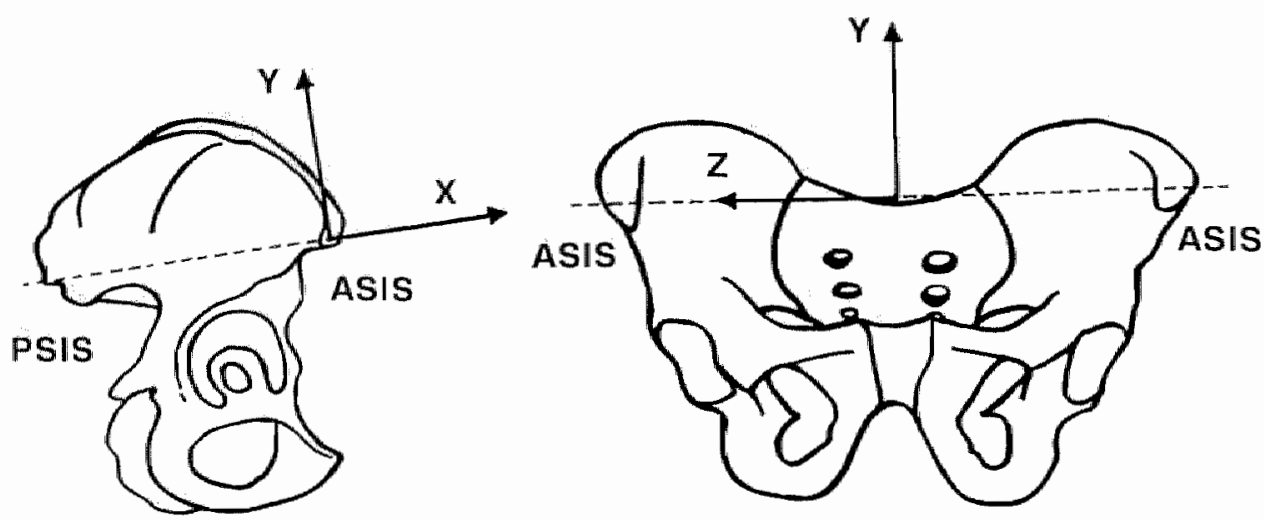

Laterall and anterior view of the pelvis. PSIS = posterior superior iliac spine marker; ASIS = anterior superior iliac spine; $z=$ unit vector (UVC) parallel to the line between both $A S I S ; x=$ UVc, perpendicular to $z$, of which the work line crosses the midpoint between both PSIS; $y=U V_{c}$ perpendicular to $x$ and $z$.

From the force platform data changes in the CP during task execution were calculated. Average increase in pelvic tilt angle in the sagittal plane during maximal posterior $\mathrm{CP}$ displacement relative to the pelvic position prior to the ISt was calculated. An one-way analysis of variance by ranks (Kruskal-Wallis) was performed on these data. Both onset time of $\mathrm{CP}$ displacement and anterior pelvic tilt were also computed. First $\mathrm{CP}$ and anterior pelvic tilt signals were filtered using a median filter [13] with a window length of $10 \mathrm{~ms}$. Signal onset was defined as the time at which the filtered signal exceeded a predefined limit, set at signal mean plus two times SD, calculated over the WS period.

The antero-posterior force component (i.e. $y$-direction) of the force platform, normalised for body weight (FNy), was also computed. The antero-posterior force indicates forward or backward acceleration of the centre of mass. From the FNy signal maximal posterior directed FNy (FNy_max) during the initial phases of movement, i.e. between ISt onset and peripheral button press was calculated. 


\section{Results}

\section{Experiment 1}

Trials in which RT was shorter than $125 \mathrm{~ms}$ or longer than $1200 \mathrm{~ms}$ were discarcled $(0.91 \%)$, as were trials in which $\mathrm{MT}_{1}$ was shorter than $50 \mathrm{~ms}$ or longer than $1500 \mathrm{~ms}(0.24 \%)$. Trials in which wrong button press occurred, were also removed $(0.07 \%)$. Error analysis did not reveal significant differences in error occurrence between groups or conditions.

$\mathrm{CP}$ data indicate a high within subject reproducibility as has been reported by Seelen [17]. Examples of typical CP changes in the antero-posterior direction during condition $\mathrm{D}$ (reaching towards buttons at $90 \%$ of the maximum reach) for non-SCI subjects and subjects with a SCI at level T12 or T4 in experiment 1 are depicted in figure 3.5. Note the strong posterior displacement of the $\mathrm{CP}$ of the non-SCI subject shortlly after SB is released and the absolute decrease of this phenomenon in SCI subjects. Also a marked difference in $\mathrm{CP}$ displacement during the $\mathrm{MT}_{2}$ phase between the non-SCI subject, the T12 SCI subject and the T4 SCl subject can be observed in figure 3.5 .

Figure 3.5. A typical example of antero-posterior $\mathrm{CP}$ displacement during bimanual forward reaching.

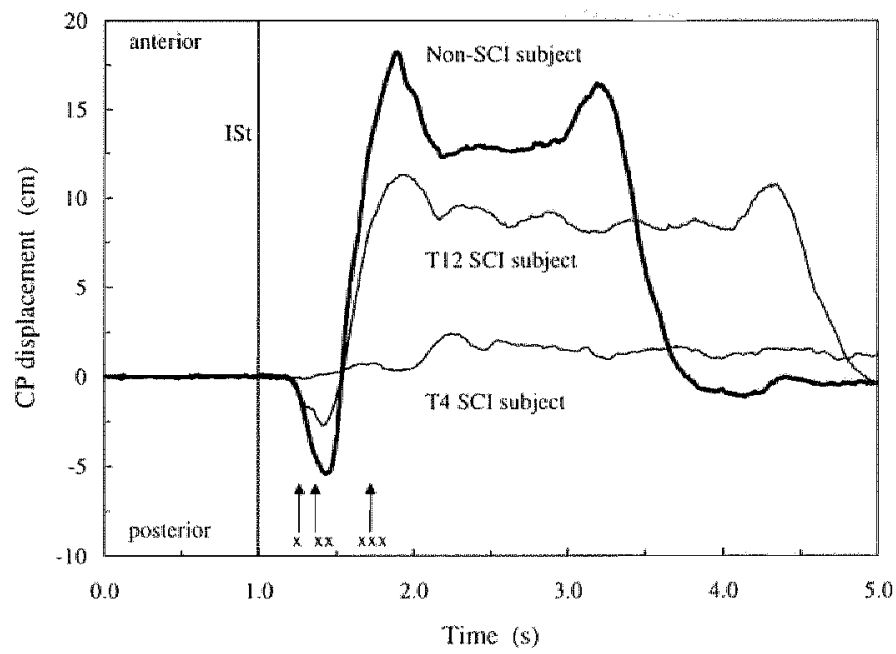

$\mathrm{CP}=$ centre of pressure; $\mathrm{ISt}=$ imperative stimulus.

The moment of start button release, indicated by the vertical arrows, was at $t=1268$ ms for the nonSCI subject $(x), t=1370 \mathrm{~ms}$ for the T12 subject $(x x)$ and $t=1725 \mathrm{~ms}$ for the TA subject $(x \times x)$. 
The absolute range in which non-SCI group members were able to shift their $\mathrm{CP}$ was significantly larger than in both $\mathrm{SCI}$ groups $(\mathrm{p}<0.001)$. Although $\mathrm{CPmax}$ increased simultaneously with reaching distance in all groups $(p<0.001)$, results indicate that this increase was less in SCI subjects, as is signified by a group by reaching distance interaction $(\mathrm{p}<0.001)$. Results and statistical analysis also show significant differences between the $\mathrm{L}$ - and the H-group, whereby mean CPmax is larger in the L-group ( $<<0.001)$, as is the increase in CPmax during increase of reaching distance $(p<0.001)$. Average $C P \max$ data, recorded during bimanual forward reaching, and $99 \%$ confidence intervals of the mean, for all groups, for all conditions, are presented in ligure 3.6.

Figure 3.6. Average CPmax values and $99 \%$ confidence interval of the mean for all groups, for all four reaching distance conditions.

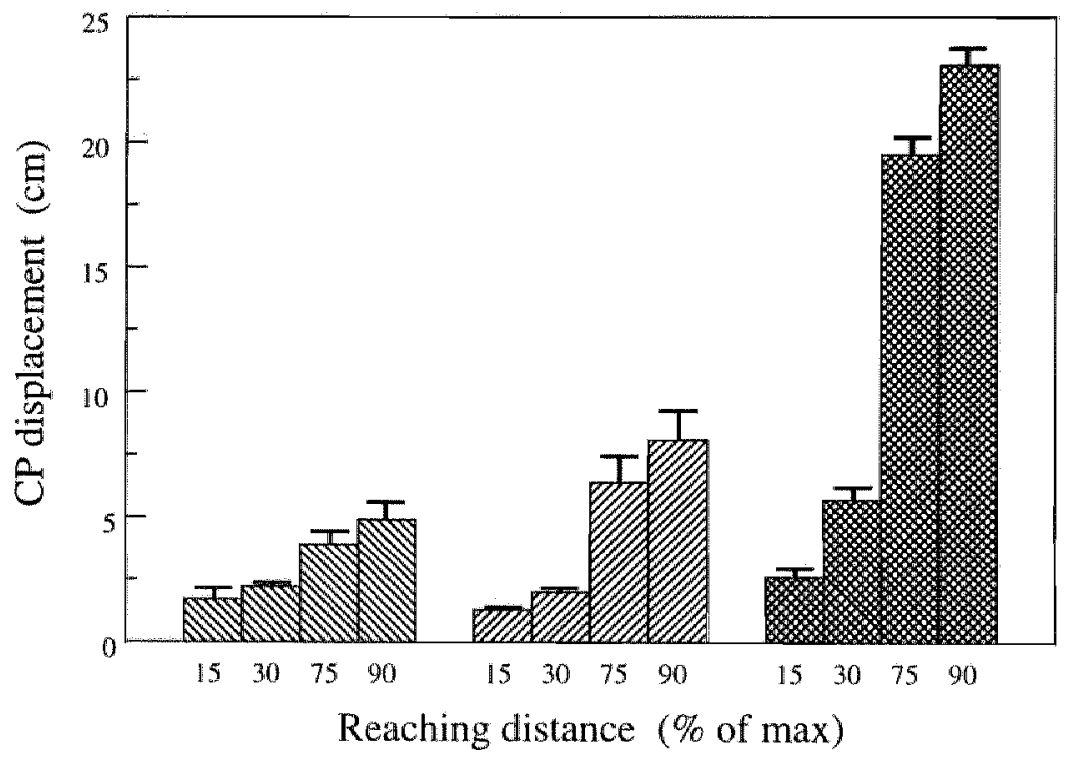

$\mathbb{W}_{\text {H-group }} \mathbb{Z}_{\text {L-group }}$ Nagroup

$\mathrm{CP}=$ centre of pressure.

Mean rectified EMG values of the left and right ES-L3, ES-T9 ES-T3, SA, OA, PM, $L D$ and TPA recordled during period $Y$ for all groups and for all conditions, are presented in figure 3.7 and 3.8 . 
Figure 3.7. Mean rectified EMG values and corresponding linear regression lines for the bilateral ES-L3, ES-T9, ES-T3 and SA, for all balance perturbation conditions, for all groups, during period $Y$.

left
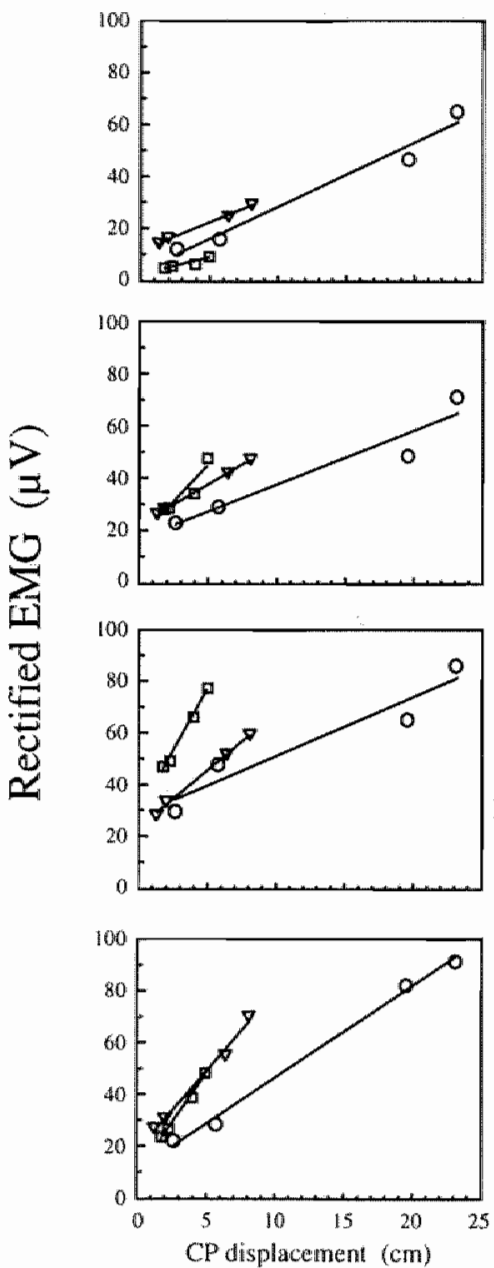

right
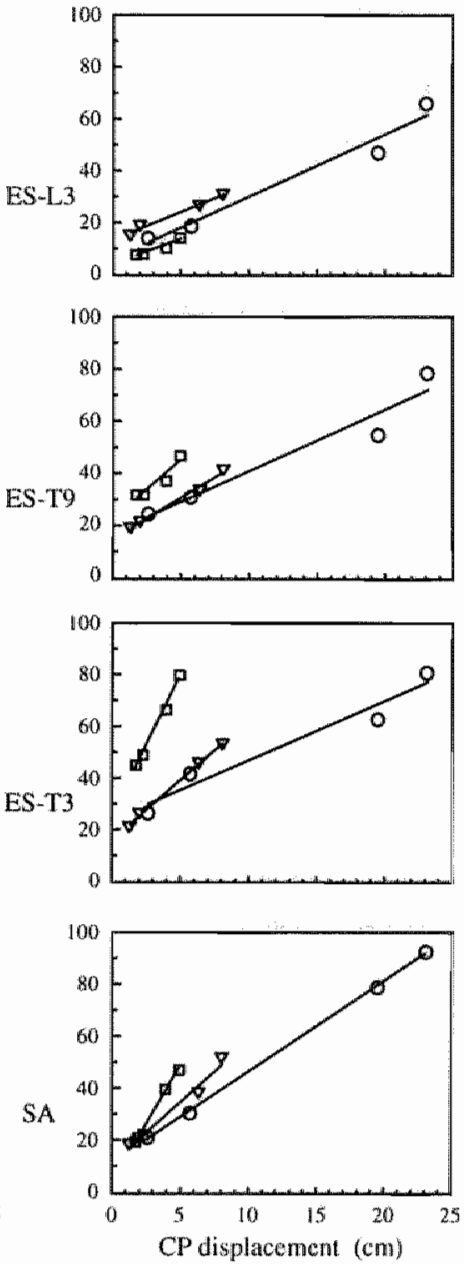

\section{$\square$ H-group $\quad \nabla$ L-group O N-group}

$\mathrm{ES}-\mathrm{L} 3$ = erector spinae $\mathrm{L} 3 ; \mathrm{ES}-\mathrm{T} 9=$ erector spinae $\mathrm{T} 9 ; \mathrm{ES}-\mathrm{T} 3=$ erector spinae $\mathrm{T} 3 ; \mathrm{SA}=$ serratus anterior; $\mathrm{CP}=$ centre of pressure. 
Figure 3.8. Mean rectified EMG walues and corresponding linear regression lines for the bilateral OA, PM, LD and TPA, for all balance perturbation conditions, for all groups, during period $Y$.
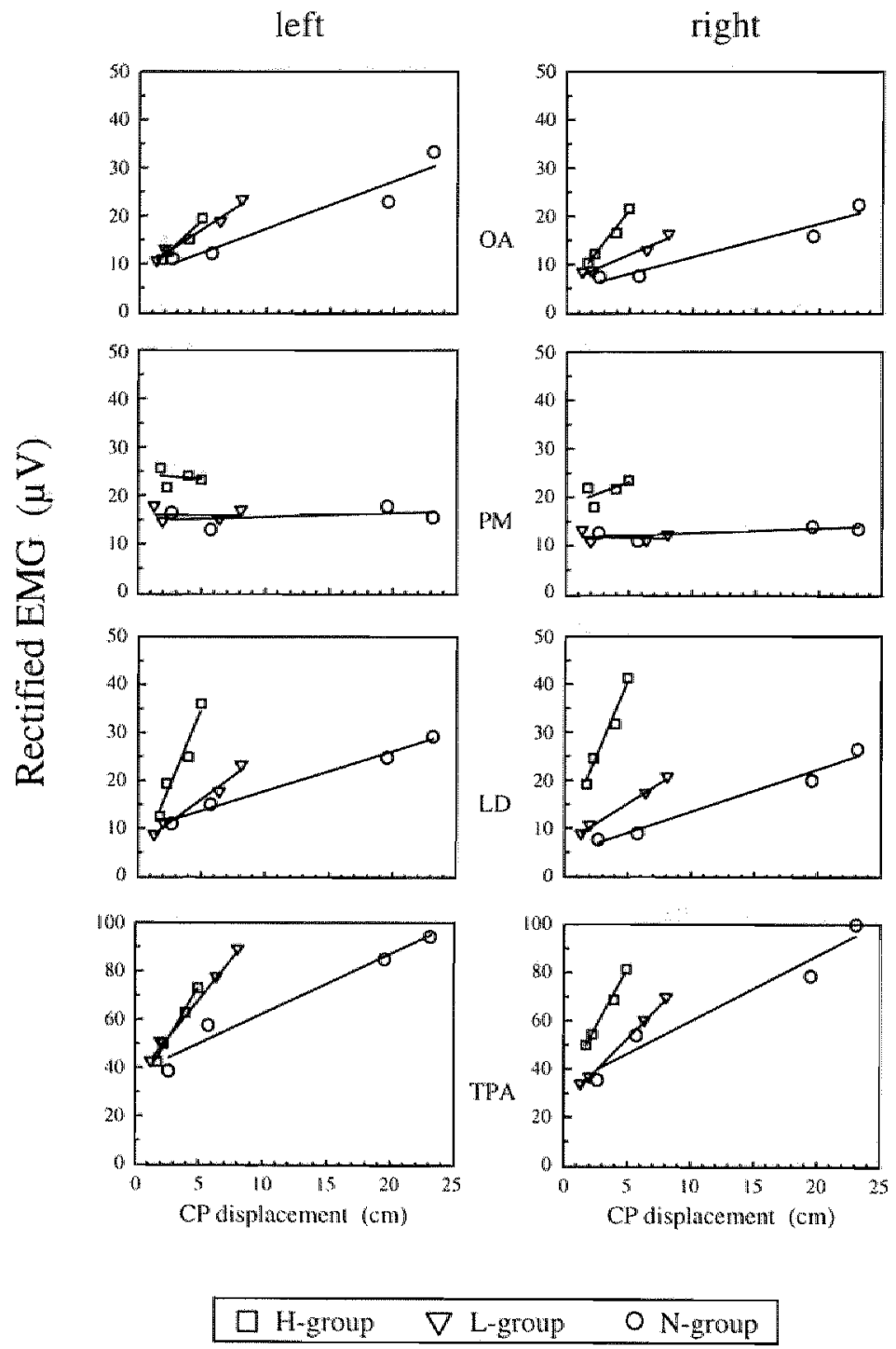

$\mathrm{OA}=$ obliquus abdominis; $\mathrm{PM}=$ pectoralis major $\mathrm{LD}=$ latissimus dorsi; $\mathrm{TPA}=$ ascending part of the trapezius: $\mathrm{CP}=$ centre of pressure. 
When comparing conditions in which relative sitting balance perturbation was equivalent among groups, significant main effects $(p<0.001)$ for the factor group and for the factor reaching distance were found for all muscle activity during period Y. Mean activity of the bilateral ES-L3 was higher in the N-group than in both the $\mathrm{L}$ - and H-group. Such group differences, although present $(\mathrm{p}<0.001)$, decreased for the bilateral ES-T9. Mean bilateral ES-T3 activity was found to be higher in the Hgroup than in the N-group, whereas it was lowest in the L-group. Significantly higher mean EMG activity for the bilateral PM and LD can be seen for the H-group $(\mathrm{p}<0.001)$, for all conditions. For the bilateral SA and the left TPA mean activity was highest in the $\mathrm{N}$-group and lowest for the H-group $(\mathrm{p}<0.001)$. Mean EMG activity for the right TPA in these conditions was lowest in the L-group. Also a significant interaction between group and reaching distance $(\mathrm{p}<0.001)$ was found for the bilateral ES-L3, ES-T9, ES-T3, SA, OA and the right LD and TPA, indicating that the increase in muscular activity at different graded balance perturbations differed among groups (figure 3.7 and 3.8). At relatively graded increase of balance perturbation absolute increase in mean EMG activity of the ES-T9, ES-T3, SA, OA and right TPA was less in SCI subjects, compared to non-SCl participants. For the billateral LD this absolute EMG increase was higher for the H-group than for both other groups.

Also myoelectric activity in conditions in which absolute sitting balance perturbation was equivalent for all three groups was compared. For the H-group CPmax in condition D was approximately the same as CPmax in condition C for the L-group and CPmax in condition B for the $\mathrm{N}$-group (figure 3.6). An example of mean rectified EMG values for these conditions for all groups is given in figure 3.9. One-way MANOVA's (factor: group), performed for these conditions for all muscles, showed that between-group differences were significant $(p<0.00 \rrbracket)$ for all muscle activity recorded during period Y. Multiple comparison between groups confirmed that mean EMG activity of the bilateral ES-T9, ES-T3, SA, OA, PM, LD and TPA recorded during period $Y$ in the $H$-group was significantly higher compared to the N-group, whereas mean ES-L3 activity was lower in the H-group. However, when comparing the L-group to the N-group, in general, differences in muscle activity decreased. Data analysis revealed no significant differences between the L-group and N-group for activity of the bilateral PM, ES-T3, right ES-T9, right $S A$, right TPA and left $L D$ during period $Y$. The bilateral ES-L3, OA, right LD, left ES-T9, SA and TPA showed higher mean EMG activity in the L-group relative to the $\mathrm{N}$-group. Main finding when comparing the H-group to the L-group was that no between-group EMG differences were recorded for the bilateral SA, the left TPA, OA and ES-T9. Mean activity of the bilateral ES-T3, PM, LD and right ES-T9, OA and TPA was higher in the H-group compared to the L-group $(\mathrm{p}<0.001)$. On the other hand, bilateral ES-L3 activity was lower in the H-group $(p<0.001)$. 
Figure 3.9. Example of mean rectified EMG values for muscle activity (of the right LD) during period $\mathrm{Y}_{*}$ in conditions of equivalent balance perturbation among groups, i.e. $D_{n} C$ and $B$ conditions for the $\mathrm{H}_{-}, \mathrm{L}-$, and $\mathrm{N}$-group respectively.

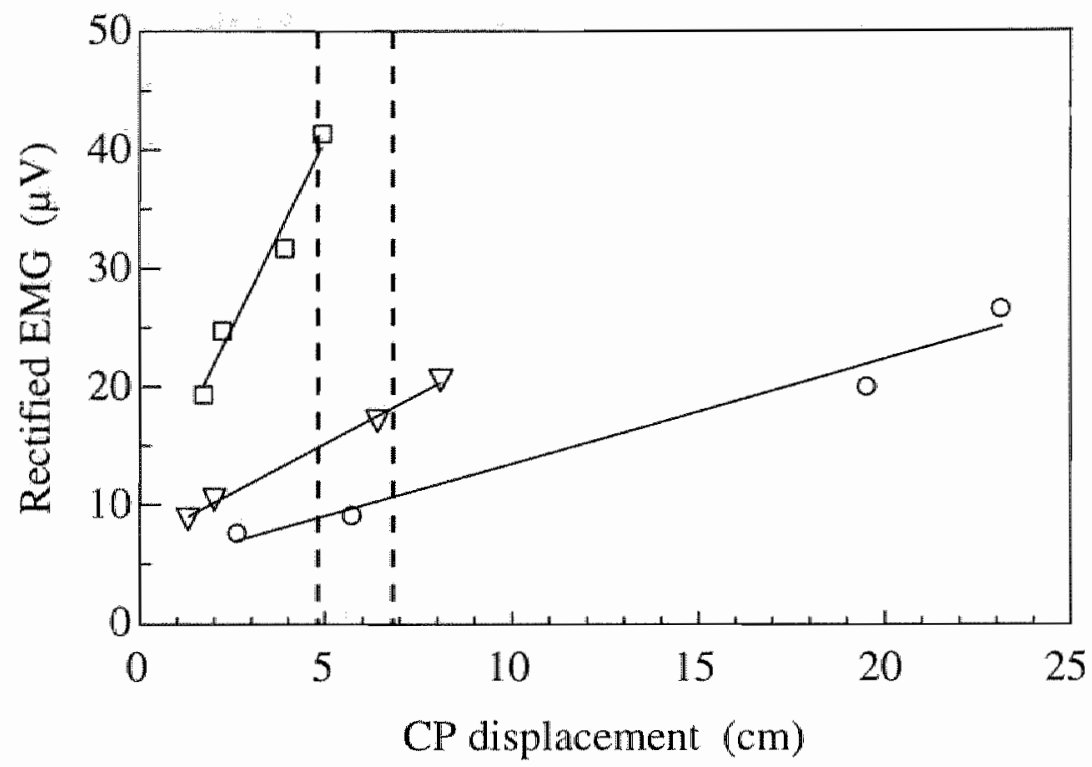

․ H-group $\nabla$ L-group $O \mathrm{~N}$-group

$\mathrm{CP}=$ centre of pressure. The area of equivalent balance perturbation among groups is delimited by the dashod lines.

\section{Experiment 2}

During the initial posterior displacement of the $\mathrm{CP}$ the pelvis was tilted anteriorly in all subjects. Data showed that the time delay between the start of the initial posterior $\mathrm{CP}$ movement and the anterior pelvic tilt was short. Mean phase

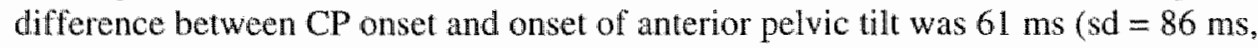
range $=-106$ to $232 \mathrm{~ms}$ ). Average pelvic tilt angle in the sagittal plane during maximal posterior $\mathrm{CP}$ displacement was $2.2^{\circ}$ ( $\mathrm{sd}=1.1^{\circ}$ ) relative to the initial position of the pelvis prior to the ISt onset $(\mathrm{p}<0.001)$. Maximal anterior pelvic tilt, which occurred when the peripheral buttons were pressed, was $22.6^{\circ}$ (sd $=5.1^{\circ}$ ). 
Typical anterior pelvic tilt and $\mathrm{CP}$ displacement data of a non-SCl subject are depicted in figure 3.10 .

Figure 3.10. Antero-posterior $\mathrm{CP}$ displacement and relative pelvic tilt during bimamal forward reaching of a non-SCI subject.

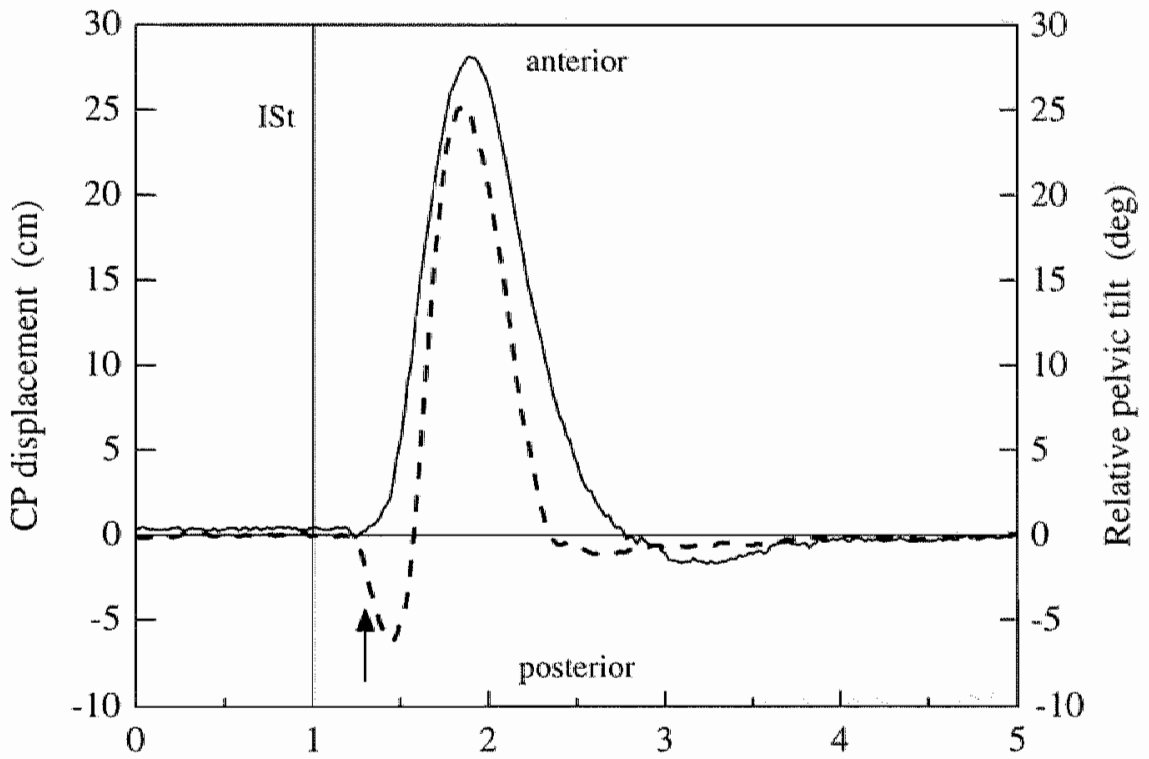

Time (s)

- - relative antero-posterior pelvic tilt during task execution; - - - - - = anteroposterior centre of pressure changes during task execution; $\mathrm{ISt}=$ imperative stimulus; $\mathrm{CP}=$ centre of pressure. The moment of start button release, inclicated by the vertical arrow, was at $t=1302 \mathrm{~ms}$.

Measurement of the displacement of the markers on the spine (at level L3, L1, TII and T9) revealed no significant posterior shift between ISt onset and peripheral button press. A small posterior shift of both GT's (mean $=-9.3 \mathrm{~mm} ; \mathrm{sd}=4.4 \mathrm{~mm}$ ) and the bilateral PSIS (mean $=-8.1 \mathrm{~mm} ; \mathrm{sd}=4.2 \mathrm{~mm}$ ) occurred simultaneously to the posterior shift of the CP between ISt onset and peripheral button press. Maximal posterior directed FNy (FNy_max) for the non-SCI participants during this initial phase of the movement in experiment 2 was averaged. Mean values amounted to $-22.4 \%$ body weight (s.d. $=7.8 \%$ body weight). The minus sign of the mean FNy_max value indicates the posterior direction of the normalised force vector. 


\section{Experiment 1 and 2}

In view of the FNy results of experiment 2 mentioned above, similar FNy calculations for data of experiment 1 were performed to assess possible differences for this parameter between the $\mathrm{H}-$, $\mathrm{L}$ - and $\mathrm{N}$-group. Data were statistically analysed using MANOVA's and multiple comparison techniques. Results of these calculations, given in table 3.3, show that non-SCI subjects produce larger posterior directed forces during the initial stage of the movement as opposed to L-group $(p<0.01)$ and $\mathrm{H}$-group participants $(\mathrm{p}<0.01$ ).

Table 3.3. Maximal posterior directed FNy (in \% body weight) recorded between ISt onset and peripheral button press, for all groups and all reaching conditions in experiment 1 .

\begin{tabular}{|c|c|c|c|c|c|c|c|c|}
\hline & \multicolumn{8}{|c|}{ Reaching distance } \\
\hline & \multicolumn{2}{|c|}{$15 \%$} & \multicolumn{2}{|c|}{$30 \%$} & \multicolumn{2}{|c|}{$75 \%$} & \multicolumn{2}{|c|}{$90 \%$} \\
\hline & mean & s.d. & mean & s.d. & mean & s.d. & mean & s.d. \\
\hline H-group & -1.4 & 0.6 & -2.3 & 1.1 & -3.7 & 2.3 & -4.6 & 2.4 \\
\hline L-group & -1.4 & 0.6 & -2.3 & 0.7 & -3.9 & 1.4 & -4.8 & 1.4 \\
\hline N-group & -3.2 & 1.8 & -6.5 & 3.1 & -14.6 & 4.8 & -16.6 & 5.6 \\
\hline
\end{tabular}

$\mathrm{N}$-group = non-SCI group; L-group $=$ low thoracic SCI group; H-group $=$ high thoracic SCI group; FNy = antero-posterior force from force platform, normalised for body weight. The minus sign of mean $\mathrm{FNy}_{\ldots} \max$ indicates the posterior direction of the normalised force vector.

No significant group differences for FNy_max were found between the L-group and the H-group. In trials where participants were requested to reach further (e.g. condition C or D) larger FNy_max values were found during the initial phase of the movement than in situations where subjects were asked to reach towards the proximally placed buttons (e.g. condition $A$ or $B)(p<0.001)$. The increase in FNy_max was highest in non-SCI subjects $(p<0.001)$, whereas this increase in FNy_max did not differ significantly between both SCI groups. The non-SCI subjects who performed the reaching task in experiment 1 showed lower FNy_max values during the initial stage of the movement in reaching condition $\mathrm{D}$ than the non-SCl subjects participating in experiment 2. This difference in FNy_max amounted to $5.8 \%$ (i.e. $\%$ body weight). 


\section{Discussion}

The main question addressed in this research concerns the adaptive mechanisms by which SCI subjects try to compensate for the loss of postural muscle activity during perturbed sitting. First, the extent to which sitting balance can stably be maintained in SCI and non-SCI subjects was determined in terms of maximum reaching distance. The biomechanical data of experiment 1 show that the domain in which SCI subjects can actively move their CP has decreased considerably in comparison to non-SCI subjects. It is unlikely that differences in anthropometrical measures between groups could have caused this $\mathrm{CP}$ phenomenon, since groups were matched for sex, weight and height. This reduced $\mathrm{CP}$ displacement, which was observed in dynamic situations (i.e. forward and backward reaching movements) as well as in semi-static situations (i.e. during the prolonged period of forward positioning of the subject during $\mathrm{MT}_{2}$ ), may be due to the loss of co-ordinated muscle function in the legs and the pelvic and low back region in persons with a complete thoracic paraplegia. Secondly, our data show that, in general, non-SCI subjects show a typical initial backward movement of the $\mathrm{CP}$ at the beginning of a reaching movement in the medio-sagittal plane. This initial deflection of the anteroposterior CP signal is less in subjects with a low thoracic SCI and may even be absent in subjects with a high thoracic SCI. The 3D kinematic data, obtained from experiment 2 , indicate that this posterior movement of the $\mathrm{CP}$ in non-SCI subjects coincides with an anterior pelvic tilt and a small posterior shift of the bilateral PSIS and GT. Simultaneously, the antero-posterior force vector from the force platform indicates a forward acceleration of the centre of mass. In the same interval no further extension of the lower part of the spine was measured in the non-SCl subjects. A muscle most likely involved in this forward acceleration and anterior pelvic tilt in non-SCI persons is the iliopsoas muscle. However, temporal changes in muscle activity of the iliopsoas muscle were not recorded, because of the inaccessibility to surface EMG. Forward acceleration of the centre of mass during the initial stage of the reaching movement was less in SCI subjects, as was indicated by a lower FNy_max. Obviously, not onlly the range in which thoracic SCI subjects can change sitting posture, but also the acceleration with which they can change sitting posture decreases. This would explain why in SCI subjects the initial posterior shift in $\mathrm{CP}$ is less. Next to the reduced ability of generating larger forward accelerations of the centre of mass, paraplegic people may also be less able to decelerate to counteract a (forceful) flexion of the trunk and upper part of the body, caused by forward reaching, due to the growing lack of activity of the lumbar and (lower) thoracic ES at more cranial levels of SCI. Also pelvic motion is less possible at more cranial levels of SCI. To compensate for the instability of the pelvis and the lower part of the spine the (high) thoracic SCI subject has no alternative but to passively tillt his pelvis backward against the backrest for support [20]. This position may be advantageous for a second reason. In this position the 
punctum fixurn of the upper part of the body rises relative to the base of support, creating possibilities for more cranial muscles, like the LD and TPA, to become active in support of the erect position of the trunk. These findings are corroborated by the EMG data from experiment 1. Data suggest that people with a high thoracic $\mathrm{SCl}$, in comparison to non-SCI subjects, use their LD, TPA, PM and SA more during restoration of sitting balance after equivalent absolute balance perturbation. In people with a low thoracic SCI this phenomenon of alternative muscle use during sitting balance restoration is less than in subjects with a high thoracic lesion. Results also show an increased use of the cranial parts of the thoracic ES in subjects with a high thoracic SCI which may signify an effort to extend the upper part of the spine and reduce mass displacement in the anterior direction. This effect is less in people with a low thoracic SCI. If sitting balance is perturbed relative to each person's maximum the aforementioned differences in postural muscle use between SCI and non-SCI subjects becomes more diffuse, because in these conditions non-SCI participants were able to reach further, thus introducing more phasic muscle activity during e.g. arm stretching and scapular protraction. In situations of equivalent sitting balance perturbation the OA was activated more in people with a SCI than in nonSCI subjects, despite the SCI level. A combination of two phenomena may explain this contradiction. First, SCI subjects with paretic OA muscles could have used the remaining still actively controllable muscle parts more in synergy with the PM and SA to act as antagonists for the ES-LD-TPA synergy in an effort to balance the trunk and spine. Secondly, mechanical stretch of the OA caused by PM and SA activity may have introduced spinal reflex activity, causing involuntary muscle activation in the $\mathrm{OA}$. On the specific cause of the OA activation no conclusive evidence can be drawn from the present data. For this, more in-depth neurophysiological research is necessary.

We argue that the EMG data from experiment 1 signify an alternative postural movement strategy in (high) thoracic SCI subjects, whereby the (cranial part of the) spine and the trunk is stabilised by increased use of the ES-T3 and in addition by using non-postural muscles like the LD and the TPA. The latter muscles have both a favourable innervation cranial to the lesion site of the spinal cord and a biomeclianically favourable position with an insertion in the low thoracic and lumbar region. To prevent mere retraction of the scapulae, the PM and SA are activated in order to stabilise the shoulder girdle. In subjects with more caudal lesion sites, whose ES is less functionally impaired, this phenomenon of augmented (alternative) muscle use during balance restoration is less. When comparing the range in which subjects are able to shift their $\mathrm{CP}$, it becomes clear that impaired sitting balance and postural control in $\mathrm{SCI}$ can not be compensated fully by using this alternative strategy of non-postural muscle use. This strategy can only partly reduce functional disability. A trade-off between either spinal stability or trunk and upper extremity movement has to be made by the SCI subject.

This paper describes alternative postural muscle use and altered movement in seated thoracic SCI subjects. To further transform our findings into a genuine 
biomechanical and neurophysiological model more research is necessary. This paper can be viewed as an initial step towards such a model.

\section{References}

1. Andersson GBJ: Biomechamical aspects of sitting: An application to VDT terminals. In: Behavior and Irformation Technology, Taylor and Francis, London, pp 257-269, 1987.

2. Andersson GBJ: Loads on the spine during sitting. In: The ergonomics of working postures, ed by Corlett N, Wilson J, Manenica T, Taylor and Francis, London, pp 309-318, 1986.

3. Andersson BJG, Jonsson B, Örtengren R: Myoelectric activity in individual erector spimae muscles in sitting. A study with surface and wire ellectrodes. Scand J Rehabil Med, suppl. $3: 91-108,1974 \mathrm{a}$.

4. Andersson BJG, Örtengren R: Myoelectric back muscle activity during sitting. Scand J Rehabil Med, suppl. 3:73-90, 1974 b.

5. Andersson BJG, Winters JM: Role of muscle in postural tasks: spinal loading and postural stability. In: Multiple muscle systems, ed by Winters JM, Woo SLY, Springer-Verlag, New York, pp 377-395, 1990.

6. Bach-Y-Rita P: Theory-based neurorehabilitation. Arch Phys Med Rehabil 70(2):162, 1989

7. Chari VR, Kirby RL: Lower limb influence on sitting balance while reaching forward. Arch Phys Med Rehab 67:730-733, 1986.

8. Do MC, Bouisset $S$, Moynot C: Are paraplegics handicapped in the execution of a manual task? Ergonomics 28:1363-1375, 1985.

9. Maki BE, Holliday PJ, Fernie GR: A postural control model and balance test for the prediction of relative postural stability. IEEE Biomed 34: 797-810, 1987.

10. Massion J: Movement, posture and equilibrium: interaction and coordination. Progress in Neurobiology 38, 35-56, 1992.

11. Massion J, Dufossé M: Coordination between posture and movement: why and how? NIPS 3,88-93, 1988.

12. Moore S, Brunt D: Effects of trunk support and target distance on postural adjustment prior to a rapid reaching task by seated subjects. Arch Phys Med Rehabil 72:638-64l, 1991.

13. Press WH, Flannery BP. Teukolsky SA, Vetterling WT: Numerical recipes in C. The an of Scientific Computing. Cambridge Universuty Press, Cambridge, pp 516.1988.

14. Sandin KJ, Smith BS: The measure of balance in sitting in stroke rehabilitation prognosis. Stroke 21:82-86, 1990 .

15. Schobert H: Orthopädie des Sizzern.s. In German. Springer-Verlag, Berlin, 1989.

16. Seelen HAM, Vuurman EPFM: Compensatory muscle activity for siung posture during upper extremity task performance in paraplegic persons. Scand $J$ Rehab Med 23:89-96, 1991.

17. Seelen HAM: Reorganisation of postural control in spinal cord injury. In: Proceedings Clinical Biomechanics, XIVth I.S.B. Congress, Paris, pp 1220-1221, 1993.

18. Soderberg GL, Blanco MK, Cosentino TL, Kurdelmeier KA: An EMG analysis of posterior trunk rausculature cluring flat and anteriorly inclined sitting. Humam Factors 28:483-491, 1986.

19. Winter DA: Biomechanics and motor control of human movement. John Wiley \& Sons, Inc., New York, pp. 93-96, 1990.

20. Zacharkow D: Wheelchair posture and pressure sores. Charles $\mathrm{C}$ Thomas Publishers, Springfield, Illinois, 1984. 


\section{4}

\section{Development of new muscle synergies in postural control in spinal cord injured subjects}

H.A.M. Seelen ${ }^{1}$, Y.J.M. Potten ${ }^{1,2}$, J. Drukker ${ }^{2}$, J.P.H. Reulen ${ }^{3}$, C. Pons ${ }^{4}$

I Institute for Rehabilitation Research, Hoensbroek, the Neiherlands

2 University Maastricht, Department of Anatomy and Embryology, Maastricht, the Netherlands

3 University Hospital Maastricht, Department of Clinical Neurophysiology, Maastricht, the Netherlands

4 Rehabilitation Centre Hoensbroeck, Spinal Cord Injury Unit, Hoensbroek, the Netherlands

Reprinted from Journal of Electromyography and Kinesiology, Seelen HAM, Potten YJM, Drukker J, Reulen JPH, Pons C: Development of new muscle synergies in postural control in spinal cord injured subjects, (in press), with kind permission from Elsevier Science Ltd, The Boulevard, Langford Lane, Kidlington 0X5 1GB, UK. 


\section{Summary}

The development of new patterns of postural control in patients with a complete thoracic spinal cord injury (SCI) during their active clinical rehabilitation was studied. Especially the role of non-postural muscles, like the latissimus dorsi (LD) and the ascending part of the trapezius (TPA), in maintaining and restoring sitting balance during standardised bimanual task performance was investigated. Twelve patients; diagnosed with an acute complete thoracic SCI between spinal cord level T2 and T12, participated in a longitudinal experimental study. Changes in the centre of pressure (CP) and electromyographic activity of the erector spinae (ES) at level L3, T9 and T3, the LD, the TPA, the pectoralis major (PM), the serratus anterior and the oblique abdominal muscles were investigated at several moments in the rehabilitation process. Results show a gradual development of specific muscle activation patterns for both high and low thoracic SCI patients. These patterns seem to be related to a combination of restoration of function of the ES-L3 and ES-T9 in the low thoracic SCI subjects and increased compensatory muscle use of the LD, TPA and PM in high SCI patients. The range in which low thoracic SCI patients can actively vary their $\mathrm{CP}$ increased slightly during rehabilitation.

\section{Introduction}

Activity of trunk muscles related to spinal loading and postural control in healthy subjects has been studied both in supported and unsupported sitting conditions $[3,4,6,7,14,18,23,25,32]$ as well as in specific working and exercise conditions $[1,10,15,36]$. In thoracic spinal cord injured (SCl) persons maintaining sitting balance during task execution is impaired. This is due to the loss of activity of e.g. parts of the erector spinae (ES) muscle controlled by spinal segments caudal to the lesion site. Do et al. [13] who investigated manual task performance, i.e. manual load shifting, in SCI subjects with a T4 lesion and in non-SCI subjects, found that the $\mathrm{SCI}$ subjects adopted a different postural strategy to counteract postural perturbations elicited by the load shifting and arm movement, involving residual muscle functions of trunk and scapular muscles. Andersson and Örtengren [5] investigated lumbar disc pressure and back muscle activity in two healthy and two SCI patients with a T12 lesion. They found only minor differences in EMG activity between the $\mathrm{SCI}$ and non-SCI subjects during several sitting conditions. In recent research by Seelen et al. [26] differences in postural muscle use were observed not only between thoracic SCI and non-SCI subjects, but also between groups of thoracic SCI subjects with different levels of sensorimotor function loss. In this study it was hypothesised that such differences in impairments (and in residual sensorimotor potential) between high and low thoracic SCI subjects would lead to different compensatory patterns of postural muscle use alternative to postural 
muscle strategies in non-SCI subjects. These altemative strategies, which could most prominently be observed in high thoracic SCI subjects, involved an increased use of the cranial parts of the thoracic ES, the LD, the TPA, the cranial section of the sternocostal head of the pectoralis major (PM) and the serratus anterior (SA) muscles. However, it was concluded that this use of alternative postural muscles could only partly reduce functional disability regarding balance control in thoracic SCI subjects, whereby a trade-off between spirnal stability and upper extremity task performance had to be made by the SCI subjects $[26,27]$. From these studies, the question arose whether the development of these new patterns of postural muscle activation could be observed during the active clinical rehabilitation of patients with different levels of thoracic SCI. Aim of this study was to gain insight in the course of this development, independently of the therapy subjects received, which could then serve as a sound basis for future research into the effects of specific rehabilitation training programs on the reorganisation of postural control in $\mathrm{SCl}$ patients.

A second question addressed in the present study concerns the limitations of sitting posture perturbations during upper extremity task performance. In seated, non-sensorimotor impaired man the centre of pressure (CP) is under control of muscle synergies involving leg, pelvis and hip muscles (e.g. the rectus femoris, glutei, tensor fasciae latae, iliopsoas) and trunk muscles like the ES and the abdominal muscles [25]. Winter [35] described the CP, i.e. the location of the vertical ground reaction vector, as the neuromuscullar response to imbalances of the body's centre of gravity. In thoracic SCI subjects the muscle function in the majority of the aforementioned leg, pelvic, hip and trunk muscles is lost leading to reduced possibilities in maintaining sitting balance during postural changes and to a reduction in the range in which the $\mathrm{CP}$ can actively be varied. The second aim of this study was to evaluate to what extent the range in which thoracic $\mathrm{SCI}$ subjects could actively move their $\mathrm{CP}$ increased during clinical rehabilitation. Reorganisation of postural motor control was evaluated during seated upper extremity task performance in which maintaining sitting balance was more difficult for $\mathrm{SCl}$ subjects. Changes in postural muscle synergies as well as the accompanying changes in the range of $\mathrm{CP}$ displacement were investigated across the clinical rehabilitation process in a longitudinal, experimental study.

\section{Methods}

\section{Subjects}

In this study 12 patients participated who were clinically diagnosed with either a complete, high (H) thoracic SCI at segmental level T2-T8 $(n=5)$ or a complete, low (L) thoracic SCl at segmental level T9-T12 $(n=7)$. Eleven patients sustained an acute, traumatic paraplegia. One patient sustained acute paraplegia 
after spinal surgery. Subjects entered the rehabilitation and research program over a period of two years. Apart from treatment for possible secondary pathology or complications (e.g. pressure ulcers), the physical rehabilitation program followed a similar pattern in all of these subjects, based on their residual functional capacities. It included physiotherapy and occupational therapy as well as sports exercise. The more basic elements within this therapy encompassed mobility training, training of muscle strength and co-ordination, endurance training, functional training of activities of daily living and wheelchair training. Group composition is given in table 4.1. Levels of complete spinal cord injury for both the L-group and the $\mathrm{H}$ group are given in table 4.2 .

Table 4.1. Group composition at admission to the rehabilitation clinic.

\begin{tabular}{|c|c|c|c|}
\hline & & L-group & H-group \\
\hline & $\mathrm{n}$ & 7 & 5 \\
\hline age (year) & mean (s.d.) & $34.0(10)$ & $28.6(9)$ \\
\hline & range & $17-46$ & $22-45$ \\
\hline weight $(\mathrm{kg})$ & mean (s.d.) & $72.3(9)$ & $65.6(9)$ \\
\hline & range & $64.5-91.6$ & $58.2-79.1$ \\
\hline height $(\mathrm{m})$ & mean (s.d.) & $1.84(0.09)$ & $1.80(0.05)$ \\
\hline & range & $1.77-2.00$ & $1.75-1.88$ \\
\hline handedness & left / right & $1 / 6$ & $1 / 4$ \\
\hline $\operatorname{sex}$ & $M / F$ & $7 / 0$ & $3 / 2$ \\
\hline stay in rehab. & mean (s.d.) & $28.1(10)$ & $41.2(17)$ \\
\hline clinic (weeks) & range & $15-42$ & 21.59 \\
\hline
\end{tabular}

L-group = low thoracic SCI group; $\mathrm{H}$-group $=$ high thoracic SCI group; $\mathrm{M}=$ male; $\mathrm{F}=$ female.

Table 4.2. Levels of complete spinal cord injury diagnosed at admission to the rehabilitation clinic.

high SCI (H-group) low SCI (L-group)

\begin{tabular}{cccccccccccc} 
& $\mathrm{T} 2$ & $\mathrm{~T} 3$ & $\mathrm{~T} 4$ & $\mathrm{~T} 5$ & $\mathrm{~T} 6$ & $\mathrm{~T} 7$ & $\mathrm{~T} 8$ & $\mathrm{~T} 9$ & $\mathrm{~T} 10$ & $\mathrm{~T} 11$ & $\mathrm{~T} 12$ \\
$\mathrm{n}$ & 0 & 0 & 1 & 1 & 0 & 1 & 2 & 1 & 1 & 2 & 3 \\
\hline
\end{tabular}


Experiments started as soon as the patient was able to maintain a vertical position for at least 1 hour without suffering from orthostatic hypotension. The presence of e.g. sacro-tuberal pressure ulcers was a contraindication for immediate participation in the experiments. After an initial post-intake period, which generally took 1.5 to 2 weeks, subjects were tested at two weeks intervals during 12 weeks. Subsequent test intervals amounted to four weeks until discharge from the rehabilitation clinic. An example is given in figure 4.1. For one subject the initial period was approximately 30 weeks in which he was confined to a bed, because he had to be extensively treated for a complicated larynx trauma, subsequent ventilation problems and pressure ulcers.

Figure 4.1. An example of experimental observation dates during the clinical rehabilitation period of one of the spinal cord injured patients.

\section{Rehabilitation clinic}

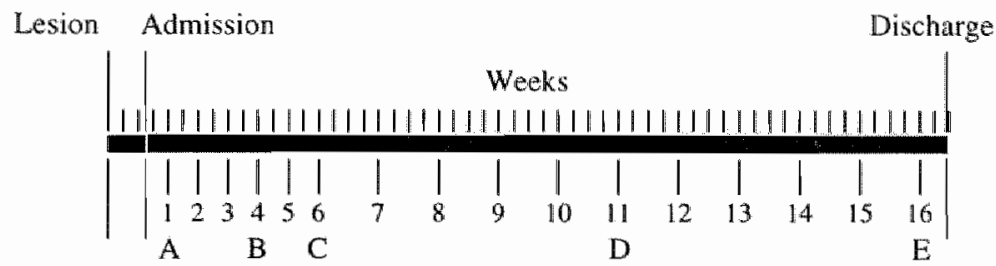

Sessions

The numbers ( 1 to 16 ) indicate the experimental observation dates, $A, \mathbb{B}, \mathbb{C}, D, E$ signify the consecutive experimental sessions used in the data analyses.

The total number of sessions varied among subjects, depending on the length of stay in the clinic. For further in-depth data analysis group data, collected during five specific sessions (A, B, C, D and E) which were approximately equivalent for all subjects, were selected. In the first session (session A), i.e. in the first week of the longitudinal study, all subjects still wore braces to stabilise the spine [22], except one subject from the H-group. The second session selected (session B) was when braces were finally removed. The third session (session $C$ ) was taken four weeks after session B. The fourth session (session D) was halfway between session C and the discharge date. The fifth session (session E) was just before clinical discharge from the rehabilitation centre. One subject, from the $\mathrm{H}$-group, disengaged from further participation in this study prematurely 19 weeks after clinical intake. Informed consent was obtained from all participants prior to the beginning of the study. All experimental protocols used in this study were approved by the local medical ethical committee. 


\section{Task and apparatus:}

Participants sat in a multi-adaptable chair behind a table. The seat angle was $0^{\circ}$, backrest angle was $100^{\circ}$ relative to the horizontal plane. Seat depth and position of the foot rests were adjusted to the body measures of each subject. The chair was bolted onto an AMTI force platform (Biovec-1000, AMTI, Watertown, Mass.). Participants were asked to perform a reaching task consisting of multiple trials. Every trial consisted of one bimanual reaching movement towards one of four peripherally placed button (PB) pairs placed on the table (figure 4.2) at $15,30,75$ and $90 \%$ of each subjects maximal unsupported reaching distance in anterior direction (reaching condition 1, 2, 3 and 4 respectively). These different reaching movements caused a graded shift of the body weight in antero-posterior direction. During task execution postural muscle activity was required to prevent loss of sitting balance. Distance between buttons within each pair was $15 \mathrm{~cm}$. PB diameter was $1.5 \mathrm{~cm}$.

Figure 4.2. Arrangement of the experiment.

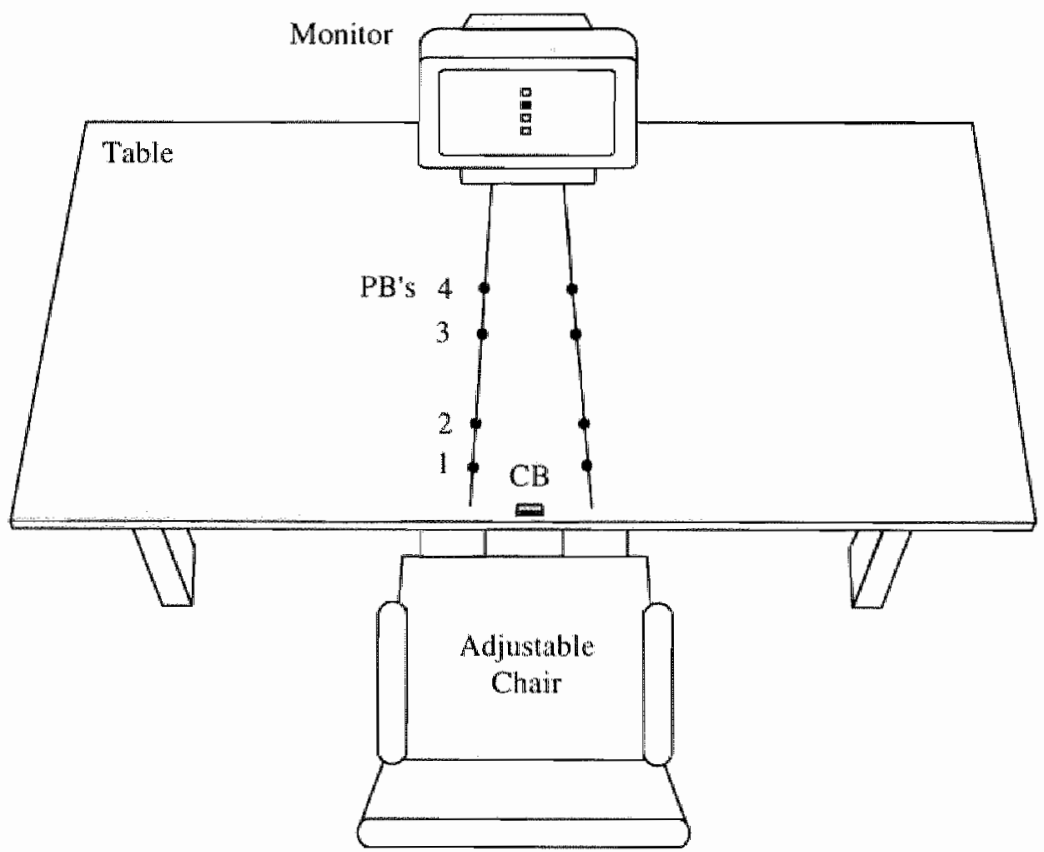

$\mathrm{PB}=$ Peripheral button; $\mathrm{CB}=$ Centrally placed button; $1,2,3,4=$ Reaching condition $1,2,3$ and 4 in which button pairs are placed at $15 \%, 30 \%, 75 \%$ and $90 \%$ of the individual maximum reach respectively. 
On a 14 inch VGA monitor, located $1.25 \mathrm{~m}$ in front of the seated subject, four open squares were depicted, representing the four PB pairs. Each trial started after the subject operated a centrally placed button (CB) located on the table at a distance of approximately $25 \mathrm{~cm}$ anterior to the trunk with both hands. $\mathrm{CB}$ size was $1.5 \times 2.3 \mathrm{~cm}$. After $3,250 \mathrm{~ms}$ a warning signal (WS) was shown on the screen, shaped like an array of 4 small open squares within the 4 button array already present on the screen (figure 4.3). Next, an imperative stimulus (ISt) appeared as a " sign in one of the open squares on the screen, starting $750 \mathrm{~ms}$ after the WS onset. The location of the ISt indicated the PB pair to be operated. On detection of the ISt the subject had to release the CB and reach towards the correct PB pair as fast as possible and lightly press them five times using both hands, introducing a prolonged period of semi-static forward reaching. He or she then had to move back to the initial sitting position as fast as possible and press the $\mathrm{CB}$ again with both hands. An example of a task display on the screen is given in figure 4.3.

Figure 4.3. Example of task display on screen.

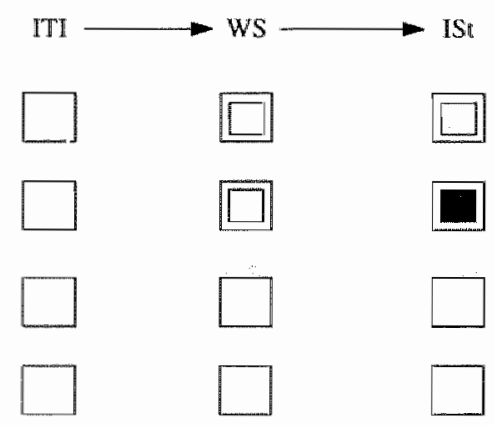

ITI $=$ intertrial interval; $W S=$ warning signal; $I S t=$ imperative stimulus.

Timing of the experiment as well as the synchronisation between task display and signal acquisition was performed by a PCL830 timer/counter card (Advantech Co, Taiwan) on a Compaq Deskpro 386sx PC (Compaq Computer Co., Houston, Texas).

Two series of 48 trials each were presented to the subject. Each of the four reaching distance conditions was to be executed 12 times per series. The order of the different reaching distances was randomly distributed within each series. Intertrial interval was at least $3 \mathrm{~s}$. Each series of this experiment lasted about 10 minutes. Preexperimental procedures, i.e. transfer of the paraplegic subject from his bed, positioning of the patient in the experimental chair, application of the EMG electrodes and instruction of the patient took about 25 minutes, whereas postexperimental procedures took about 15 minutes. For clinical reasons, patients were 
allowed to sit in a chair only for a limited amount of time per day during the initial stages of the rehabilitation process, because of the danger of e.g. the occurrence of orthostatic hypotension or the development of pressure ulcers. Therefore the two task series were executed separately on two consecutive days. Written instruction was given to the patient prior to the experiment.

During each trial bilateral surface EMG of the ES at level L3, T9 and T3 was recorded, as well as activity of the $L D, T P A, P M, S A$ and the oblique abdominal muscles (OA). SPA20/12 pre-amplifiers (K_Lab, Amsterdam, Neth.) directly mounted on top of $\mathrm{Ag}-\mathrm{AgCl}$ disposable electrodes with a surface area of $1 \mathrm{~cm}^{2}$ (Graphics Control Corp., Buffalo, NY) were used (CMRR $>110 \mathrm{~dB}$; input impedance $>500 \mathrm{M} \Omega$; signal amplification 100 ; noise referred to input $<2 \mu \mathrm{V}_{\mathrm{rms}}$ ). Inter-electrode distance was $2.3 \mathrm{~cm}$. Furthermore a K_Lab MF-118 amplifier (K_Lab, Amsterdam, Neth.) with a 3rd order Butterworth high pass filter (cut-off frequency $20 \mathrm{~Hz}$ ) was used. A sample rate of $500 \mathrm{~Hz}$ was used as spinal and other trunk muscle EMG signals have high frequency components up to $250 \mathrm{~Hz}$. After removal of hair (if applicable) and cleaning the subject's skin with alcohol the EMG electrode pairs were placed parallel to the muscle fibre direction of the different muscles. Position of the ES electrodes was $2.5 \mathrm{~cm}$ lateral to the spinous processes. LD electrodes were placed $3.5 \mathrm{~cm}$ caudo-lateral to the inferior angle of the scapula. TPA and OA electrodes were placed on the bulkiest part of the muscle belly. SA electrodes were placed on the muscle part originating from the fifth rib anterior to the LD muscle. PM electrodes were placed in the middle of the cranial part of the sternocostal head. A grounding electrode was attached to the anterior part of the lower leg. Also force plate signals were recorded. Button status was recorded on a separate event channel. All analog signals were A/D-converted using a 16 channel DT2824 PGL data-acquisition board (Data Translations, Marlboro, Mass.) and MUCAPS software (Institute for Rehabilitation Research, Hoensbroek, Neth.). During each trial data acquisition started $3 \mathrm{~s}$ after each subject had pressed the $\mathrm{CB}$, 1.e. $250 \mathrm{~ms}$ before WS onset, and lasted for $5 \mathrm{~s}$. Due to restrictions in the number of AD channels the reaching task series of 48 trials was carried out two times to record activity of all muscles as well as force plate and button status signals. Per series 1 event signal, 8 EMG signals and all 6 force plate signals were recorded. The order of series was randomised. Digitised data were primarily stored on computer disk of a second Compaq 386sx PC. After each experiment data were transferred to magnetic computer tape (Tape Shuttle 1000, Shuttle Technology Lid, India).

\section{Data analysis}

The data were analysed off-line using MATLAB software (The Math Works Inc, Natick, Mass.). From the event channel signal reaction time (RT), i.e. time between ISt onset and release of the $\mathrm{CB}$ with both hands, was calculated. Also the time between release of the $\mathrm{CB}$ and initial contact of the peripheral buttons, i.e. the time used for forward reaching $\left(\mathrm{MT}_{1}\right)$, was determined. In the same way the time needed by the subject to press the PB's 5 times $\left(\mathrm{MT}_{2}\right)$ and the time for subsequent 
restoring sitting position $\left(\mathrm{MT}_{3}\right)$ were calculated. During the $M T_{1}$ and $M T_{3}$ time periods a dynamic change in sitting posture was performed by each subject, whereas during $\mathrm{MT}_{2}$ a semi-static position was maintained. An example of these time periods for one trial are given in figure 4.4. Also maximal $\mathrm{CP}$ displacement (CPmax) in antero-posterior direction per trial was calculated for all subjects. Mean rectified EMG values for all muscles, for all reaching distance conditions were calculated from a period in which maintaining sitting balance was thought to be most difficult for all subjects, i.e. a time period (Y) of $+1-20 \%$ of $\mathrm{MT}_{3}$ around final peripheral button release (see figure 4.4). In this phase concentric activity of muscles involved in extending the spine was expected. Epoch $\mathrm{Y}$ coincided with a phase in which CP displacement in antero-posterior direction, as an indication of postural perturbation, was maximal. Furthermore, epoch $\mathrm{Y}$ also represented a semistatic situation within each trial from which mean rectified EMG values could be calculated, in contrast to other time periods which represented more dynamic conditions. From these calculations patterns of (synergistic) muscle activity across multiple muscles during epoch $\mathrm{Y}$ emerged, which were associated with different magnitudes of sitting balance restoration efforts and restoration of posture. These calculations were performed for all data collected during this longitudinal study.

Figure 4.4. Example of task execution and timing of the task.
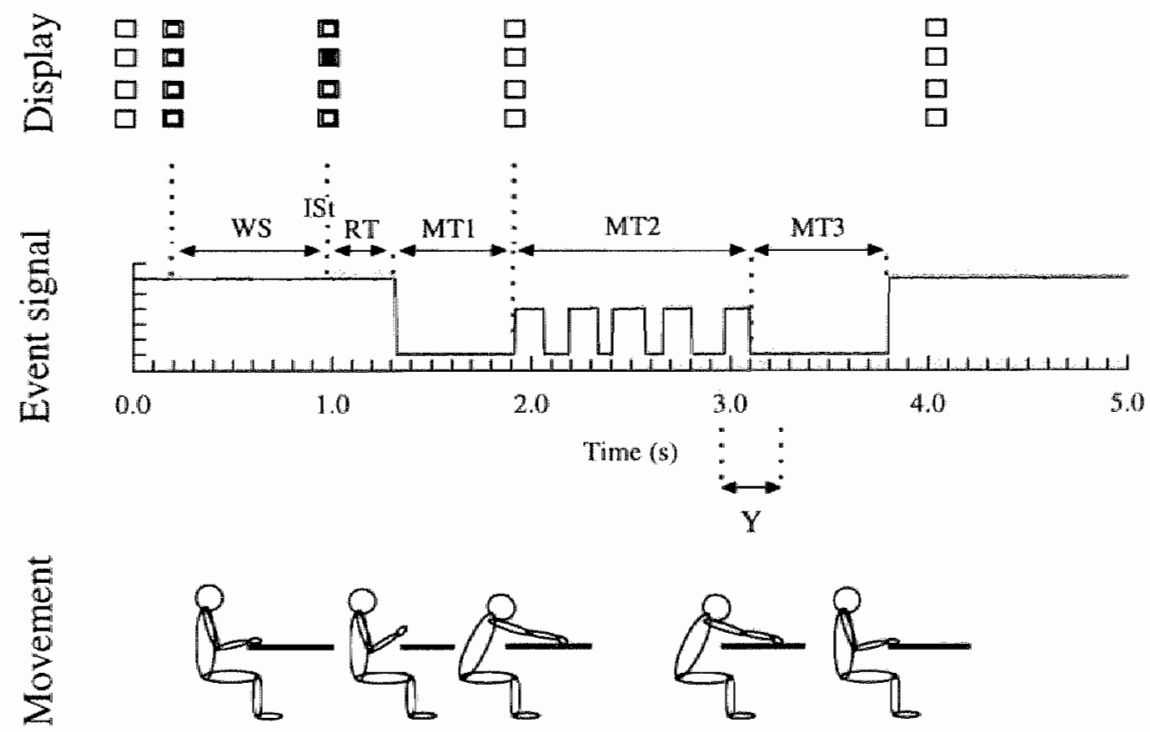

$\mathrm{WS}=$ warning signal; $1 \mathrm{St}=$ imperative stimulus; $\mathrm{RT}=$ reaction time; $\mathrm{MT} 1, \mathrm{MT} 2, \mathrm{MT} 3=$ movement time 1,2 and 3 respectively; $Y=$ time period of $+/-(0.2 *$ MT3) around final peripheral button release. 
Changes in EMG and CPmax across all reaching conditions at all separate stages (sessions) in the rehabilitation process were statistically tested in both groups independently using the Page test for ordered alternatives [28]. Conceptually this non-parametric statistical procedure tests whether $k$ related measures (or conditions) are the same $\left(\mathrm{H}_{0}\right)$ or if measures are ordered in a specific, a priori defined sequence with respect to the magnitude of their median $\left(\mathrm{H}_{1}\right)$, i.e. does the sequence of consecutive measures show a gradual progress, increase or trend in magnitude. This trend is established from each subject within the group. $\mathrm{H}_{0}$ is rejected in favour of $\mathrm{H}_{1}$ when the calculated Page test L-statistic is greater or equal than the critical Lvalue for a given level of significance (e.g. $\alpha=0.01$ ). It was tested whether a trend could be observed between the increase in reaching distance (a priori defined as 15 , 30,75 and $90 \%$ of the maximum reach per subject) and CP increases per session, within groups. The same statistical tests were performed for the EMG data. Furthermore, within-group changes in EMG and CPmax for reaching condition 4 (i.e. $90 \%$ of the maximum reach) across sessions were statistically tested using the Page test. It was tested if a within-group trend could be found across the rehabilitation period, i.e. involving successive sessions (A through E), for 1) EMG activity of muscles and 2) CPmax values recorded during reaching condition 4. Also between-group EMG and CPmax differences were tested using the Mann-Whitney U-test [24].

\section{Results}

\section{Error analysis}

Trials in which subjects pressed the wrong peripheral buttons were discarded $(0.30 \%)$. In order to exclude erroneous trials, resulting from too early or too late button press or button release, trials in which RT was shorter than $125 \mathrm{~ms}$ or longer than $1200 \mathrm{~ms}$ were also excluded from further data analysis $(0.27 \%)$, as were trials in which $\mathrm{MT}_{1}$ was shorter than $50 \mathrm{~ms}$ or longer than $1500 \mathrm{~ms}(0.27 \%)$. Statistical analysis on these error data did not reveal significant differences between groups, reaching conditions or sessions.

\section{Postural changes}

Average CPmax data and $99 \%$ confidence intervals of the mean, for all reaching conditions for both $\mathrm{SCl}$ groups, for all five sessions are given in figure 4.5. The L-group showed a small increase in CPmax across the rehabilitation phase in the 75 and $90 \%$ reaching conditions $(\mathrm{p}<0.01)$. At the start of rehabilitation (i.e. during the first session) the high $\mathrm{SCl}$ subjects showed, on average, a larger shift of their CP than subjects from the L-group as can be seen in figure 4.5. Towards the end of the rehabilitation the L-group produced higher maximal CP displacements during task execution in reaching condition $4(p<0.05)$. After a significant reduction 
Figure 4.5. Average CPmax values and $99 \%$ confidence intervalls of the mean, for all four reaching conditions for both SCI groups, for session A through $\mathrm{E}$.

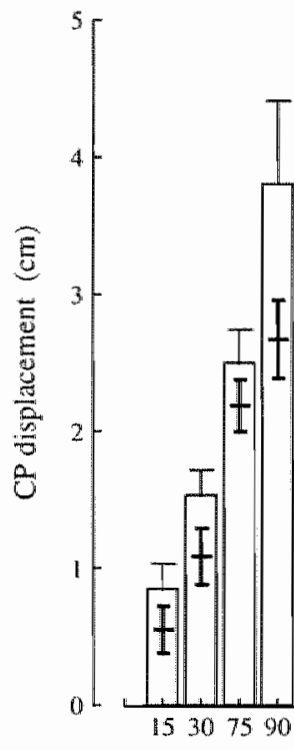

A
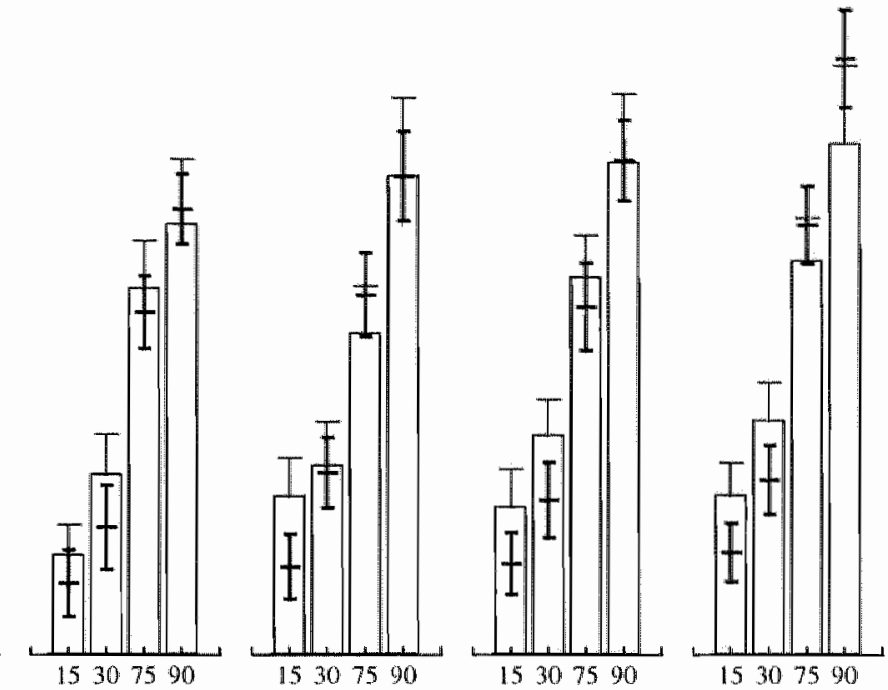

Reaching conditions ( $\%$ of $\max$ ) per session

B

$\mathrm{C}$

$\mathrm{D}$

$\mathbb{E}$

Columns = average CPmax values for the high thoracic SCI subjects; Solid line = average CPmax values for the low thoracic SCl subjects; $C P=$ centre of pressure; $A, B, C, D, E=$ subsequent experimental sessions during the rehabilitation process.

in CPmax in reaching condition 4 between the first and the second session $(p<0.01)$, i.e. after thoraco-lumbar bracing was stopped, a small increase of CPmax from session B onwards was observed in the high SCI group. However, this increase just failed to attain statistical significance at $\alpha=0.05$.

\section{Muscle activity}

Mean rectified EMG values, calculated over period $Y$, of the bilateral ES-L3, ES-T9, ES-T3, SA, OA, PM, LD and TPA for both thoracic SCI groups, for all reaching conditions at five consecutive points in time during rehabilitation are presented in figures 4.6 and 4.7. Data of left and right muscles were pooled per muscle pair. To give an indication as to the trend of changes in muscle activity as a function of CP displacement, linear regression lines are depicted in figure 4.6 and 4.7 . 
Figure 4.6. Mean rectified EMG values during period $Y$ and corresponding linear regression lines for the ES-L3, ES-T9, ES-T3 and SA for all four reaching conditions, for all groups, for all five sessions.

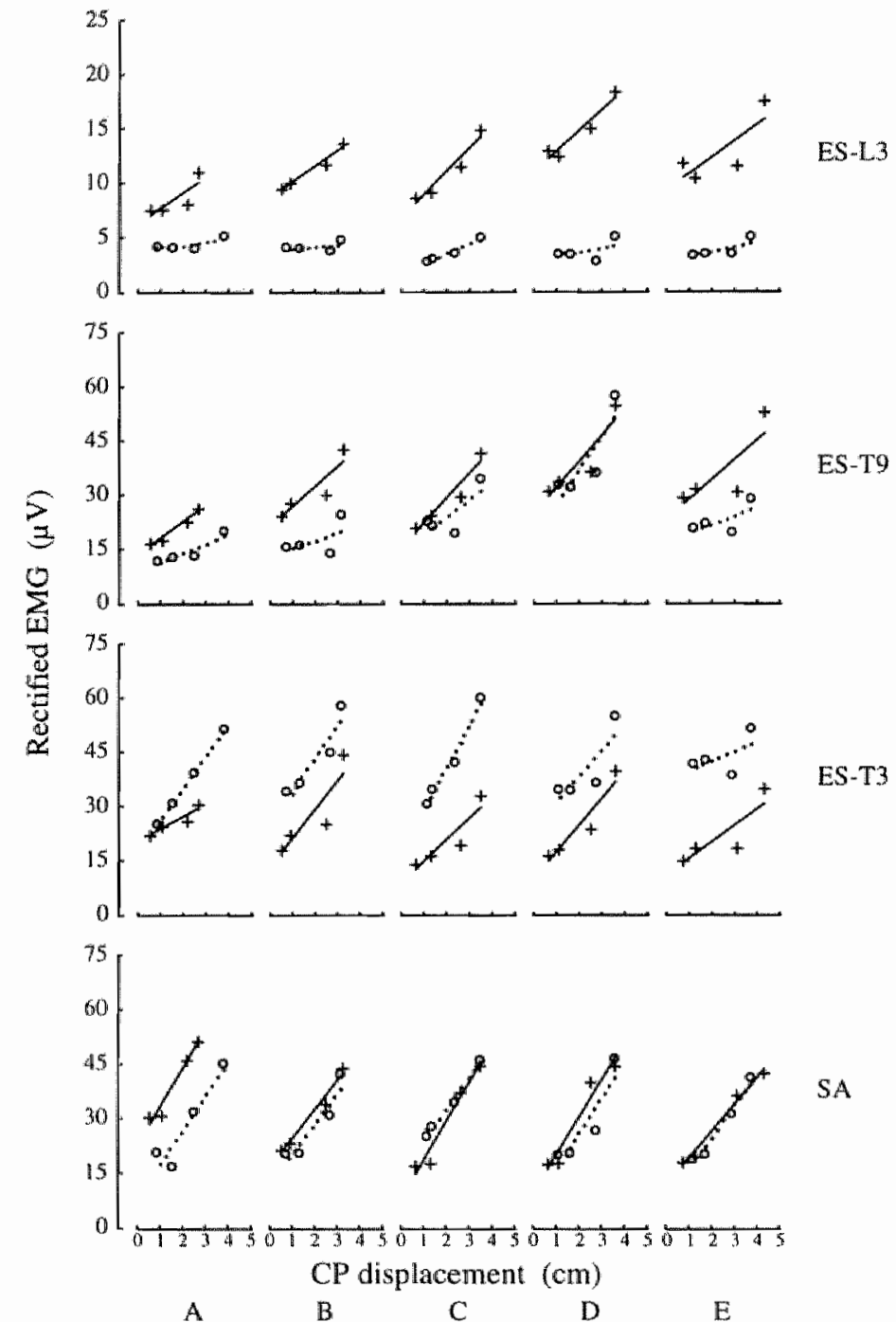

$+=$ mean rectified EMG values for the low thoracic SCI (L-)group; o = mean rectified EMG values for the high thoracic SCI ( $\mathrm{H}$-)group; Solid line = linear regression line for the L-group; Dotted line = linear regression line for the H-group; $\mathrm{ES}=$ erector spinae; $\mathrm{L} . .=$ lumbar; $\mathrm{T}$. . = thoracic; $\mathrm{SA}=$ serratus anterior; $\mathrm{CP}=$ centre of pressure; $\mathrm{A}, \mathrm{B}, \mathrm{C}, \mathrm{D}, \mathrm{E}=$ subsequent experimental sessions during the rehabilitation process. 
Figure 4.7. Mean rectified EMG values during period $Y$ and corresponding linear regression lines for the OA, PM, LD and TPA, for all four balance perturbation conditions, for al] groups, for all five sessions

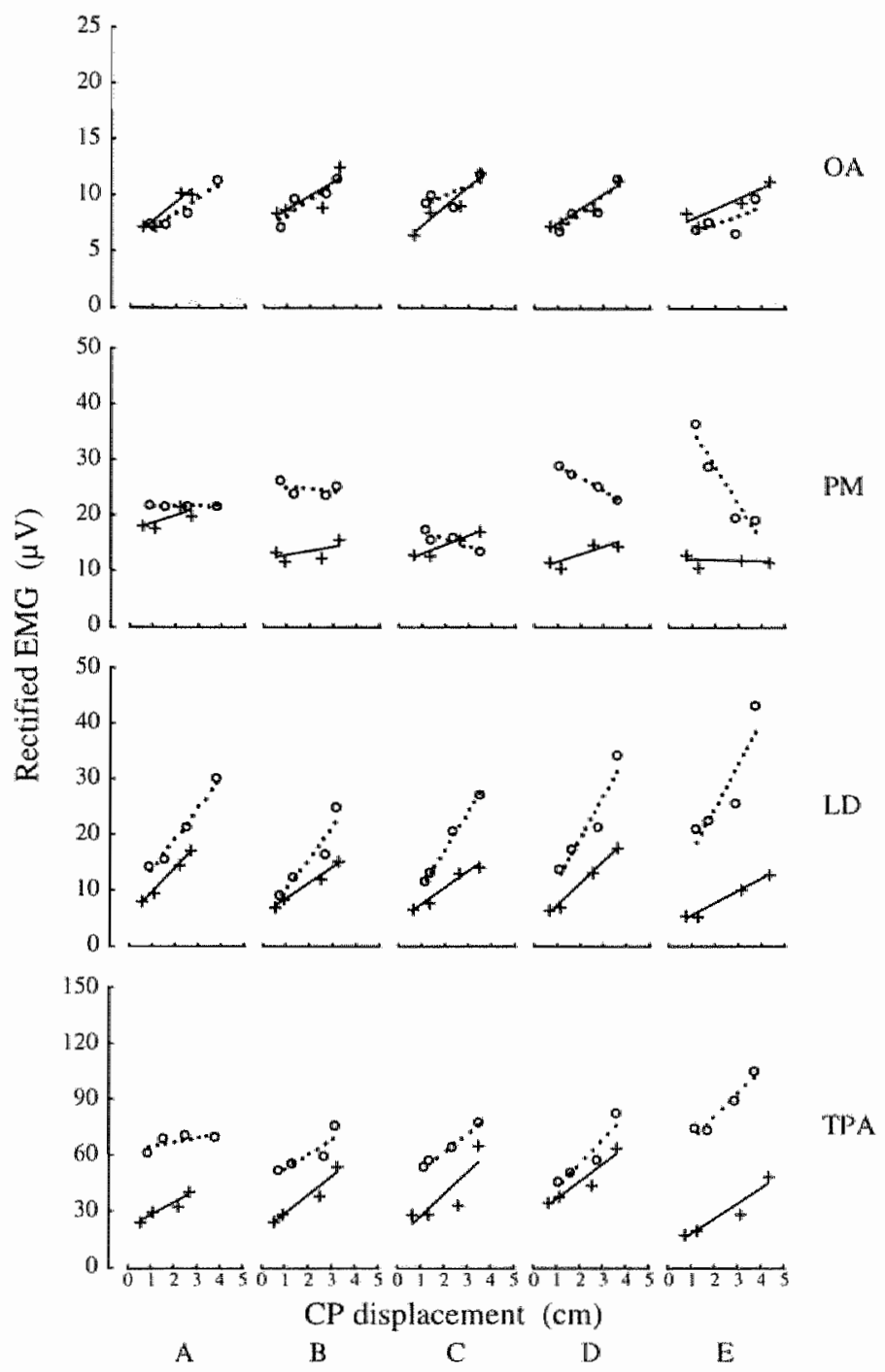

* = mean rectified EMG values for the Iow thoracic SCI (L-)group; o = mean rectified EMG values for the high thoracic SCI (H-)group; Solid line = linear regression line for the L-group; Dotted line $=$ linear regression line for the $\mathrm{H}$-group; $\mathrm{OA}=$ obliquus abdominis; $\mathrm{PM}=$ pectoralis major; $\mathrm{LD}=$ latissimus dorsi; $\mathrm{TPA}=$ ascending part of the trapezius; $\mathrm{CP}=$ centre of pressure; $\mathrm{A}$, $B, C, D, E=$ subsequent experimental sessions during the rehabilitation process. 
a) Within-group EMG results concerning graded $C P$ displacements per session

In the L-group an increase in muscle activity at increased CP displacements during time period $\mathrm{Y}$, in all sessions, was observed for the ES-T9, ES-T3, SA, LD, TPA $(p<0.001), E S-L 3$ and OA ( $<<0.01)$. A similar effect in the L-group was found for the PM during session $C$ and $D(p<0.05)$. In the H-group an increase in EMG coinciding with increased $\mathrm{CP}$ displacements during epoch $\mathrm{Y}$ at all stages in the rehabilitation process was observed in the LD (p<0.001), ES-T9, ES-T3, TPA and $S A(p<0.01)$. Such effects were also found in the H-group for the OA during session $A, B$ and $D(p<0.05)$ and the ES-L3 during session $C(p<0.05)$.

\section{b) Within-group EMG changes across the rehabilitation phase}

When comparing mean rectified EMG values, collected during reaching condition 4 across the rehabilitation process, a significant increase in muscle use was found for the ES-T9 for the H-group across the period spanning the first four sessions $(p<0,01)$, whereas a decrease from session $D$ to $E$ was found. For the $H-$ group an increase in TPA activity across the whole rehabilitation period $(p<0.05)$ was found, as was an increase in LD activity $(p<0.001)$ from session $B$ onwards. The L-group showed a significant increase in the use of the ES-L3, TPA $(p<0.01)$ and ES-T9 $(p<0.001)$ throughout the rehabilitation period spanning the first four sessions, which levelled or decreased slightly towards the last session. For all other muscles no significant increase in EMG activity for reaching condition 4 over all sessions during the rehabilitation period was found.

\section{c) Between-group differences across the rehabilitation phase}

Between-group differences in surface EMG activity in reaching condition 4 during all five sessions were also evaluated. In these conditions the L-group showed significantly higher mean rectified EMG amplitudes in the ES-L3 during all sessions, except for the first one, as opposed to the H-group ( $p<0.01)$. For the ES-T9 the L-group showed more myoelectric activity during the last session, i.e. just before clinical discharge $(p<0.05)$, whereas the H-group showed more activity of the EST3 during session $C$ and $E(p<0.05)$. No between-group differences for reaching condition 4 in any of the sessions were found bilaterally in the SA and OA. Significant between-group differences for the PM were only found in session B and $\mathrm{D}$ in which the H-group showed higher PM activity. The H-group generated higher muscle activity in the $\mathrm{LD}$ during session $\mathrm{C}, \mathrm{D}(\mathrm{p}<0.01)$ and during the last session ( $p<0.001$ ). Between-group differences in EMG activity for the TPA were only significant during the last session. Here the H-group showed more EMG activity as opposed to the L-group $(p<0.01)$. 


\section{Discussion}

The aim of this study was to investigate the development of patterns of alternative postural muscle use in thoracic SCI patients during their active rehabilitation period and the effectiveness of these muscle synergies in maintaining sitting balance during task execution. The extent of ES function loss and the subsequent partial restoration of ES function during rehabilitation were assessed, the ES being the prime postural muscle to be used in maintaining an erect sitting position $[7,10,25]$. Additionally, activity of non-postural muscles like the LD and TPA, used in stabilising the trunk in seated thoracic SCI subjects $[26,27]$, was monitored throughout clinical rehabilitation, as were muscles that have a stabilising effect on the shoulder girdle, like the PM and SA [9]. Changes in activity patterns in these muscles were studied in several conditions of perturbed sitting balance throughout the active clinical rehabilitation process of thoracic SCI patients, analogous to earlier experiments involving thoracic SCI subjects who had completed their active rehabilitation process [26].

In the low thoracic SCI subjects an improvement in ES-L3 activity for sitting balance restoration during the rehabilitation process was observed, which started just after thoraco-lumbar spinal bracing was stopped. This EMG phenomenon could only be due to increased activity of the multi-segmental muscle fibres of the $\mathbb{E S}$ in the thoraco-lumbar region still centrally controlled via spinal segments cranial to the lesion site, especially in patients with a T11 or T12 lesion, five of which were present in the L-group. For example the multifidus muscle and the longissimus muscle are multi-segmental ES muscles [2] that could have generated the EMG activity detected. The iliocostalis muscle is also a polysegmental muscle. However, the contribution of this muscle to the EMG signal recorded in the present research is low, since the position of the surface electrodes used at level L3 was close to the spine. This has also been pointed out by Vink and co-workers [33, 34], who investigated the relation between EMG electrode position and the specificity of detecting intrinsic lumbar back muscle activity. Local spinal reflex activity, induced by the movement of the trunk, might also have caused some EMG increase in the ES-L3 $[11,16,19]$. However, it is not very likely that reflex activity solely caused such a pronounced EMG phenomenon. If spinal reflex mechanisms would have generated such large EMG increases as seen in the L-group, one would expect similar activity levels in the ES-L3 of the H-group participants. This phenomenon, however, was not found in these subjects. In both SCI groups the use of the ES-T9 to restore sitting posture after balance perturbation generally increased to the same extent during rehabilitation indicating (partial) restoration of function of these muscles. In both groups this increase ceased towards the end of the rehabilitation process. The H-group even showed a decline in ES-T9 use during sitting balance restoration shortly before clinical discharge. The progression in the rehabilitation 
process seems not to be accompanied by an increased use of the ES at level T3 in either SCI group. Furthermore, significant differences between the high and low thoracic SCI group were found for the ES-T3 only during session C and E, although a tendency towards significant group differences, in which the ES-T3 seemed to be used more by the high SCI subjects, could be observed in session D. The absence of a distinct progress in muscle activation in the ES-T3 during rehabilitation is probably due to the fact that at this level the ES was fully functional at all times in all subjects. These data are consistent with earlier findings in SCI subjects who had completed their clinical rehabilitation [26]. In summary it seems that, although the spinal cord lesion was complete, partial restoration of function took place in the ES, as prime postural muscle, at nearby levels just caudal to the segmental lesion height. A number of authors have reported partial restoration of function occurring in the early stages after the SCI (3-6 weeks [20]) to be potentially associated with 'residual spinal cord connections' in so-called 'discomplete' lesions $[12,20,37]$, recovery from spinal concussion, reduction of oedema, restoration of regional capillary perfusion, improvement of axonal conduction and regeneration of axons [20,37]. We argue that the aforementioned increase in EMG activity of the ES, which occurs mainly well after the initial period of several weeks, may be due to hypertrophy of polysegmental muscle elements of the $\mathbb{E S}$, acquired through rehabilitation.

Of all non-postural muscles under observation in this study, the LD and TPA show the highest increase in muscular activity both as a function of $\mathrm{CP}$ displacement and as a function of (rehabilitation) time in the high thoracic SCI patients. This increase in EMG activity of the LD and TPA while restoring sitting balance after reaching over almost maximal reaching distances, evaluated across time, started immediately after the thoraco-lumbar brace was removed (i.e. session B). The latter phenomenon was not observed in the low thoracic SCI patients. As a consequence, differences in LD and TPA use for sitting balance restoration between groups grew as rehabilitation progressed. Stabilisation of the spine through bilateral activation of the LD in thoracic SCI subjects, as was found in this study, as well as in earlier studies [26,27], is supported by findings of Ito et al. [17] who investigated the role of different parts of the LD. They found that activity of the lower part of the LD increased during lateral tilting of the pelvis and, as a consequence, lateral bending of the spine, in healthy subjects, making the humerus punctum fixum for the LD.

In previous research [26] it was argued that the increased use of the PM and SA during sitting balance restoration in high thoracic SCI subjects contributed to stabilisation of the shoulder girdle and prevent retraction of the scapulae caused by higher levels of LD and TPA activity. Data from the present study show that the amount of SA activity positively correlates with sitting balance restoration efforts in both $\mathrm{SCl}$ groups from the start of clinical rehabilitation onwards. However, no evidence as to further improvement of performance of the SA in sitting balance restoration during the clinical stay was found. The cranial region of the sternocostal part of the PM seems to be active independent of the grade of sitting balance 
perturbation in low SCI patients and during the initial period of the rehabilitation process in high SCI patients. In the latter group however, PM activity seems to be inversely related to sitting balance perturbation towards the end of the rehabilitation. Basmajian et al. [9] state that the sternocostal head of the PM is active in the adduction and depression of the humerus. A possible explanation for the behaviour of the PM observed in the present study is that high thoracic SCI subjects try to stabilise further their sitting posture through adduction of the humerus against the ribcage while reaching. This strategy is only possible while reaching towards targets close to the body, i.e. in positions in which the humerus is parallel to the ribcage. However, this remains to be investigated through collection of e.g. kinematic data on spatial displacement of the humerus relative to the trunk. The combined activity of the PM and LD, as was seen in high thoracic SCI subjects, also causes depression of the humerus [9], which would have to be counteracted by increased activation of the rotator cuff muscles to prevent the humerus from being dislocated in the glenohumeral joint. Our concept of alternative postural muscle use in thoracic SCI subjects therefore predicts an increased use of the rotator cuff muscles in high thoracic SCI subjects, compared to non-SCI subjects, during sitting balance restoration after submaximal reaching. Also endorotation of the humerus caused by LD activity should be counteracted by exorotatory muscle use.

The role of $\mathrm{OA}$ muscles in seated non-SCI subjects has been investigated by Snijders and co-workers [29, 30]. In non-SCI subjects bilateral activation of the OA contributes to trunk flexion [31], and causes detraction of the ribcage $[9,21]$. The OA also supply torsional stability of the trunk and may help in stabilising the basis of the spine [29]. In our research the OA muscles in both SCI groups showed to be weakly active at the different reaching distances throughout the rehabilitation period, without showing any change in activation levels over time. The segmental innervation levels of the OA range from T5 to T12 (external OA muscle) and from T8 to L2 (internal OA muscle) [21]. Activity of these muscles during balance restoration may have been triggered by a combination of mechanical stretch of the paretic muscle fibres, leading to spinal reflex activity, and by recruitment through central control of the non-paretic fibres of the OA.

In patients with a high thoracic SCI the removal of the thoracic brace initially caused a reduction in range in which they were able to control sitting posture, signified by reduced $\mathrm{CP} \max$ values during semi-static reaching conditions. However, during the subsequent rehabilitation period in which alternative postural muscle use was trained, this reduction disappeared. This small trend in $\mathrm{CP}$ displacement in high thoracic SCI patients coincided with an increase in LD and TPA activity over time. In low thoracic SCI patients a clear improvement in controlling sitting posture took place throughout the whole rehabilitation period. When spinal bracing was stopped these patients showed higher levels of CP displacement than previously, in contrast to the patients with more cranial lesions. 
In the low SCl subjects the changes of postural control performance over time coincided more with an increase in ES-L3 and ES-T9 activity.

In conclusion, different patterns of postural control in high and low thoracic $\mathrm{SCI}$ patients emerge during the clinical rehabilitation period. In low thoracic SCI subjects the contribution of the ES-L3 and ES-T9 in restoring and maintaining sitting balance improves, as a result of which less alternative postural muscle activity of the LD and TPA seems necessary. The latter is also corroborated by previous findings [26]. In contrast, the high thoracic SCI patients depend more on increased ES-T3 activity in combination with increased use of the LD and TPA and to a lesser extent the PM.

The present study gives rise to additional research on a number of topics. The role of the superficial and deep muscles of the shoulder, especially the rotator cuff muscles, in stabilising the shoulder girdle during balance restoration in high thoracic $\mathrm{SCl}$ patients needs to be further investigated. Also research into the biomechanical efficiency of alternative postural muscle use in SCI subjects and the further development of genuine biomechanical models of alternative postural muscle use is necessary. As for rehabilitation of SCl patients, research into effects of specific therapy interventions on the development of new postural muscle synergies is strongly recommended, not only because of the contribution to theory-based neurorehabilitation [8], but also because it may contribute to improvement of therapy and therapy-outcome.

\section{References}

1. Andersson GBJ: Biomechanical aspects of sitting: An application to VDT terminals. In: Behavior and Information Technology, Taylor and Francis, London, pp 257-269, 1987.

2. Andersson GBJ: Evaluation of muscle function. In: The adult spine: Principles and pracice, ed by Frymoyer JW, Ducker TB, Hadler NM, Kostuik JP, Weinstein JN. Whitecloud TS, Raven Press, New York, pp 241-274, 1991.

3. Andersson GBJ: Loads on the spine during sitting. In: The ergonomics of working postures, ed by Corlett N, Wilson J, Manenica T, Taylor and Francis, London, pp 309-318. 1986.

4. Andersson GB., Jonsson B, Ortengren R: Myoelectric activity in individual erector spinae muscles in sitting. A study with surface and wire electrodes. Scand J Rehabil Med, suppl. $3: 91-108,1974$.

5. Anclersson GBJ, Örtengren R: Lumbar disc pressure and myoelectric back muscle activity during sitting: studies on a wheelchair. Scand J Rehabil Med, 6:122-127, 1974a.

6. Andersson GBJ, Ortengren R: Myoelectric back muscle activity during silting. Scand $J$ Rehabil Med, suppl. 3:73-90, 1974 b.

7. Andersson GBJ, Winters JM: Role of muscle in postural tasks: spinal loading and postural stability. In: Mutriple muscle systems, ed by Winters JM, Woo SLY, Springer-Verlag, New York, pp 377-395, 1990.

8. Bachy-Y-Rita P: Theory-based neurorehabilitation. Arch Phys Med Rehabil 70(2):162, 1989. 
9. Basmajian IV, De Luca CJ: Muscles alive: Their fonchon revealed by electrompography. Williams and Wilkins, Baltimore, 1985.

10. Chaffin DB, Andersson GBJ: Occupational biomechanics, John Wiley \& Sons Inc., New York. 1991.

11. Denier van der Gon JJ, Coolen ACC. Erkelens CJ, Jonker HJJ: Self-organizing neural mechanisms possibly responsible for muscle coordination. In: Multiple muscle systems, ed by Winters JM, Woo SLY, Springer-Verlag, New York, pp 335-342, 1990.

12. Dimitrijevic MR, Hsu CY, McKay WB: Neurophysiological Assessment of spinal cord and head injury. I Neurotrauma 9, suppl 1:293-300, 1992.

13. Do MC, Bouisset S, Moynot C: Are paraplegics handicapped in the execution of a manual task? Ergonomics 28:1363-1375, 1985.

14. Eklund JAE, Corlett EN, Johnson F: A method for measuring the load imposed on the back of a sitting person. Ergonomics 26:1063-1076, 1983 .

15. Groot JP de: Electromyographic analysis of a postural sorting task. Ergonomics 30(7): 1079-1088, 1987 .

16. Guyton AC, Hall JE: Textbook of medical physiology, Saunders, Philadelphia, 1996.

17. Ito $\mathrm{H}$, Iwasaki $\mathrm{T}$, Yamada $\mathrm{M}$, Yasaki $\mathrm{K}$, Tanaka $\mathrm{S}$, lida $\mathrm{M}$ : Electromyography of the latissimus dorsi muscle. J Jpn Ph Assoc 3:23-36, 1976.

18. Johanson ME: Electromyographic investigation of trunk control in the sitting position. In: Electrophysiological kinesiology, ed by Wallinga W, Boom HBK, Vries J de. Elsevier Science Publishers BV, Amsterdam, pp.463-466, 1988.

19. Johansson R, Magnusson, M: Human postural dynamics. Crit Rev Biomed Eng 18(6):413437, 1991.

20. Kakulas A: The applied neurobiology of human spinal cond injury: a review. Paraplegia $26: 371-379,1988$.

21. Kendall HO, Kendall FP, Wadsworth GE: Muscle testing and function, Williams and Wilkins, Baltimore, 1978 .

22. Lorenz $M$, Patwardhan A, Zindrick M: Instability and mechanics of implants and braces for thoracic and lumbar fractures. In: Spinal rauma, ed by Errico TJ, Bawer RD, Waugh T, JB Lippincott Company, Philadelphia, pp 271-280, 1991.

23. Mouton LJ, Besseling S, Hidding A, Bij J wan der: Different EMG-force relationships of the low-back muscles during standing and sitting. In: Electrophysiological kinesiology, ed by Wallinga W, Boom HBK, Vries $J$ de, Elsevier Science Publishers BV, Ansterdam, pp $459-462,1988$.

24. Norussis MJ, SPSS Inc.: SPSS/PC+Base system user's guide, SPSS Inc., Chicago, Illinois, 1992.

25. Schobert H: Orthopadie des Sizens. In German. Springer Verlag, Berlin, 1989.

26. Seelen HAM, Potten YJM. Huson A, Spaans F, Reulen JPH: Impaired balance control in paraplegic subjects. J Electromyogr Kinesiol 7(2): 149-160, 1997.

27. Seelen HAM, Vuurman EFPM: Compensatory muscle activity for sitting posture during upper extremity task performance in paraplegic persons. Scand I Rehab Med 23:89-96. 1991 .

28. Siegel S, Castellan NJ: Nonparametric statistics for the behavioral sciences, McGraw-Hill Book Company, New York, pp. 184-189, 1988.

29. Snijders CJ, Bakker MP, Vleeming A, Stoeckart R: Oblique abdominal muscle activily in standing and sitting on hard and soft seats. J Clin Biomech 10:73-78, 1995.

30. Snijders CJ, Slagter AHE, Strik R van, Vleeming A, Stoeckart R, Stam HJ: Why leg crossing? The influence of common postures on abdominal muscle activity. Spine $20(18): 1989-1993,1995$. 
31. Soderberg GL: Kinesiology: Applications vo pathological motion, Williams and Wilkins, Baltimore, 1986.

32. Soderberg GL, Blanco MK. Cosentino TL, Kurdelmeler KA: An EMG analysis of posterior trunk musculature during flat and anteriorly inclined sitting. Hum Factors $28: 483-491,1986$.

33. Vink P, Daanen HAM, Verbout AJ: Specificity of surface EMG on the intrinsic lumbar back muscles. Hum Mov Sci 8:67-78, 1989.

34. Vink P, Velde EA van der, Verbout AJ: A functional subdivision of the lumbar extensor musculature. Recruitment patterns and foree-RA EMG relationships under isometric conditions. Electromyogr Clin Nestophysiol 28:517-525, 1987.

35. Winter DA: Biomechanics and motor control of human movement, John Wiley \& Sons, Inc., New York, pp. 93-96, 1990.

36. Yates JW, Karwowski W: An electromyographic analysis of seated and standing lifting tausks. Ergonomics 35(7/8):889-898, 1992.

37. Young W: Neurophysiology of spinal cord injury. In: Spinal trauma, ed by Errico TJ, Bauer RD, Waugh T, JB Lippincott Company, Philadelphia, Pp 377-414, 1991. 


\title{
Motor preparation in postural control in seated spinal cord injured people
}

\author{
H.A.M. Seelen ${ }^{1}$, Y.J.M. Potten ${ }^{1,2}$, J.J. Adam ${ }^{3}$
}

I Institute for Rehabilitation Research, Hoensbroek, the Netherlands

2 University Maastricht, Department of Anatomy and Embryology, Maastricht, the Netherlands

3 University Maastricht, Department of Movement Sciences, Maastricht, the Netherlands

This paper has been submitted for publication. 


\section{Summary}

Spinal cord injured ( $\mathrm{SCl}$ ) people try to compensate the loss of postural muscle function by increased use of non-postural muscles when sitting balance is perturbed during e.g. activities of daily living. Such alternative motor actions imply alterations in motor control. In this study motor programming in sitting balance control was investigated in three groups of either high thoracic SCI, low thoracic $\mathrm{SCI}$ or non-SCI subjects. All SCI participants were clinically diagnosed with a complete lesion below the level of T1. They had completed their rehabilitation at least one year prior to this study. A bimanual forward reaching task, in which graded sitting balance perturbation was systematically invoked, was presented to the participants as a visual precue choice reaction time (RT) task. Effects of movement preparation were examined by precuing reaching distance information. RT and movement times were recorded. Sitting balance perturbation was quantified in terms of centre of pressure (CP) displacement and $\mathrm{CP}$ velocity (Vcp) in antero-posterior direction.

Results indicated that high thoracic SCI subjects program balance perturbing reaching movements as fast as non-SCI subjects, in contrast to low thoracic $\mathrm{SCI}$ people who reacted slower. Movement velocity differences can not account for the RT differences among SCI groups, since peak Vcp was equivalent in these groups. Precue benefit regarding movement extent in both $\mathrm{SCI}$ groups was at least as large as in the non-SCI group. Evidence for the occurrence of different movement preparation strategies regarding movement extent in cued and uncued conditions was found. Our data support the hypothesis that low thoracic SCI subjects adopt more complex postural control strategies involving residual motor functions in an attempt to actively compensate loss of postural muscle function during task performance. High thoracic SCI subjects adopt postural control strategy in which they rely more on passive postural support, which seems to be more simple to program. Our lindings also confirm the sensitivity of the task we presented to postural control phenomena in $\mathrm{SCI}$ and in non-SCl subjects.

\section{Introduction}

A major part of the spinal cord injured ( $\mathrm{SCI}$ ) population is physically restricted to the use of a wheelchair, because of problems in postural control. The necessity for compensation of loss of function in postural control grows at ascending SCI levels, whereas the possibilities for this kind of compensation decrease, leading to poorer task performance in more focal movement activity of e.g. the upper extremities and to avoidance strategies. Clinical observations suggested that subjects with (high) thoracic spinal cord (SC) lesions might partially compensate the loss of postural muscle activity by using non-postural muscles. 
Indeed, Do et al. [4] and Seelen et al. [28, 29] showed that, at increasing SCI levels, thoracic SCI subjects try to compensate the loss of erector spinae (ES) activity by increased use of the latissimus dorsi, the ascending part of the trapezius, the sternocostal head of the pectoralis major and the serratus anterior. Also partial restoration of postural muscle function at segmental levels near to the lesion and raised use of ES activity cranial to the lesion site in SCI were reported $[27,28]$. Although alternative postural muscle use and partial restoration of function of the ES were observed in SCI subjects, they could not fully compensate loss of balance control. The range in which they were able to shift their centre of pressure during sitting was smaller compared to non-SCI subjects. Apart from the more biomechanical considerations regarding sitting balance the question remains how the necessary neural motor control mechanisms adapt to the new situation in seated $\mathrm{SCI}$ subjects. Both exterocepsis and propriocepsis are impaired in thoracic $\mathrm{SCl}$ as well as the motor system which inevitably leads to impairments in feedback and feedforward control loops necessary for adequate postural control $[5,15-18,20,21]$.

The rehabilitation of SCI patients is focused on (re-)acquisition of skills [8] and the re-automatisation of postural control and (focal) movement. This also involves the ability of a subject to anticipate forthcoming (balance perturbing) events and postural changes $[1,2,5-7,14-16,21,36]$. Experimental data by Seelen et al. [27-29] suggest the development of new patterns in postural muscle use. This implies the development of new strategies in supraspinal motor control and central programming in thoracic SCI subjects. The question arises how effective these new motor programs are in incorporating (advance) information concerning the magnitude of balance perturbation and restoration. The aim of the present study was to assess to what extent the aforementioned newly acquired motor activation patterns in postural control in SCI subjects are open for pre-programming or motor preparation. An earlier study by Seelen and Vuurman [29] revealed that thoracic SCI subjects (SCI levels $\mathrm{T} 2$ - T12) who had completed rehabilitation were (a) generally slower in the preparation of balance perturbing reaching movements as opposed to non-SCI control subjects and (b) were less able to use precued movement direction information to increase upper extremity task performance. It was argued that, according to a two-stage model of programming proposed by Sternberg and co-workers [33] Spijkers and Sanders [30] and Spijkers and Walter [31], both motor programming and program loading concerning upper extremity reaching movements may have changed due to discrepancies between the required (compensatory) motor control parameters and the impaired postural motor system. However, no distinction was made between the extent of sensorimotor function loss caused by different levels of SCI. Seelen et al. [28] showed that alternative postural muscle use differed between high and low thoracic SCI subjects. The present study was carried out to determine whether, in view of the abovementioned sensorimotor function loss and subsequent development of alternative postural muscle use, postural motor programming and upper extremity movement preparation differed in 
high and low thoracic SCI subjects. Possible differences in complexity of the postural control strategies, used by high and low thoracic SCI subjects, were investigated and compared to the performance of non-SCI subjects. Reaction time (RT) was used as an indicator of response complexity in line with the work of Henry and Rogers [10], Christina et al. [3] and Klapp [13]. Because programming is assumed to occur during the RT interval, differences in programming should influence RT [13]. It was hypothesised that, depending on the level of the lesion, SCI would necessitate more complex postural control strategies, involving residual muscle functions to compensate postural muscle function loss, leading to higher reaction times (hypothesis 1). Furthermore, effects of different levels or grades of sitting balance perturbation, as an additional manipulation of task complexity, on movement preparation in SCI and non-SCI were investigated. It was hypothesised that, in line with work of Goodman and Kelso [9] and Rosenbaum [26] absence of advance information on reaching extent would lead to a strategy of readying all movement alternatives, i.e. general preparation, whereas precuing movement extent would not only lead to a strategy of specifying individual movement values, i.e. selective preparation, but would also lead to differential effects in RT performance caused by different grades of balance perturbation (hypothesis 2).

To test these hypotheses a precue choice reaction time experiment, aimed at investigating effects of visually precued information, concerning graded balance perturbation, on motor preparation in thoracic SCI and non-SCI subjects, was carried out. The general idea of the precuing technique, put forward by Rosenbaum $[25,26]$, is "(..) to supply the subject with partial information about the defining characteristics of a motor response and then observe how long it takes the subject to perform the response when its corresponding reaction signal is presented.". To explore possible differences in basic visual perception and simple upper extremity motor execution between SCI and non-SCI participants, which might obscure motor preparation results regarding reaction time, a short experiment presented as a simple visual RT task was held prior to the precue choice RT experiment.

\section{Methods}

\section{Experiment 1}

\section{Subjects}

Fifteen subjects with a complete low thoracic SCI at spinal level T9 - T12 (Lgroup), 15 subjects with a complete high thoracic SCI at spinal level T2 - T8 (Hgroup) and 15 non-SCI subjects ( $\mathrm{N}$-group) participated in this study. All SCI subjects finished their active rehabilitation program at least one year before participation in this experiment. No secondary pathology was present in any of the subjects. None of the participants had any arm or hand function impairment. All 
subjects had normal vision. Groups were matched for age, sex, height, weight, left or right handedness (Table 5.1) and for educational level according to school types of the Dutch educational system (Table 5.2).

Table 5.1. Group composition.

\begin{tabular}{|c|c|c|c|c|}
\hline & & N-group & L-group & H-group \\
\hline & $\mathrm{n}$ & 15 & 15 & 15 \\
\hline age (year) & mean (s.d.) & $34.8(10)$ & $36.8(1.0)$ & $34.3(8)$ \\
\hline & range & $22-56$ & $26-55$ & $24-51$ \\
\hline weight $(\mathrm{kg})$ & mean (s.d.) & $73.9(8)$ & $69.6(13)$ & $73.4(13)$ \\
\hline & range & $53.7-88.9$ & $45.7-91.8$ & $49.3-102.6$ \\
\hline height (m) & mean (s.d.) & $1.78(0.06)$ & $1.78(0.11)$ & $1.81(0.11)$ \\
\hline & range & $1.68-1.86$ & $1.53-1.98$ & $1.58-2.00$ \\
\hline sex & $\mathrm{M} / \mathrm{F}$ & $14 / 1$ & $14 / 1$ & $13 / 2$ \\
\hline handedness. & left / right & $1 / 14$ & $1 / 14$ & $1 / 14$ \\
\hline
\end{tabular}

$\mathrm{N}$-group = non-SCI group; L-group = low thoracic SCI group; H-group = high thoracic $\mathrm{SCI}$ group; $\mathrm{M}=$ male; $\mathrm{F}=$ female.

Table 5.2. Educational level of all subjects per group.

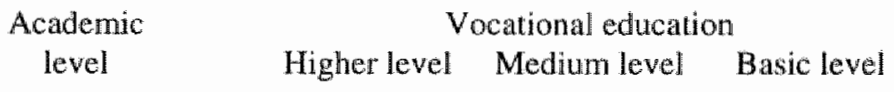

\begin{tabular}{lllll} 
N-group & 1 & 5 & 5 & 4 \\
L-group & 1 & 4 & 6 & 4 \\
H-group & 1 & 4 & 6 & 4 \\
\hline
\end{tabular}

The levels of spinal cord injury of subjects from the L- and H-group are given in table 5.3 . 
Table 5.3. Levels of complete spinal cord lesion of subjects in the L- and the Hugroup.

high SCI (H-group)

low SCI (L-group)

\begin{tabular}{cccccccccccc} 
& $\mathrm{T} 2$ & $\mathrm{~T} 3$ & $\mathrm{~T} 4$ & $\mathrm{~T} 5$ & $\mathrm{~T} 6$ & $\mathrm{~T} 7$ & $\mathrm{~T} 8$ & $\mathrm{~T} 9$ & $\mathrm{~T} 10$ & $\mathrm{~T} 11$ & $\mathrm{~T} 12$ \\
$\mathrm{n}$ & 1 & 0 & 4 & 3 & 2 & 3 & 2 & 1 & 5 & 3 & 6 \\
\hline
\end{tabular}

All the experimental procedures in this study were approved by the local medical ethical committee. Informed consent was obtained from all. participants prior to the beginning of this study.

\section{Task and apparatus}

Subjects were comfortably seated in a multi-adaptable chair behind a table. The reclination angle of the backrest was $10^{\circ}$. Arm rest were either very low or removed from the chair. The angle of the leg rests was $10^{\circ}$ relative to the frontal plane. Participants were issued a hand-held button mounted on top of a soft foam rubber cylinder (length: $12 \mathrm{~cm}$, diameter: $4 \mathrm{~cm}$ ). Button diameter was $1.5 \mathrm{~cm}$. Positive contact force for this button was approximately $2 \mathrm{~N}$. The cylinder was held in the dominant hand. Hands were positioned comfortably on the subjects lap. The button was operated through thumb movement by the participants.

A simple forewarning visual reaction time task was presented to participants. On a monitor one open square $(17 \times 17 \mathrm{~mm})$ representing the hand held button was depicted. The subject had to start each trial by pressing and holding down the button using his thumb. After $3000 \mathrm{~ms}$ a visual warning signal (WS) was presented for a period between 1000 and $4000 \mathrm{~ms}$ to avoid stimulus anticipation. The WS was depicted as a small open square $(8 \times 8 \mathrm{~mm})$ within the original square already present on the screen. To assure that all subjects were presented similar WS conditions the order of the different WS lengths used in this experiment was randomly assigned from a fixed pool of alternatives. This pool was randomly drawn before the start of the experiment. After the WS an imperative stimulus (ISt) (i.e. a " sign) was displayed at the same location as the small square of the WS, instructing the subject to release the button as fast as possible. Dimensions of the ISt were $8 \times 8 \mathrm{~mm}$. During this task only small movements of the thumb on the dominant side were required to release the hand-held button. Sitting balance was not perturbed during the execution of this task. The intertrial interval (ITI) was at least 3 s. The ITI could also be prolonged by the experimenter to facilitate a so-called 'lift'manoeuvre (i.e. a technique for pressure sore prevention in which temporary pressure reduction on the buttocks is obtained) carried out by the $\mathrm{SCI}$ participants. The experiment consisted of two series of 10 trials each. Written instructions regarding the task were given at the beginning of the experiment. Five training trials 
were given in advance to familiarise the participant with the task. A standard 14 inch VGA monitor was placed in front of the seated subject at approximately $1.25 \mathrm{~m}$ distance. Timing of the RT task was performed on a personal computer (Compaq Deskpro 386sx, Compaq Computer CO., Houston, Texas) interfaced with a PCL830 timer/counter board (Advantech Co., Taiwan). RT, i.e. the time between the onset of the ISt and the release of the button by the subject, was recorded for all trials.

\section{Data analysis}

Statistical analyses were performed using SPSS (SPSS Inc., Chicago, IIl.). Between group differences in RT were tested using one-way analysis of variance (ANOVA) and additional multiple comparison techniques. Logarithmic transformations on the RT data were carried out to reduce positive skewness of the data distribution before the ANOVA was applied. The antilog of the mean of the aforementioned transformed RT data is reported in terms of the original units (i.e. ms). The quintessence of this transformation procedure has extensively been described by Howell [12] and Hoaglin, Mosteller and Tukey [11].

\section{Experiment 2}

\section{Subjects}

In the second experiment the same subjects as in experiment 1 participated.

\section{Task and apparatus}

Subjects sat behind a table in the same chair as in experiment 1. Tabletop was approx. $3 \mathrm{~cm}$ above elbow height. One rectangular central start button (SB) (dimensions: $1.5 \times 2.3 \mathrm{~cm}$ ) was placed on the table about $25 \mathrm{~cm}$ in front of the seated subject. Also eight round peripheral target buttons were placed on the table in two rows of four, in parasagittal direction. These target button pairs were placed at لocations marking $15 \%, 30 \%, 75 \%$ and $90 \%$ of the individual unsupported maximal reaching distance of the participant (conditions $\mathrm{A}, \mathrm{B}, \mathrm{C}$ and $\mathrm{D}$ ) as is depicted in figure 5.1. Distance between target buttons in the left and right row was $15 \mathrm{~cm}$. Target button diameter was $1.5 \mathrm{~cm}$. Positive contact force for all buttons was aboul $2 \mathrm{~N}$.

Maximal reaching distance in the sagittal plane, which the participant was able to cover without manual support on the table, was measured. Subjects were asked to perform muitiple bimanual reaching movements in the sagittal plane towards the target button pairs placed at $15 \%, 30 \%, 75 \%$ or $90 \%$ of their individual maximal reaching distance, introducing graded systematic sitting balance perturbation. The $90 \%$ reaching distance was chosen to avoid complete balance loss in $\mathrm{SCl}$ subjects during task execution. A clear distinction was made between relatively easy coverable reaching distances of $15 \%$ and $30 \%$ on the one hand and 
Figure 5.1. Arrangement of the precuing task in experiment 2 .

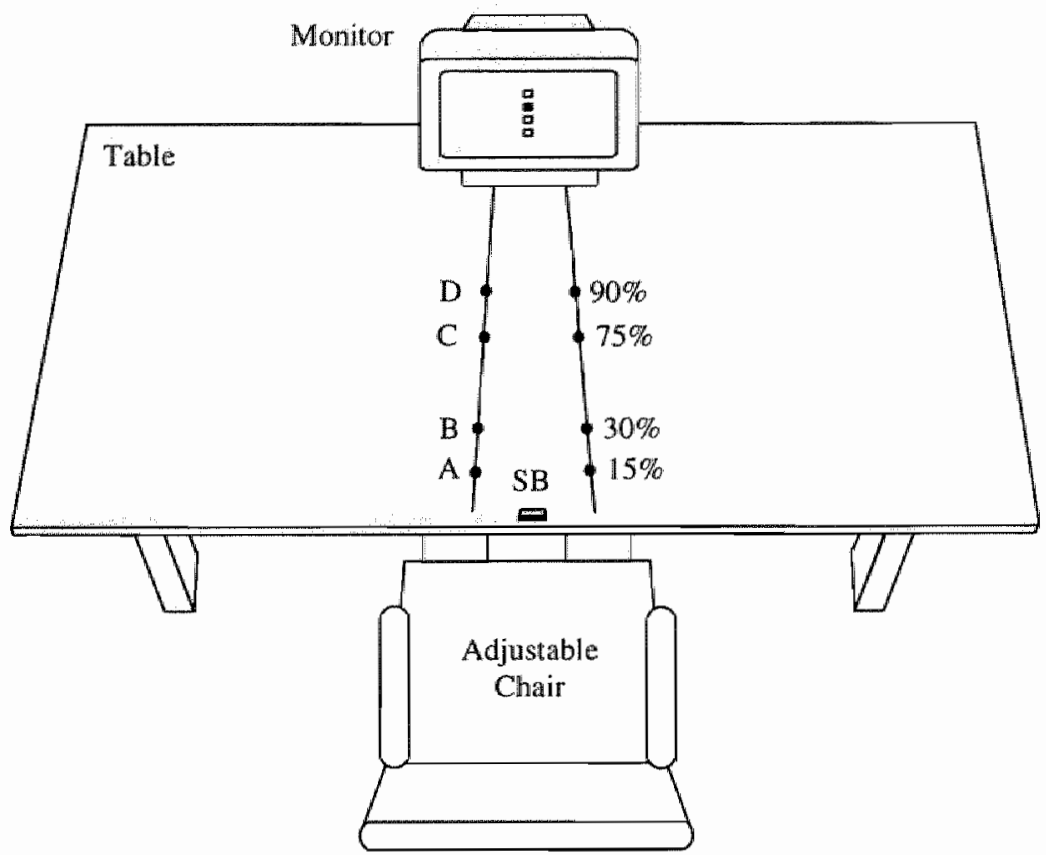

$\mathrm{SB}=$ start button; $\mathrm{A}, \mathrm{B}, \mathrm{C}$ and $\mathrm{D}=$ reaching conditions in which button pairs are placed at $15 \%$, $30 \%, 75 \%$ and $90 \%$ of the individual maximal reach.

$75 \%$ and $90 \%$ on the other hand which were thought to be more difficult to cover by SCI subjects. During initial sitting position the proximally placed start button (SB) was lightly pressed with the index fingers of both hands. Information as to reaching distance was presented as a visual precue choice reaction time task on a personal computer (Compaq deskpro 386sx, Compaq Computer Co., Houston, Texas). Timing of the task was performed using a PCL830 timer/counter board (Advantech $\mathrm{Co}$, Taiwan). A standard 14 inch VGA monitor was located at a distance of approximately $1.25 \mathrm{~m}$ in front of the subject. On the monitor one centrally located vertical row of four squares that spatially corresponded to the four pairs of target buttons was displayed during the whole experiment. The subject had to start each trial by pressing and holding down the SB with both hands. After $3250 \mathrm{~ms}$ a visual warning signal (WS) was presented as small open squares within the original squares already present on the screen. In the precue conditions only two small open squares appeared in either the upper two or lower two squares already present on 
screen pre-informing the subject about the possible location of the subsequent ISt and the possible reaching distance to be covered (i.e. "near" or "far"). Precue information was always valid. In the non-precue conditions the warning signal consisted of four small squares presented in all four larger squares. No preinformation as to reaching distance could be drawn from this WS condition. The WS alternatives are shown in figure 5.2 .

Figure 5.2. Warning signal alternatives for experiment 2 .

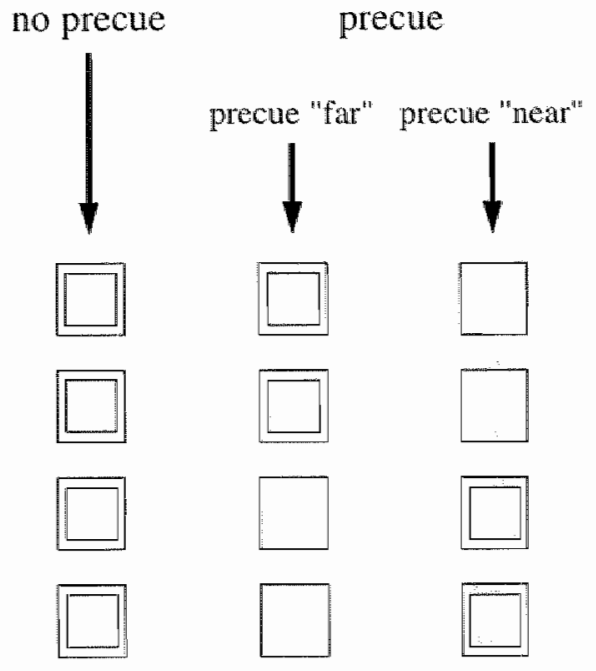

$750 \mathrm{~ms}$ after the WS-onset an imperative stimulus (ISt) (i.e. a "m" sign) was displayed in one of the small squares. The ISt indicated the location of the button pair the subject had to reach to. When the ISt appeared the subject had to release the $\mathrm{SB}$ and move both hands as fast as possible towards the correct button pair. Peripheral buttons were to be pressed 5 times, causing a prolonged period in which maintaining sitting balance was thought to be more difficult, especially in $\mathrm{SCl}$ subjects. Subsequently the participant had to move back to his initial sitting position as fast as possible and press SB again. An example of the task sequence displayed on the monitor is depicted in figure 5.3. The experiment consisted of 128 trials divided over two series of 64 trials. Each of the eight reaching conditions (i.e. four reaching distances (A, B, C and D) and two precue conditions (no-precue and precue)) was presented 16 times in random order. The intertrial interval was at least $3 \mathrm{~s}$. To avoid fatigue small resting periods were introduced between trials. Furthermore ample resting times between series were given. Written instructions regarding the task and the reaching movement were given at the start of the 
Fingure 5 3. Example of display of a task sequence.
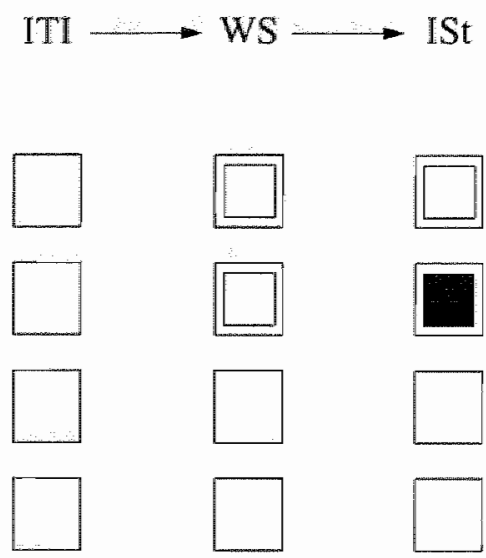

$\mathbb{I T I}=$ intertrial interval; WS $=$ warning signal; ISt $=$ imperative stimulus

experiment. Six to eight training trials were given in advance to familiarise the subject with the task. Trial number, reaching condition, precue condition, reaction time (RT), movement time (MT) and button status were recorded.

Differences in movement velocity have been known to influence RT performance $[30,31]$. In order to obtain an indication of the speed with which sitting balance perturbation occurred during the forward reaching movement, additional recordings of the 'centre of pressure' (CP) were made. Winter [35] states that the $\mathrm{CP}$ can be viewed as the neuromuscular response to the imbalance of the body"s centre of gravity. To record the CP displacements an AMTI force platform (Biovec-1000, AMTI, Watertown, Mass.) was mounted underneath the chair. Analog force platform signals were computer recorded using a DT2824 PGL dataacquisition board (Data Translations, Marlboro, Mass.), a second Compaq deskpro 386sx personal computer and MUCAPS data-acquisition software (IRV, Hoensbroek, The Netherlands). Signal sampling started $250 \mathrm{~ms}$ before the WS-onset and lasted $5 \mathrm{~s}$ per trial. Sample frequency was $500 \mathrm{~Hz}$. From the force platform signals maximum $C P$ velocity (peak Vcp) during forward reaching was calculated per trial. An example of antero-posterior CP displacement and $V_{c p}$ for a non-SCI subject is given in figure 5.4.

\section{Data analysis}

Statistical analyses were performed using SPSS (SPSS Inc., Chicago, IIl.). Both between-group and within-group differences in RT were tested using multivariate analyses of variance for repeated measures $[22,34]$. Since the 
Figure 5.4. An example of antero-posterior CP displacement and $v e p$ for a non-SCl subject.
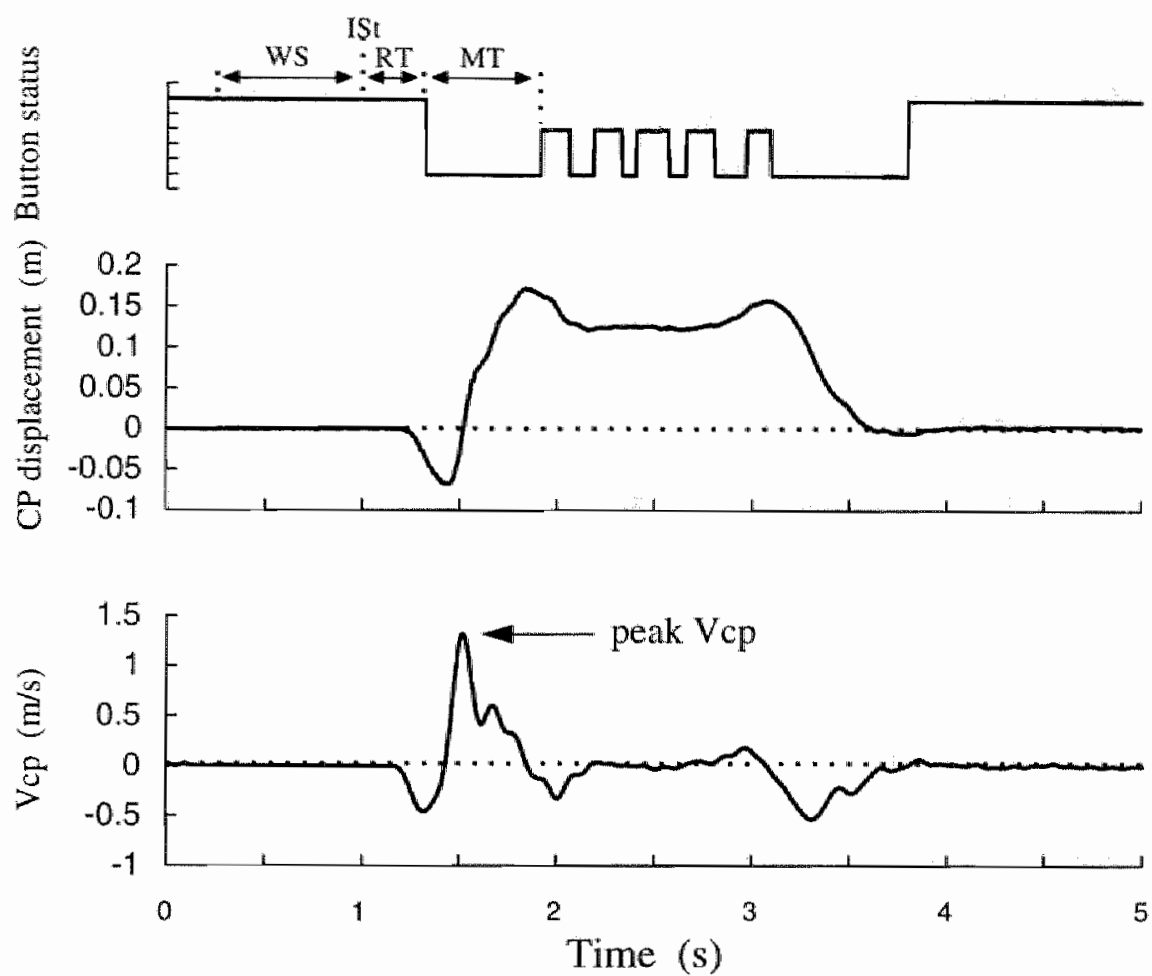

WS = warning signal; $I S t=$ imperative stimulus; $\mathrm{RT}=$ reaction time; $\mathrm{MT}=$ movement time; $\mathrm{CP}=$ centre of pressure; $V_{c p}=$ centre of pressure velocity.

individual maximal reaching distance differed among subjects, this $100 \%$ reaching distance was entered as a co-variable in the analyses (MANCOVA's). Withinsubject factors for the MANCOVA for repeated measures were 'reaching distance' (i.e. $15 \%, 30 \%, 75 \%$ and $90 \%$, i.e. condition $\mathrm{A}, \mathrm{B}, \mathrm{C}$ and $\mathrm{D}$ respectively) and "precue condition" (i.e. precue and no precue), whereas the factor 'group' was a between-subject factor. Logarithmic transformation procedures were similar as applied in experiment 1 . Where statistically applicable, multiple comparison analyses were carried out in order to further differentiate between results among the aforementioned MANCOVA factors using the Bonferroni approach. Similar statistical analyses, without logarithmic transformation, were carried out for the peak $\mathrm{Vcp}$ data. 


\section{Results}

\section{Experiment 1}

Erroneous trials in which subjects released the hand held button too soon or to late were identified. Such trials, in which RT was shorter than $125 \mathrm{~ms}$ or longer than $1200 \mathrm{~ms}$, were discarded (1.89\%). Task error occurrence amounted to $0.67 \%$ in the H-group, $0.56 \%$ in the L-group and $0.67 \%$ in the $\mathrm{N}$-group. No statistical difference in RT was found between the two series of 10 experimental trials. Therefore RT data of both series were pooled. Mean RT (and $99 \%$ confidence interval of the mean $\left(\mathrm{Cl}_{9 g}\right)$ ) recorded during the simple forewarned visual reaction time task was $298 \mathrm{~ms}\left(\mathrm{Cl}_{99}= \pm 55 \mathrm{~ms}\right)$ for the $\mathrm{H}$-group, $300 \mathrm{~ms}\left(\mathrm{Cl}_{99}= \pm 59 \mathrm{~ms}\right)$ for the L-group and $289 \mathrm{~ms}\left(\mathrm{Cl}_{99}= \pm 60 \mathrm{~ms}\right)$ for the $\mathrm{N}$-group. Statistical analysis did not reveal any significant $\mathrm{RT}$ differences between groups in this experiment.

\section{Experiment 2}

Trials in which RT was shorter than $125 \mathrm{~ms}$ or longer than $1200 \mathrm{~ms}$ were discarded $(0.27 \%)$, as were trials in which MT was shorter than $50 \mathrm{~ms}$ or longer than $1500 \mathrm{~ms}(0.27 \%)$. Trials in which wrong button press occurred, were also removed $(0.30 \%)$. Error analysis did not reveal significant differences in error occurrence between groups or conditions. No statistical differences were found between the two series whereupon RT data were pooled.

Mean RT's for the H-, L- and N-group were $428 \mathrm{~ms}, 503 \mathrm{~ms}$ and $443 \mathrm{~ms}$ respectively. The results of an overall MANCOVA are shown in table 5.4. There was a significant main effect for 'group'. Post-hoc analyses revealed that the L-group reacted significantly slower than the $\mathrm{N}$-group and the $\mathrm{H}$-group $(\mathrm{p}<0.02)$. No significant "group" differences were found between the N-group and the H-group. There was a main effect for 'precue" indicating that RT's in the "precue' conditions ( $m e a n=428 \mathrm{~ms}$ ) were shorter than in the 'no-precue' conditions (mean $=487 \mathrm{~ms}$ ). 
Table 5.4. Overall (log transformed) RT MANCOVA statistics factors: "group", 'precue" and "reaching distance') of experiment 2.

\begin{tabular}{|c|c|c|c|c|c|}
\hline Source of variation & $\mathrm{DF}$ & SS & MS & $F$ & $\mathrm{p}$ \\
\hline Within cells & 41 & 1.8895 & 0.0461 & & \\
\hline Regression & 1 & 0.1855 & 0.1855 & 4.03 & 0,051 \\
\hline Constant & 1 & 115.6409 & 115.6409 & $2,509.27$ & $<0.001$ \\
\hline Group & 2 & 0.5015 & 0.2508 & 5.44 & 0.008 \\
\hline Within cells & 42 & 0.0288 & 0.0007 & & \\
\hline Precue & 1 & 0.3019 & 0.3019 & 440.90 & $<0.001$ \\
\hline Group x Precue & 2 & 0.0060 & 0.0030 & 4.39 & 0.019 \\
\hline Within cells & 126 & 0.0890 & 0.0007 & & \\
\hline Reaching distance & 3 & 0.0227 & 0.0076 & 10.70 & $<0.001$ \\
\hline $\begin{array}{l}\text { Group } x \text { Reaching } \\
\text { distance }\end{array}$ & 6 & 0.0042 & 0.0007 & 0.99 & 0.438 \\
\hline Within cells & 126 & 0.0492 & 0.0004 & & \\
\hline $\begin{array}{l}\text { Precue x Reaching } \\
\text { distance }\end{array}$ & 3 & 0.0147 & 0.0049 & 12.58 & $<0.001$ \\
\hline $\begin{array}{l}\text { Group } x \text { Precue } x \\
\text { Reaching distance }\end{array}$ & 6 & 0.0020 & 0.0003 & 0.85 & 0.535 \\
\hline
\end{tabular}

$\mathrm{DF}=$ degrees of freedom; $\mathrm{SS}=$ sum of squares; $\mathrm{MS}=$ mean square; $\mathrm{F}=\mathrm{MANCOVA} F$ value.

Analysis of the 'reaching distance' main effect showed that subjects generally responded faster in conditions where they had to reach towards the button pair closest to the body (15\% reaching condition (A) (see figure 5.1)) as opposed to reaching towards button pairs placed at $30 \%(\mathrm{~B}), 75 \%$ (C) or $90 \%$ (D) of their individual maximal reach ( $<<0.002$ ). Mean RT's were $445 \mathrm{~ms}, 459 \mathrm{~ms}, 466 \mathrm{~ms}$ and $461 \mathrm{~ms}$ respectively. Differences in $\mathrm{RT}$ between all other reaching distance conditions were not statistically significant. A significant "group' $\mathrm{x}$ 'precue' interaction was found between the $\mathrm{L}$ - and H-group ( $\mathrm{p}=0.006$ ), whereby the precue benefit was slightly larger for the H-group (figure 5.5). Such interaction between the $\mathrm{H}$ - and $\mathrm{N}$-group and the $\mathrm{L}$ - and $\mathrm{N}$-group failed to attain significance. 
Figure 5.5. Mean reaction time and 99\% confidence interval of the mean for all groups as a function of preciue condition.

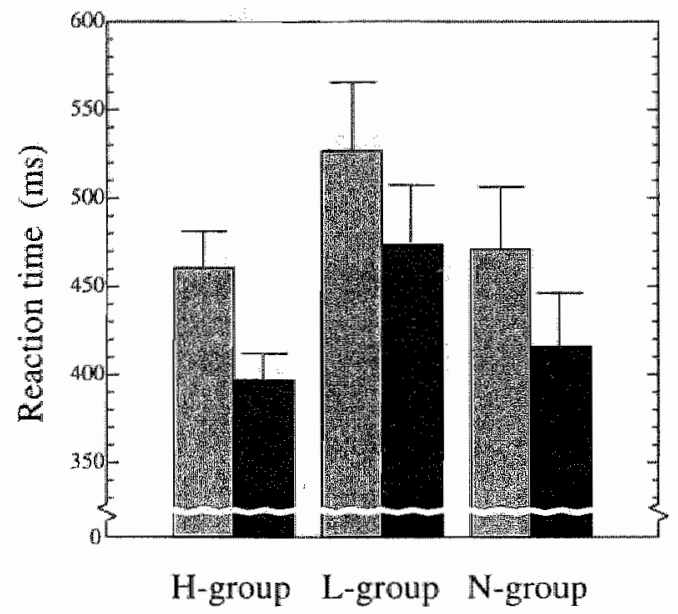

H-group = high thoracic SCI group; L-group = low thoracic SCI group; N-group = non-SCI group; Dark bars = mean RT during precue conditions; Light bars = mean RT during non-precue conditions.

Figure 5.6. Mean reaction time and $99 \%$ confidence interval of the mean as a function of precue condition and reaching distance.

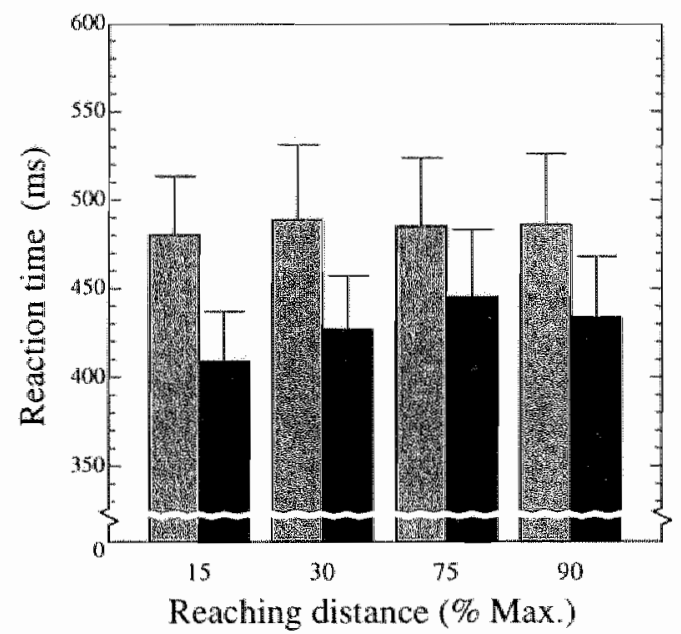

Dark bars = mean RT during precue conditions; Light bars = mean RT during non-precue conditions 
The significant 'precue' $\mathrm{x}$ 'reaching distance' interaction between reaching condition $A$ and $D, A$ and $C$ the $B$ and $C(p<0.001)$ (figure 5.6) indicated that generally the difference between the uncued and the precued conditions decreased as reaching distance increased. In other words, with longer reaching movements the facilitative effect of the precue decreased.

Mean peak Vcp for all groups are presented in figure 5.7.

Figure 5.7. Mean peak $\mathrm{CP}$ velocity as a function of group and reaching distance.

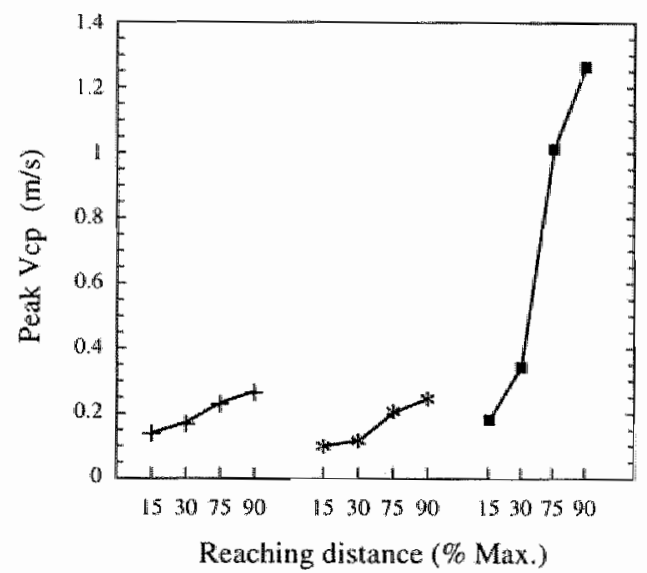

$+=$ high SCI group; ${ }^{*}=$ low $\mathrm{SCI}$ group; $\mathbf{a}=$ non-SCI group; peak $\mathrm{V}_{\mathrm{cp}}=$ maximum velocity of the centre of pressure in anterior direction.

Statistical analysis revealed a main effect for 'group'. Post-hoc analyses showed that peak Vcp in the $\mathrm{N}$-group (mean $=0.70 \mathrm{~m} / \mathrm{s}$ ) was higher than in both the $\mathrm{H}$-group $($ mean $=0.20 \mathrm{~m} / \mathrm{s})$ and L-group $($ mean $=0.17 \mathrm{~m} / \mathrm{s})(p<0.001)$, whereas the $\mathrm{L}-$ and $\mathrm{H}$ group did not differ significantly in this respect.

No significant differences in peak $\mathrm{Vcp}$ between precue and no-precue conditions were found. A significant main effect for 'reaching distance' was found $(\mathrm{p}<0.001)$, whereby reaching further led to higher peak $V_{c p}$ values in all three groups of participants.

At similar relative reaching distances (i.e. \% of maximum reach) the non-SCI subjects generated higher peak Vcp's compared to both SCI group members. This was reflected in a significant 'group' $\mathrm{x}$ 'reaching distance' interaction for peak Vcp $(\mathrm{p}<0.001)$. However, no such differences in peak $\mathrm{Vcp}$ at different reaching distances were found between both SCI groups. 


\section{Discussion}

Aim of this study was to investigate possible differences in motor preparation in postural control of thoracic SCI and non-SCI people during upper extremity task performance. Earlier research has shown that both low and high thoracic SCI subjects try to compensate postural muscle function loss by using alternative muscle synergies, involving non-postural muscles of the trunk and shoulder girdle $[4,27$, 28]. The development of these new muscle synergies implies new strategies in motor control. Changes in motor preparation phenomena could give insight in the quality of these newly acquired motor programs in SCI subjects. The general idea is that movement complexity during balance perturbing task execution is influenced by the extent of reduction in postural functions in SCI patients. An inverse relationship exists between the necessity to compensate sensorimotor function loss at increasing levels of $\mathrm{SCI}$ and the possibility to do so. Whereas low SCI subjects may try to actively compensate postural muscle function loss by using non-postural muscles, high thoracic SCI subjects have to rely even more on non-postural muscles but also considerably on passive support structures like the backrest of the (wheel-) chair. The importance of an adequate modulation of postural control mechanisms in the execution of movements and the influence of movement preparation on this modulation has been stressed by Stelmach et al. [32] and Requin [24].

The first experiment was carried out to investigate whether basic differences in perception and action between both $\mathrm{SCI}$ groups and the non-SCI group existed, since this might lead to misinterpretation of the RT data relating movement preparation and reduced postural control mechanisms in SCI. The task involved only visual detection and simple thumb movement. Subjects were not required to make large balance perturbing movements. In view of the absence of any differences in RT among the $\mathrm{SCI}$ and non-SCI groups in the simple visual reaction time task it is unlikely that basic differences in visual perception (i.e. detection) and motor execution (thumb release response) between groups existed.

As to our first hypothesis, the results from the second experiment indicated that low thoracic $\mathrm{SCI}$ subjects generally reacted slower than non-SCI subjects in their control of posture accompanying upper extremity movements during task performance. The programming of movements in which sitting posture is perturbed seems to be more complex in low SCI subjects. This phenomenon may be attributed to the alterations in both postural muscle use in a strategy to maximally compensate function loss of the ES and the reduced exteroceptive and proprioceptive information mediation from body regions caudal to the lesion site. Neurophysiological evidence for the former was presented by Seelen et al. [28], who found that thoracic SCI subjects used their latissimus dorsi and ascending part of the trapezius muscles to stabilise posture and maintain equilibrium during task performance. Upper extremity impairment could not have caused the 
aforementioned RT difference, since, from a neurological point of view, arm and hand function were equivalent for all groups.

Subjects with a high thoracic SCI, in contrast to low thoracic SCI people, showed quite a different RT pattern. They generally reacted faster than low SCI subjects in both precued and non-precued conditions, despite their higher level of sensorimotor impairment (hypothesis 1). Moreover, no differences in RT were found between the high thoracic SCl and the non-SCI subjects. Differences in movement velocity during task execution cannot account for the RT contrasts between the high and low thoracic SCI participants, since peak velocity of $\mathrm{CP}$ displacement did not differ between both SCI groups. A possible explanation for our finding could be that, since the alternatives to compensate loss of postural muscle function are reduced in high thoracic $\mathrm{SCl}$ people, they use a quantitatively different and more simple strategy when performing bimanual reaching movements, i.e. one in which postural changes accompanying the arm movement are less. This would also explain the fact that high SCI thoracic subjects benefited slightly more from the precued movement information in contrast to the low thoracic SCI group members (hypothesis 2). The interference of poorer balance control on upper extremity task performance seems to have been minimised by adopting a conservative, more passive strategy in which trunk movement was reduced due to the lack of adequate postural muscle force to both generate and counteract extensive trunk movement. Only relatively simple arm extension could be used by high thoracic SCI people to cover reaching distances. Further biomechanical evidence to support this view was found in our earlier work, when strongly reduced displacements of the centre of pressure as well as diminished antero-posterior body acceleration forces were found in high thoracic SCI subjects in contrast to non-SCI people [28]. This was also the case, but to a lesser degree, in low thoracic SCI subjects.

As to our second hypothesis, no evidence was found that would indicate that low thoracic SCl subjects were less able to benefit from precued reaching distance information associated with different grades of balance perturbation compared to non-SCI subjects, which might have indicated suboptimal motor preparation opportunities. This study revealed that movement extent was of no influence in the uncued conditions in contrast to the precue conditions. In the latter conditions results showed that in all groups under investigation, motor programming took longer time when the subsequent reaching distance was larger. In the no-precue conditions both $\mathrm{SCI}$ and non-SCI subjects could have used a strategy of readying all the possible responses in a response buffer from which eventually one movement response was selected. This would account for the lack of RT differences between the four uncued reaching conditions. In the precue conditions a more selective preparation strategy in which individual movement parameters are specified, seems to have been used. In this study the parameter was movement extent. These findings are in agreement with the movement preparation concept of Rosenbaum [26] and Goodman and Kelso [9]. As reaching distance to be covered increases, maintaining 
sitting balance will involve larger muscle synergies in both $\mathrm{SCr}$ and non-SCI subjects. For example, while small postural perturbations during sitting in non-SCI subjects involve moderate ES activity, larger perturbations will involve higher ES activity [28] and, additionally, both increased pelvic and lower extremity muscle activity, in order to prevent loss of sitting balance. Similar increases in activity of (alternative) postural muscles have been recorded in low and high thoracic SCI subjects during sitting balance restoration [27-29]. Miller [19] and also Reeve and Proctor [23] in their research on information processing state that more complex movements are more difficult to prepare and need longer preparation intervals. The fact that in the present study a differential effect for reaching extent on precued $R T$ performance was found, could signify that $750 \mathrm{~ms}$ preparation time was to short to fully prepare the more complex movements, i.e. reaching far. This implies that, if precue time would be extended, the aforementioned differential effects would decrease or even disappear. This, however, needs to be further investigated.

To summarise, our first hypothesis is supported by the fact that the low SCI group generally reacted slower. However, according to this hypothesis high thoracic SCl subjects should have even higher RT's than low thoracic SCI subjects, since the extent of their sensorimotor impairment was larger. This was not found. High thoracic SCI people seem to use a more passive and less complex movement strategy. Movement preparation did occur in all groups when precue information was presented. Movement preparation of the thoracic SCl group members in this study, who had completed their clinical rehabilitation, was at least as good as preparation of the non-SCI group participants. The second hypothesis in this study can be accepted. Methodologically, our findings also confirm the sensitivity of the task to balance control phenomena, i.e. precuing information on different grades of balance perturbation leads to different RT results and precue benefits in both SCI and non-SCI people. From this study the question arises how and when reautomatisation in the control of alternative postural muscle synergies in seated SCI subjects during their active clinical rehabilitation takes place. Results from this study may serve as a basis for further investigation of this issue.

\section{References}

1. Bouisset S, Zattara M: Segmental movennent as a perturbation to balance? Facts and concepts. In: Multiple muscle systems, ed by Winters JM, Woo SLY, Springer-Verlag, New York, pp 498-506, 1990.

2. Brown JE, Frank JS: Influence of event anticipation on postural actions accompanying voluntary movement. Exp Brain Res 67:645-650, 1987.

3. Christina RW, Rose DJ: Premotor and motor reaction time as a function of response complexity. Res Quart Exerc Spont 56:306-315, 1985.

4. Do MC, Bouisset S, Moynot C: Are paraplegics handicapped in the execution of a manual task? Ergonomics 28:1363-1375, 1985. 
5. Dufossé M. Massion J: Posturo-kinetic interactions: Modeling and modes of control. In: Tutorials of motor behavior $I I$, ed by Stelmach GE, Requin J, Elsevier Science Publishers BV, Amsterdam, pp 125-155, 1992.

6. Friedli WG, Hallett $\mathrm{M}_{\mathrm{w}}$ Simon SR: Postural adjustments associated with rapid voluntary ann movements 1. Electromyographic data. Neurol Neurosurg Psychiatry 47:611-622, 1984.

7. Firiedli WG, Cohen L, Hallett $M_{1}$ Stanhope S, Simon SR: Postural adjustments associated with rapid voluntary arm movements. II. Biomechanical analysis. I Neurol Neurosurg Psychiatry 51:232-243, 1988.

8. Geurts $\mathrm{ACH}$, Mulder Th, Rijken RAJ, Nienhuis B: From the analysis of movements to the analysis of skills: Bridging the gap between laboratory and clinic. I Rehab Sci 4:9-12, 1991 .

9. Goodman D. Kelso JAS: Are movements prepared in parts? Not under compatible (naturalized) conditions. J Exp Psychol Gen 109:475-495, 1980.

10. Henry FM, Rogers DE: Increased response latency for complicated movements and a "memory drum" theory of neuromotor reaction. Research Quarterly 31:448-458, 1960.

11. Hoaglin DC, Mosteller F, Tukey JW: Understanding robust and exploratory data analysis. John Wiley \& Sons, New York, 1983.

12. Howell DC: Statistical methods for psychology. PWS-Kent Publishing Co. Boston, 1991 .

13. Klapp ST: Reaction time analysis of central motor control. In: Advances in moror learning and control, ed by Zelaznik HN, Human Kinetics, Champaign, 1996.

14. Lee WA: Anticipatory control of posture and task muscles during rapid arm flexion. $J$ Mot Behav 12:185-196, 1980.

15. Massion J: Feedforward controll of posture and equilibrium during movement performance. In: Electrophysiological Kinesialogy: Proceedings of the ISEK 92 Congress, Florence. June 29-July 2, 1992 ed by Pedottii A, IOS Press, Amsterdam, pp 9-17, 1993.

16. Massion J: Movement, posture and equilibrium: interaction and coordination. Progr Neurobiol 38.35-56, 1992.

17. Massion J: Postural reactions. In: Sensorimotor plasticity. Theorerical, experimental and clinical aspects, ed by Ron S, Schmid R, Jeannerod M, INSERM, Paris, pp 71-99, 1986.

18. Massion J, Dufossé $\mathrm{M}$ : Coordination between posture and movement: why and how? NIPS $3: 88-93,1988$.

19. Miller J: Discrete versus continuous models of human information pracessing: In search of partial output. I Exp Psychol Him Percept Perform 8:273-296, 1982.

20. Mori 5 : Motor control in relation to postural and locomotion control. In: Electrophysiological Kinesiology: Proceedings of the ISEK'92 Congress, Florence, June 29-July 2, 1992, ed by Pedotti A, IOS Press, Amsterdam, pp 1.-8, 1993.

21. Mulder T: A process-oriented model of human motor behavior: Towards a theory-based rehabilitation approach. Phys Ther $71: 156-164,1991$.

22. Nonusis MJ: SPSS/PC Adwanced statistics. SPSS Inc, Chicago, 1992.

23. Reeve TG, Proctor RW: The salient-features coding principle for spatial and symbolic compatibility effects. In: Stimulus-response compatibility, ed by Proctor RW, Reeve TG, North-Holland Publishing Co., Amsterdam, pp 163-180, 1990.

24. Requin J: Towards a psychobiology of preparation for action. In: Tutorials in moror behavior ed by Stelmach GE, Requin J, North-Holland Publishing Co. Amsterdam, pp $373-398,1985$.

25. Rosenbaum DA: Human movement initiation: specification of arm, direction and extent. $J$ Exp Psychol Gen 109:444-474, 1980.

26. Rosenbaum DA: The movement precuing technique: Assumptions, applications and extensions. In: Memory and controt of action, ed by Magill RA, North Holland Publishing Co... Amsterdam, pp 231-274, 1983. 
27. Seeien HAM, Potten YJM, Drukker J, Reulen JPH, Pons C: Development of new muscle synergies in postural control in spinal cord injured subjects. I Electromyogr Kinesiol (in press).

28. Seelen HAM, Potten YJM, Huson A, Spans $F$, Reulen JPH: Impaired balance contral in paraplegic subjects. J Electromyogr Kinesiol 7(2): 149-160, 1997.

29. Seelen HAM, Vuurman EFPM: Compensatory muscle activity for sitting posture during upper extremity task performance in paraplegic persons. Scand J Rehabil Med 23:89-96, 1991.

30. Spijkers WAC, Sanders AF: Spatial accuracy and programming of movement velocity. Bulletisi of the Psychonomic Society 22:531-534, 1984.

31. Spijkers WAC, Walter A: Response processing stages in choice reactions. Acta Psychol $58: 191204,1985$.

32. Stelmach GE, Populin L, Müller F: Postural muscle onset and voluntary movement in the elderly. Neurosci Lett 117:188-193, 1990.

33. Stemberg S, Monsell S, Knoll $\mathrm{R}$, Wright CE: The latency and duration of rapid movement sequences: comparisons of speech and typewriting. In: Information processing in motor control and leaming, ed by Stelmach GE, Academic Press, New York, pp 117-152, 1978

34. Winer BJ: Staristical principles in experimental design. McGraw-Hill Book. Company, New York, 1971.

35. Winter DA: Biomechanics and motor control of human movement. Jolnn Wiley \& Sons Inc, New York, 1990.

36. Zattara M, Bouisset S: Posturo-kinetic organisation during the early phase of voluntary upper limb movement. I Normal subjects. J Neurol Neurosurg Psych 51:956-965, 1988. 


\section{6}

\section{Postural motor programming in paraplegic patients during rehabilitation}

H.A.M. Seelen ${ }^{\text {}, ~ Y . J . M . ~ P o t t e n ~}{ }^{1,2}$, J.J. Adarn ${ }^{3}$, J. Drukker ${ }^{2}$, F. Spaans ${ }^{4}$, A. Huson ${ }^{3}$

Institute for Rehabilitation Research, Hoensbroek, the Netherlands

2 University Maastricht, Department of Anatomy and Embryology, Maastricht, the Netherlands University Maastricht, Department of Movement Sciences, Maastricht, the Netherlands

4 University Hospital Maastricht, Department of Clinical Neurophysiology, Maastricht, the Netherlands

Reprinted from Ergonomics, Seelen HAM, Potten YJM, Adam JJ, Drukker J, Spaans $\mathbb{F}$, Huson $A$ : Postural motor programming in paraplegic patients during rehabilitation, (in press), with kind permission from Taylor \& Francis Ltd, 1 Gunpowder Square, London EC4A 3DE, UK. 


\section{Summary}

One of the basic aims in the rehabilitation of thoracic spinal cord injured (SCl) patients concerns the regaining of sitting posture control. This implies the development of new postural strategies requiring the adjustment of motor programming processes. The aim of this study was to investigate the time course of postural re-organisation during active, clinical rehabilitation of thoracic SCI patients with different $\mathrm{SCI}$ levels. Thus changes in motor programming in sitting balance control were investigated in two groups of complete low or high thoracic $\mathrm{SCI}$ patients. At several stages during the rehabilitation process an experiment was held in which sitting posture was perturbed systematically using submaximal reaching movements over four reaching distances. This bimanual reaching task was presented as a visual precue choice reaction time (RT) task in which reaching distance (i.e. grade of postural perturbation) was precued. Results indicated that in both high and low thoracic SCI patients RTs in movements involving postural perturbation became shorter during the course of the rehabilitation period. However, low thoracic SCI patients were generally slower in the programming of balance perturbing movements than high thoracic SCI patients, a phenomenon which did not change over time. Furthermore, initial differences in RTs as a function of grade of postural perturbation disappeared in both groups in the course of the rehabilitation phase. Precue benefit, equally large for both groups, did not change as a function of rehabilitation time. Our conclusion is that the observed phenomena signify the gradual development of new central postural control processes in both SCl groups during rehabilitation. Low thoracic SCI patients, having more residual sensorimotor functions, seem to adopt more complex strategies in maintaining and restoring sitting balance which take longer to specify and to program. High thoracic SCI patients seem to rely on simpler strategies using more passive postural support.

\section{Introduction}

Control over (sitting) posture and balance is essential for task performance, a point made by many authors $[1,2,6,7,9,10]$. Extensive clinical rehabilitation programs have been developed to compensate for sensorimotor function loss and to reduce disability in patients suffering from spinal cord injury (SCI). New synergies in postural control and movement are acquired by the SCI patient during rehabilitation involving residual sensorimotor functions. This implies the development of new strategies in central programming of motor acts [12]. Motor programming is conceived as an abstract process incorporating the arrangement of movement parameters and details specifying the sequence of motor goals in an abstract set of rules sufficiently ahead of the ensuing movement $[23,24]$. Several 
stages of information processing concerning human motor behaviour have been described, encompassing stimulus identification or perception, stimulus recognition, response selection, response programming and movement initiation [12, 14, 18, 27].

The aim of the present study was to investigate changes in motor programming regarding postural control during clinical rehabilitation of patients suffering from a SCI at different levels. Earlier research by Seelen et al. [20-22] showed that thoracic SCI subjects try to compensate for the loss of postural muscle function of the erector spinae through increased use of different, non-postural muscles. This leads to specific muscle activation patterns while restoring sitting posture during task performance. It was shown that these muscle patterns gradually develop in the course of the rehabilitation program and the subsequent post-clinical period. Results from another experimental study involving SCI subjects who had finished their active rehabilitation at least one year earlier [19], revealed that low thoracic SCI subjects pursue a different, more active, movement strategy during restoration of posture after perturbation in contrast to high thoracic SCI people. This lead to longer reaction times (RTs) in low thoracic SCI subjects. Movement preprogramming, i.e. the process of advance specification of response characteristics or motor parameters of an ensuing (posture perturbing) movement prior to the (imperative) action stimulus, was performed equally fast in both high thoracic SCI subjects and non-SCI subjects. Low thoracic SCI participants, in contrast, proved to benefit less from precued reaching distance information associated with the extent of postural perturbation. In these experiments increased RT was used as an index of (increased) response complexity. The existence of such relation in RT tasks was proposed as early as 1960 by Henry and Rogers [5] and more recently by Christina [3] and Smiley-Oyen and Worringham [26].

From both our previous studies and from the field of clinical patient treatment the general question arose what time course the organisation of the control of alternative postural muscle synergies in SCI subjects during their active clinical rehabilitation would follow. In the present study it was hypothesised that the organisation of alternative posturall control in thoracic SCl patients would gradually lead to (a) an overall reduction in motor programming (i.e. to general shorter RTs) for movements involving substantial postural changes and balance perturbations as a function of sensorimotor rehabilitation (hypothesis 1) and (b) a reduction in reaction time differences between conditions involving different grades of postural perturbation in seated $\mathrm{SCl}$ patients (hypothesis 2).

Another, more fundamental question was whether pre-programming processes in postural control would change in thoracic SCI patients (a) as a function of rehabilitation and (b) as a function of level of sensorimotor impairment. If preprogramming is independent of the state of the peripheral sensorimotor system no effect of rehabilitation or SCI level would be expected in RT performance during a RT task involving precued information on postural perturbations (hypothesis 3 ). 
A longitudinal, quasi-experimental, clinical study was carried out. At several stages in the rehabilitation process motor programming phenomena related to restoration of sitting posture in patients with either a complete high thoracic or a complete low thoracic $\mathrm{SCI}$ were examined. A precue choice reaction time experiment $[15,16,27]$ was carried out, aimed to investigate effects of visual prectied information, regarding graded postural perturbation, on motor (pre-) programming. In order to examine possible basic perceptual differences between both SCI groups, a simple visual RT task, involving simple non-balance perturbing movements, was also presented to the participants in this study.

\section{Methods}

\section{Subjects}

Twelve patients, clinically diagnosed with an acute and complete thoracic SCI, participated in this study which consisted of two experiments. This group was subdivided into two groups consisting of patients with either a low thoracic SCI at level T9-T12 $(n=7)$ or a high thoracic SCI at level T2-T8 $(n=5)$. The levels of SCI are given in table 6.1.

Table 6.1. Levels of complete spinal cord injury diagnosed at admission to the rehabilitation clinic.

\begin{tabular}{cccccccccccc}
\hline \multicolumn{1}{c}{ high SCI (H-group) } & \multicolumn{1}{c}{ low SCI (L-group) } \\
$\mathrm{n}$ & $\mathrm{T} 2$ & $\mathrm{~T} 3$ & $\mathrm{~T} 4$ & $\mathrm{~T} 5$ & $\mathrm{~T} 6$ & $\mathrm{~T} 7$ & $\mathrm{~T} 8$ & $\mathrm{~T} 9$ & $\mathrm{~T} 10$ & $\mathrm{~T} 11$ & $\mathrm{~T} 12$ \\
$\mathrm{n}$ & 0 & 0 & 1 & 1 & 0 & 1 & 2 & 1 & 1 & 2 & 3 \\
\hline
\end{tabular}

None of the subjects had any arm or hand function impairment. Subjects had normal vision. An age over 60 years was an exclusion criterion for participation in the research as was an age under 16 years. Group composition data are presented in table 6.2. The presence of sacro-tuberal pressure ulcers and the risk of orthostatic hypotension was a contra-indication for immediate participation in the experiments. After a period of 1.5 to 2 weeks after admission to the rehabilitation clinic, subjects were tested at two weeks intervals during 12 weeks. Subsequent test intervals amounted to four weeks until discharge from the rehabilitation clinic. For one subject the period between admission and initial participation in the experiments was approximately 30 weeks. In this period he was confined to bed, because of extensive treatment for a complicated larynx trauma, ventilation problems and pressure ulcers. The total number of observation dates varied among subjects, 
Table 6.2. Group composition at admission to the rehabilitation clinic.

\begin{tabular}{|c|c|c|c|}
\hline & & L-group & H-group \\
\hline & $\mathrm{n}$ & 7 & 5 \\
\hline age (year) & mean (s.d.) & $34.0(10)$ & $28.6(9)$ \\
\hline & range & $17-46$ & $22-45$ \\
\hline weight $(\mathrm{kg})$ & mean (s.d.) & $72.3(9)$ & $65.6(9)$ \\
\hline & range & $64.5-91.6$ & $58.2-79.1$ \\
\hline height (m) & mean (s.d.) & $1.84(0.09)$ & $1.80(0.05)$ \\
\hline & range & $1.77-2.00$ & $1.75-1.88$ \\
\hline handedness & left / right & $1 / 6$ & $1 / 4$ \\
\hline sex & $M / F$ & $7 / 0$ & $3 / 2$ \\
\hline stay in rehab. & mean (s.d.) & $28.1(10)$ & $41.2(17)$ \\
\hline clinic (weeks) & range & $15-42$ & $21-59$ \\
\hline
\end{tabular}

L-group = low thoracic SCI group; $\mathrm{H}$-group = high thoracic SCl group; $\mathrm{M}=$ male; $\mathrm{F}=$ fernale.

depending on the length of stay in the clinic. For further in-depth data analysis group data, collected during five specific sessions (A, B, C, D and E) which were approximately equivalent for all subjects, were selected. In the first session (session A), i.e. in the first week of the subject's participation in the longitudinal study, all subjects still wore thoracic braces to stabilise the spine, except one subject from the $\mathrm{H}$-group who had sustained an acute $\mathrm{SCI}$ after neurosurgery. The second session selected (session B) was when braces were finally removed. The third session (session C) was taken four weeks after session B. The fourth session (session D) was halfway between session $C$ and discharge date. The fifth session (session $E$ ) was just before clinical discharge from the rehabilitation centre. One subject, from the H-group (with a SCI level at T8), disengaged from further participation in this study prematurely 19 weeks after clinical intake, resulting in missing values for this subject in session E. An example of experimental observation dates during the whole rehabilitation period is given in figure 6.1. 
Figure 6.1. An example of the experimental observation dates during the rehabilitation phase of one patient.

\section{Hospital Rehabilitation clinic}

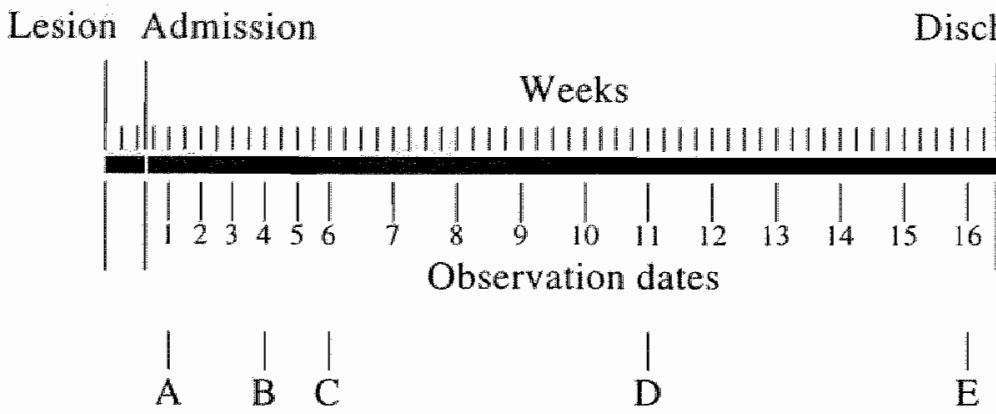

Selected sessions

$A, B, C, D, E=$ Experimental sessions selected for further data analyses.

This study was approved by the local medical ethical committee. Informed consent was given by all participants prior to the start of this study. Participants were selected according to the above mentioned criteria from the total number of SCI patients admitted to the rehabilitation centre over a period of approximately two years.

\section{Experiment 1: task and apparatus}

Subjects sat in a chair which could be adapted to the individual body measures of the participant. The participants held a round push button (diameter: 1.5 $\mathrm{cm}$, positive contact force: $2 \mathrm{~N}$ ), mounted on top of a soft foam cylinder (length: 12 $\mathrm{cm}$, diameter: $4 \mathrm{~cm}$ ) in their dominant hand placed on their lap. The experiment consisted of two series of ten trials, performed on two consecutive days, in which a simple forewarned visual reaction time task was presented on a 14 inch VGA monitor. This monitor was placed on a table in front of the subject. The distance between the monitor and the subject was approximately $1.25 \mathrm{~m}$. In the middle of the screen a $17 \times 17 \mathrm{~mm}$ open square, representing the button, was displayed. Each trial started after the subject lightly pressed and remained holding down the hand-held button with the thumb. After $3000 \mathrm{~ms}$ an open square warning signal (WS) (dimensions: $8 \times 8 \mathrm{~mm}$ ) was presented within the open square already present on screen. WS length varied between 1000 and $4000 \mathrm{~ms}$ in order to avoid stimulus anticipation. The order of trials of different WS length was randomly selected from a fixed pool of alternatives, assuring that all subjects were given similar WS 
conditions. Immediately following the WS a imperative stimulus (ISt) was depicted as a closed square having the same dimensions and location as the WS. An example of task display is presented in figure 6.2 .

Figure 6.2. Task sequence presented on the monitor during experiment 1 .

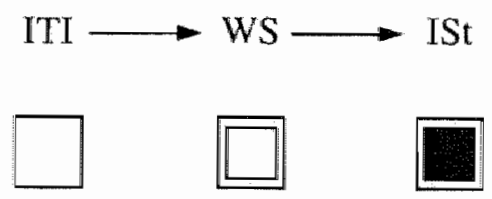

$I T I=$ intertrial interval; WS = warning signal; $I S t=$ imperative stimulus;

The subject was instructed to release the button as fast as possible after the ISt onset. Sitting balance was not perturbed during task performance. Reaction time (RT) and trial number were recorded. Intertrial interval (ITL) was at least $3 \mathrm{s.}$ Between trials the SCI patients were given the opportunity to perform a so-called "lift'-manoeuvre (i.e. a technique for sacro-tuberal pressure sore prevention) if necessary. Before the start of the experiment written instructions and 5 training trials were given. Both the timing of the experiment as well as the calculation of the RT was performed by a PCL 830 timer/counter card (Advantech Co., Taiwan) and a personal computer (Compaq Deskpro 386sx, Compaq Computer Co., Houston, Texas). The total time for performing each of the two series in this experiment was approximately $3.5 \mathrm{~min}$.

\section{Experiment 2: task and apparatus}

As in experiment 1 subjects sat in a chair which was adapted to each individual's anthropometric measures. A table stood in front of the chair. Table height was about $3 \mathrm{~cm}$ above the elbow position of the participant. Arm rests were positioned low, so that arm movement during task performance was not hampered. They were not used by the participants during task execution. On the table one rectangular start button $(\mathrm{SB})(1.5 \times 2.3 \mathrm{~cm})$ was placed in the mediosagittal plane at $25 \mathrm{~cm}$ distance of the subject's trunk. Also eight round target buttons (TB) $(1.5 \mathrm{~cm}$ in diameter) were placed on the table in four pairs of two buttons, thus forming two sagittal rows. Distance between the rows was $15 \mathrm{~cm}$. The bimanual unsupported maximum reaching distance in anterior direction was determined for each subject. TB pairs were then placed at $15 \%, 30 \%, 75 \%$ and $90 \%$ of this maximum reaching distance relative to the position of the participant. For positive button contact a force of only $2 \mathrm{~N}$ was necessary. During the experiment subjects were asked to reach towards the TB pairs with both hands simultaneously to operate one of four TB 
pairs, thus introducing graded systematical postural perturbations. In the initial sitting position, at the start of each reaching trial, the SB was held down lightly by the participant using the index fingers of both hands. Information as to which TB pair to operate was given via a 14 inch VGA monitor, located about $1.25 \mathrm{~m}$ in front of the subject. This information was presented as a visual precued choice reaction time task. A vertical array of four open squares $(17 \times 17 \mathrm{~mm})$ (TB-array), representing the four TB pairs, was located centrally on the screen during the whole experiment. The vertical position of this array was chosen to enhance spatial stimulus-response compatibility. After $3250 \mathrm{~ms}$ relative to the start of each trial a warning signal (WS) was given, consisting of smaller open squares $(8 \times 8 \mathrm{~mm}$ ) (WS-array) within the TB-array already present on the screen. In the precue conditions the WS consisted of only two smaller squares appearing in either the two top or the two bottom squares of the TB-array, pre-informing the subject about the possible location of the ISt associated with the reaching distance to be covered (i.e. reaching "far" or 'near'). In the no-precue conditions the WS consisted of four smaller squares appearing in the TB-array. No pre-information as to reaching distance to be covered could be drawn from this WS. In the no-precue conditions a choice between four response alternatives was necessary. In the precue conditions a choice between two response alternatives had to be made by the participant. The precue alternatives in the WS are depicted in figure 6.3 .

Figure 6.3. Precue signal alternatives as presented on the monitor in experiment 2.

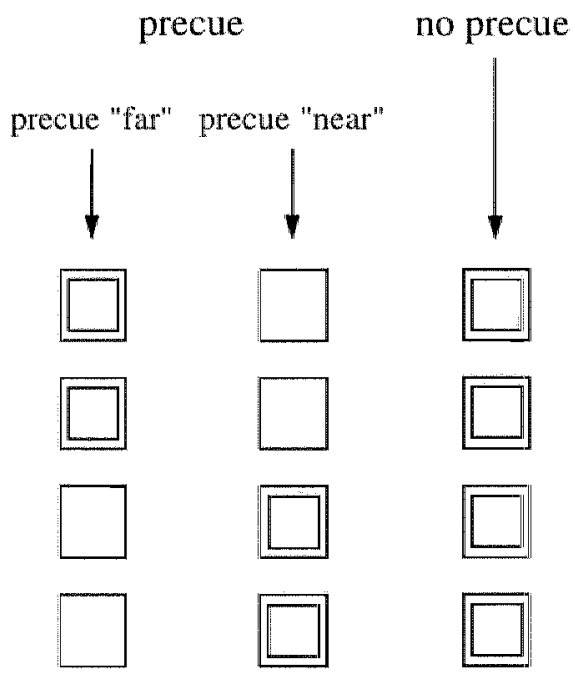


The WS length was 750 ms. An ISt (i.e. a "as was displayed immediately following the WS. This ISt completely filled one of the WS squares. The ISt indicated to which TB pair the participant had to reach. When the ISt appeared the subject had to release the SB and move to the correct TB pair with both hands. TB'S were to be lightly pressed five times, introducing a short semi-static period in which maintaining sitting balance was more difficult for the SCI subjects. Next, the subject had to move back to the initial sitting position as fast as possible and press the SB again with both hands.

The experiment consisted of two series of 48 trials, performed on two consecutive days. All eight experimental conditions, i.e. 2 precue conditions (noprecue and precue) and 4 reaching distance conditions (i.e. $15 \%, 30 \%, 75 \%$ and $90 \%$ of maximal unsupported reach), were presented six times per series. The order of presentation of the conditions was random. Intertrial interval was at least $3 \mathrm{~s}$. To avoid fatigue short resting periods were given between trials. Written instructions and a short training session were given to each subject before the start of the experiment. Trial number, reaching condition, precue condition, R'T, movement time and button status were recorded. RT was defined as the time between ISt onset and release of the SB. Movement time was defined as the time between release of the SB and the initial contact with a TB pair. The total time for performing each series in this experiment was approximately $13 \mathrm{~min}$. This included the short resting periods mentioned above.

\section{Data analysis of experiment 1 and 2}

For both experiment 1 and 2 possible between-group differences in RT data per session (A through E) were statistically analysed using the Mann-Whitney U-test [13]. Possible changes in RT performance across the whole rehabilitation period were analysed in each group using the Page test for ordered alternatives [25].

\section{Results}

\section{Experiment 1}

\section{Error analysis}

Trials in which RT was shorter than $125 \mathrm{~ms}$ or longer than $1200 \mathrm{~ms}$ were discarded in order to exclude erroneous trials resulting from too early or too late button release. Error analysis revealed no significant differences in error occurrence between both SCI groups across the rehabilitation phase. No differences were found either between the two series, whereupon RT data were pooled for series. Overall error percentages for session $\mathrm{A}$ through $\mathrm{E}$ were $2.5 \%, 1.7 \%, 2.1 \%, 0.8 \%$ and $0.8 \%$ respectively. 
RT performance

Mean RT (and 99\% confidence intervals of the mean $\left(\mathrm{Cl}_{99}\right)$ ) for session $\mathrm{A}$ through $\mathrm{E}$ for both groups are presented in table 6.3 .

Table 6.3. Mean reaction time (in $\mathrm{ms}$ ) and $99 \%$ confidence intervals of the mean for the simple reaction time task.

\begin{tabular}{cccccc} 
& \multicolumn{5}{c}{ Sessions } \\
& A & B & C & D & E \\
H-group & $284( \pm 11)$ & $273( \pm 15)$ & $290( \pm 24)$ & $273( \pm 14)$ & $279( \pm 18)$ \\
L-group & $286( \pm 24)$ & $294( \pm 27)$ & $282( \pm 22)$ & $287( \pm 15)$ & $285( \pm 23)$ \\
\hline
\end{tabular}

No significant differences in RT between groups were found in any of the sessions. RT performance did not change significantly in the course of the rehabilitation period.

\section{Experiment 2}

\section{Error analysis}

Trials in which the wrong peripheral button pair was operated were removed from further analysis $(0.3 \%)$. In order to exclude erroneous trials, resulting from too early or too late button press or button release, trials in which RT was shorter than $125 \mathrm{~ms}$ or longer than $1200 \mathrm{~ms}$ were also discarded $(0.3 \%)$, as were trials in which movement time was shorter than $50 \mathrm{~ms}$ or longer than $1500 \mathrm{~ms}(0.3 \%)$. Statistical analysis on these error data did not reveal significant differences between groups, reaching conditions or sessions.

\section{Overall RT performance}

No significant differences in RT performance were found between the two series of trials within each of the sessions in either SCI group. Therefore RT data from the two series within each session in this experiment were pooled. Mean RT values in the precue and no-precue conditions for both $\mathrm{SCl}$ groups during all five consecutive sessions ( $\mathrm{A}$ through $\mathrm{E}$ ) are presented in figure 6.4. 
Higure 6.4. Mean RT values in the precue and no-precue conditions for both SCI groups during all five consecutive sessions.

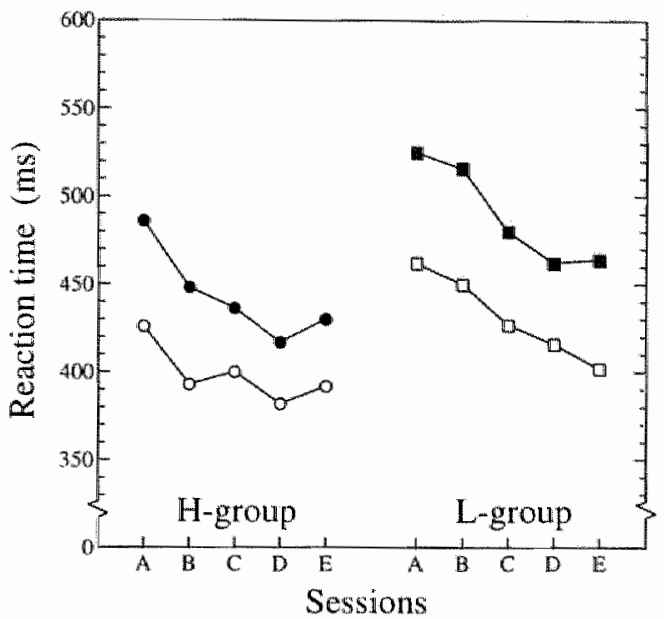

- = no-precue conditions of high thoracic SCI group; $\mathrm{O}=$ precue conditions of high thonacic $\mathrm{SCI}$ group; $\mathbf{a}$ = no-precue conditions of low thoracic SCI group; $\square=$ precue conditions of low tharacic SCI group.

Statistical analysis involving Page tests for ordered alternatives revealed that the decrease in mean RT values in the no-precue conditions across the rehabilitation period was significant for both the L-group and the H-group $(p<0.01)$. Similarly, mean RT values in the precue conditions decreased significantly across the rehabilitation phase in the L-group $(p<0.001)$, whereas such decrease in $R T$ values for the precue conditions approached significance in the H-group $(p<0.06)$.

L-group participants performed significantly slower than $\mathrm{H}$-group members in the no-precue conditions in session $A(p<0.03), B(p<0.01), C(p<0.02)$ and $D$ $(p<0.05)$, whereas in session $\mathrm{E}$ such RT differences approached significance $(p<0.06)$. Similarly, the L-group performed significantly slower than the H-group in the precue condition in session A ( $p<0.03)$, B and D $(p<0.02)$.

Additionally, coefficients of linear regression anallyses of the RT data, as an indication of changes in RT performance across the total rehabilitation phase, were calculated per subject per group, as were differences in RT results between consecutive sessions. Mann-Whitney U-tests of these results revealed no significant difference in RT decrease between groups in either precue or no-precue conditions. 


\section{Precue benefit}

Significant RT differences were found between the precue and no-precue conditions in both groups in all sessions $(p<0.001)$. Significant changes in precue benefit, i.e. mean RT differences between the no-precue and the precue conditions, across time were found neither in the L-group nor in the H-group using the Page test for ordered alternatives. Furthermore, Mann-Whitney U-tests revealed that precue benefit did not differ significantly between groups in any of the sessions.

\section{Balance perturbation influence}

To assess to what extent RT differences between conditions involving various grades of postural perturbation changed in the course of rehabilitation, mean RT in the 'far' and the 'near" reaching conditions, i.e. reaching distances of $75 \%$ and $90 \%$ ('far') versus reaching distances of $15 \%$ and $30 \%$ ('near'), as well as mean RT differences between the 'far' and 'near' conditions $\left(\delta \mathrm{RT}_{\mathrm{fn}}=\mathrm{RT}_{\mathrm{far}}-\mathrm{RT}_{\text {near }}\right)$ were calculated for each group. Results from these computations are given in figure 6.5 and 6.6.

Figure 6.5. Mean $\mathrm{R}^{\mathrm{T}}$. values in the 'far' and 'near' conditions for both $\mathrm{SCl}$ groups during all five sessions. Data are pooled for precuing conditions.

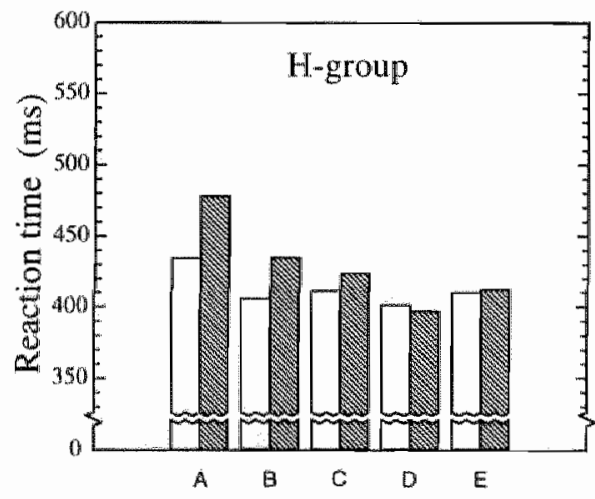

Sessions

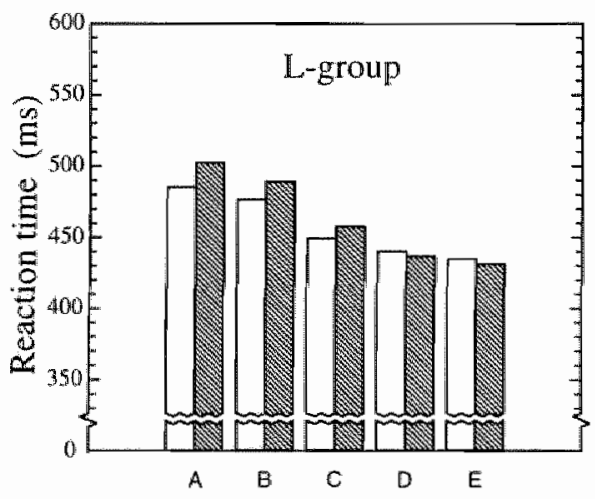

Sessions

open bars $=$ 'near' reaching conditions; hatched bars $=$ 'far' reaching conditions. 
Figure 6.6. Mean RT difference between the "far' and 'near" conditions for both SCI groups during all five sessions.

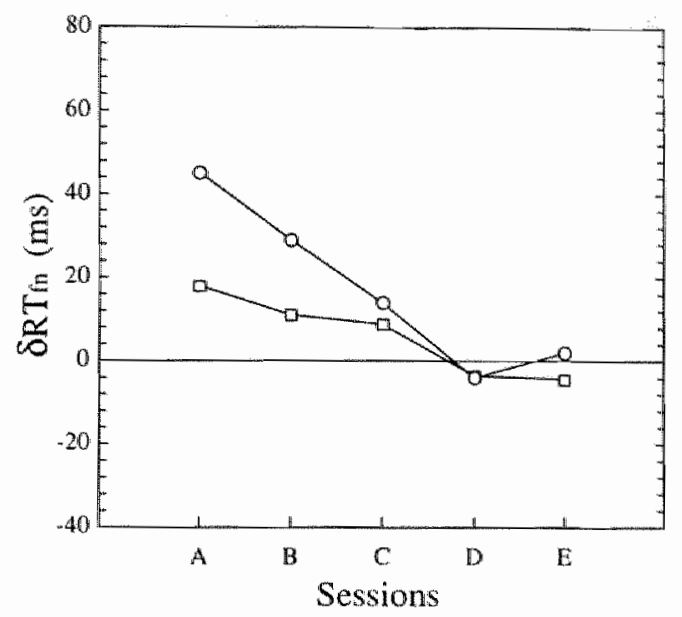

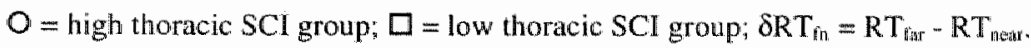

A gradual change in mean $\delta R T_{f n}$ was observed for the $H$-group $(p<0.001)$, i.e. mean RT in the 'far' reaching conditions showed a stronger decrease over time than the mean RT in the 'near' reaching conditions. At the end of the rehabilitation period this $\delta \mathrm{RT}_{\mathrm{fn}}$ had almost decreased to zero in the H-group. In the L-group such decrease across the rehabilitation period in mean $\delta \mathrm{RT}_{\mathrm{fn}}$ was less pronounced $(\mathrm{p}<0.07)$, with $\delta R T_{\text {fn }}$ values already more closely approaching zero at the beginning of the rehabilitation. Between-group differences in $\delta \mathrm{RT}_{\mathrm{fn}}$ were significant for session $A$ and $B(p<0.05)$.

\section{Discussion}

The present study was focused on revealing the time course the reorganisation of postural control takes during the rehabilitation of patients suffering from different levels of complete thoracic SCI. More specifically, motor programming and pre-programming in these SCI patients was investigated. Preprogramming is defined as the ability of advancing the specification of movement parameters during the process of motor programming.

The first experiment was carried out to investigate possible betwen-group differences as well as possible within-group changes during the rehabilitation phase 
in basic visual perception or detection and simple, non-balance perturbing, upper extremity motor action. Any changes in RT performance caused by these processes could seriously obscure the interpretation of possible RT findings concerning postural response (pre-)programming under investigation in the second experiment of this study. Results from this first experiment however, indicate that differences in visual perception and simple, non-balance perturbing motor acts action between high and low thioracic SCI patients did not exist, nor that changes in these processes occurred during the course of the rehabilitation of these patients.

As to the first hypothesis, results from the second experiment show that in both high and low thoracic SCI patients RTs in posture perturbing movernent responses became shorter as rehabilitation progressed, indicating a decrease in response complexity. One explanation for this phenomenon could be that in both high and low thoracic SCI patients new and stable programming rules for control of posture develop. These are adapted to the new situation of the peripheral motor system, thereby reducing central processing time for motor response programming. Sensorimotor function loss in thoracic SCI patients will not only lead to direct impaired postural control and loss of focal movement capacities. It will also initially lead to a disruption in the subtle co-ordinating processes between the two. It may be that during rehabilitation co-ordination of both sitting posture and upper extremity task execution in SCl subjects evolve from separate, competitive processes with respect to central processing and attentional demands to new integrated processes encompassing the residual functions, thereby reducing $\mathrm{RT}$. The underlying assumption to this interpretation is that postural stabilisation is an integral part in the motor actions involving (focal) movements like e.g. arm-hand movement and activities of daily living in general $[4,8]$. Results from research by Seelen et al. [20] revealed that new postural muscle synergies, distinctly different from postural muscle activation patterns in non-sensorimotor impaired subjects, developed in these thoracic SCI patients simultaneously to the changes in motor response programming during rehabilitation. Alternatively, the decrease in RT over time observed in this study could be interpreted simply as a test-retest effect. However, when comparing the RT data from the two series per session throughout this longitudinal study, no significant RT differences were found. This is evidence for the fact that, at least no short term retest effects were present. Similarly, no retest effect was found for the same choice RT task used in another study by Seelen and co-workers [19] involving non-SCI subjects and thoracic SCI subjects who had completed their clinical rehabilitation at least one year before. Furthermore, Sunderland et al. [28], who investigated retest phenomena in choice reaction time tasks, found that such effects were minimal in a healthy control group. In their study the interval between test and retest was one week.

In this study the relation between the extent of graded postural perturbation and movement response programming was investigated throughout the clinical rehabilitation phase of thoracic SCI patients with different levels of sensorimotor 
impairment. The underlying assumption was that conditions in which sitting posture would be perturbed more rigorously, i.e. reaching far, would address more complex postural regulatory mechanisms in terms of muscle synergies and cerebral control mechanisms involved. This in contrast to conditions in which sitting posture would be perturbed moderately, i.e. reaching near. It was hypothesised that if postural control in SCl patients would mature during rehabilitation, a decrease in RT contrasts between these different grades of postural perturbation would occur in this clinical period (hypothesis 2). Our data indeed support this hypothesis. Especially in high thoracic SCI patients the RT differences between various grades of postural perturbation decreased considerably, almost disappearing at the end of the rehabilitation phase. In low thoracic SCI patients this difference in RTs between conditions of dissimilar postural perturbation was already small at the start of the rehabilitation, making the hypothesised decrease of this phenomenon during rehabilitation less pronounced. One cause for these findings could be that in high thoracic SCI patients postural muscle function loss is larger, leading to more dramatic changes in postural control, whereas in low thoracic $\mathrm{SCl}$ patients more residual postural functions are present necessitating less alternative postural muscle co-ordination to be acquired through training.

Patients with a low thoracic SCI proved to be generally slower in programming a posture perturbing movement than high thoracic SCI patients, a contrast between groups which did not change significantly throughout the course of rehabilitation. Since both groups did not differ with respect to upper extremity function, the only explanation for the differences in RT can be the level of complexity in controlling sitting balance and maintaining sitting posture. In high thoracic SCI patients sensorimotor function loss is larger than in low thoracic SCI patients, leaving less possibilities to compensate for function loss in the former group. As a result more conservative strategies as to changes in posture will be used by these patients, involving more simple muscle synergies, necessitating less specification of spatiotemporal movement parameters. This is in contrast to low thoracic SCI patients who are able to control a larger part of their muscle potential and consequently are able to use more complex motor actions to change posture and restore sitting balance during task execution.

As to the third hypothesis concerning possible changes in motor preprogramming in SCI patients during rehabilitation, it was observed that from the start of the rehabilitation period onwards both high and low thoracic SCr patients were able to take advantage of precued reaching extent information associated with anteroposterior postural disturbance. However, no changes in precue benefit were found throughout the rehabilitation period in either group. Apparently this specific response preparation through pre-setting response parameters is less susceptible for learning effects that may have been caused by therapy, nor does this preparation seem to be related to functional recovery or compensatory processes associated with postural control in thoracic SCI patients. The latter observation is further 
substantiated by the fact that no significant differences between groups regarding precue benefit were found throughout the rehabilitation phase, despite differences in sensorimotor impairment between high and low thoracic SCI patients. Our findings. support the idea that the precuing technique addresses more general, central motor control mechanisms that are relatively independent of the state of the peripheral parts of the sensorimotor system.

In conclusion, we argue that the present findings signify the development of central control processes to maintain and restore sitting posture in thoracic $\mathrm{SCI}$ patients, involving alternative muscle synergies [20]. This development seems to lead to a general reduction in motor response programming concerning postural control at the end of rehabilitation in contrast to the earlier stages. It is suggested that this maturation is a gradual process, spanning the whole rehabilitation period, rather than a fast process during a specific rehabilitation substage. Furthermore, our data corroborate the idea that in thoracic SCI patients programming movements in which sitting posture is perturbed more drastically becomes faster during clinical rehabilitation, which in turn is a sign of the development of more efficient patterns of (central) postural control.

\section{References}

1. Berg K, Wood-Dauphinée S, Williams II, Gayton D: Measuring balance in the elderly: preliminary development of an instrument. Phys Can 41:304-3 11, 1989.

2. Chaffin DB and Andersson GBJ: Occupational Biomechanics, 2nd edn. John Wiley \& Sons Inc, New York, pp 335, 1991.

3. Christina $\mathbb{R W}$ : The $1991 \mathrm{CH}$ McCloy research lecture: Unraveling the mystery of the response complexity effect in skilled movements. Res Quart Exenc Spont 60:256-267, 1992.

4. Dufoses M. Massion J: Posturo-kinetic interactons. Modeling and modes of control. In:

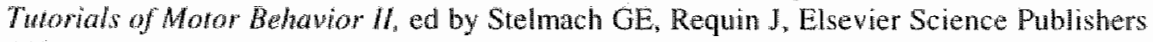
BV, Amsterdam, pp 125-155, 1992.

5. Henry FM, Rogers DE: Increased response latency for complicated movements and a "memory drum" theory of neuromotor reaction. Research Quarterly 31:448m458, 1960.

6. Johanson ME: Electromyographic investigation of trunk control in the sitting position. In: Electrophysiological Kinesiology, ed by Wallinga W, Boom HBK, de Vries J, Elsevier Science Publishers BV, Amsterdam, 463-466, 1988.

7. Johansson R, Magnusson M: Human postural dynamics. Crit Rev Biomed Eng 18:413-437, 1991.

8. Massion J: Movement, posture and equilibrium: interaction and coordination. Progr Neurobiol 38:35-56, 1992 .

9. Massion J. Dufossé M: Coordination between posture and movement: Why and how? NIPS 3:88-93, 1988.

10. McClenaghan BA: Sitting stability of selected subjects with cerebral palsy. Clin Biomech 4:213-216, 1989.

11. Miller J: Discrete versus continuous stage models of human information processing: In search of partiol ontput. $J$ Exp Psychol Hum Percep Perform 8:273-296, 1982. 
12. Mulder T: A process-oriented model of human motol behavior: Towards a theory-based rehabilitation approach. Phys Ther 71:157-164, 1991.

13. Norusis MJ: SPSS/PC Advanced Statistics, SPSS Inc., Chicago, 1992.

14. Proctor $\mathrm{RW}$, Reeve $\mathrm{TG}$, Van Zandt $\mathrm{T}$ : Salient-features coding in response seloction. In: Tutorials in Motor Behavior II, ed by Stelmach GE, Requin J, Elsevier Science Publishers BV, Amsterdam, pp 727-741, 1992.

15. Rosenbaum DA: Human movement initiation: specification of arm, direction and extent $/$ Exp Psychol Gen 109:444-474, 1980.

16. Rosenbaum DA: The movement precuing technique: Assumptions, applications and extensions. In: Memory and Control of Action, ed by Magill RA, North Holland Publishing Co., Amsterdam, pp 231-274, 1983.

17. Rosenbaum DA: Motor programming: a review and scheduling theory. In: Moror Behavior: Programming, Control and Acquistion, ed by Hener H, Kleinbeck U, Sehmidt KM, Springer Verlag, Berlin, pp 1-33, 1985.

18. Schmidt RA: Motor Control and Leaming: A Behavioral Emphasis, Human Kinetics Publishers Inc., Champaign, 1988.

19. Seelen HAM, Potten YJM, Adam JJ: Motor preparation in postural control in seated spinal cord injured people. Submitted for publication in Hum Mov Sci (a).

20. Seelen HAM, Potten YJM, Drukker J, Reulen JPH, Pons C: Development of new muscle synergies in postural control in spinal cord injured subjects. J Electromyogr Kinesiol (in press (b)).

21. Seelen HAM, Potten YJM, Huson A, Spaans F, Reulen JPH: Impaired balance control in paraplegic subjects. J Electromyogr Kinesiol 7(2): 149-160, 1997.

22. Seelen HAM, Vuurman EFPM: Compensatory muscle activity for sitting posture during upper extremity task performance in paraplegic persons. Scand J Rehabil Med 23:89-96, 1991.

23. Semjen A, Gottsdanker R: Plans and programs for short movement sequences. In; Tutorials in Motor Behavior II, ed by Stelmach GE, Requin J, Elsevier Science Publishers BV, Amsterdam, pp 211-228, 1992.

24. Shaffer LH: Motor programming and control. In: Tutorials in Motor Behavior 11 , ed by Stelmach GE, Requin J, Elsevier Science Publishers BV, Amsterdam, pp 181-194, 1992.

25. Siegel S, Castellan NJ: Nonparametric Statistics for the Behavioral Sciences, MoGrawHill Book Company, New York, pp 184-189, 1988.

26. Smiley-Oyen $\mathrm{AL}$, Worringham $\mathrm{CJ}$ : Distribution of programming in a rapid aimed sequential movement. Qwast J Exp Psychol 49A:379-397, 1996.

27. Spijkers WAC, Walter A: Response processing stages in choice reactions. Acta Psychor $58: 191-204,1985$.

28. Sunderland A, Curry S., Das $S$, Enderby PM, Kinsey C, Mortley J, Pelheram J: Monitoring information processing efficiency after stroke or head injury: \& comparison of four computerised tests for use in single case experiments. Neuropsych Rehabil 2:137-149, 1992. 


\section{7}

General discussion 
In this thesis attention has been focused on phenomena associated with reorganisation of postural control in spinal cord injured (SCI) subjects during and after their active rehabilitation period. The main aim has been to increase the understanding how control of posture in thoracic SCI subjects changes, given the sensorimotor impairments in these patients. This has been done against the background of the knowledge alleady gathered in daily clinical practice. Investigations have been conducted using a multidisciplinary approach. Postural muscle performance and its effects on postural stability have been elucidated at the level of biomechanics and electromyography (chapter 3 and 4). Additionally, investigations were carried out at the level of human motor performance to obtain insight in the possible changes in supraspinal motor control strategies assumed to accompany the changes in postural muscle use (chapter 5 and 6 ).

\section{A concept of alternative postural control}

The first step has been to evaluate alternative postural muscle use in thoracic SCI subjects who had completed their active rehabilitation program for some time and to compare their manner of postural control to that of non-SCI subjects. The assumption was that these SCI subjects would have developed stable patterns of alternative postural muscle use, in contrast to $\mathrm{SCI}$ patients who were still receiving rehabilitation therapy, i.e. who were still in an early stage of learning to use their non-impaired muscles in different postural synergies.

An answer was sought to the question how thoracic SCl subjects try to compensate for the loss of erector spinae (ES) activity during sitting. Unlike Do et al. [8], who investigated muscle activity during sitting in subjects with a spinal cord lesion at leve] T4, or Andersson and Örtengren [1], who investigated back muscle activity in two subjects with a SCI at level T12, the present research concerns two groups of thoracic $\mathrm{SCI}$ subjects. It was hypothesised that the differences in sensorimotor impairment (and in residual sensorimotor capacities), associated with the different levels of $\mathrm{SCI}$, would require different patterns of alternative postural muscle use in these groups. Clinical rehabilitation experience provided the basis for the assumption that the latissimus dorsi (LD) and the ascending part of the trapezius (TPA) may act as alternative stabilisers of the erect spine in seated thoracic SCI patients. This seemed to be in contrast to general textbook descriptions on the function of both muscles, whereby the TPA is used in retraction, depression and lateral rotation of the scapula and the activity of the LD causes endorotation, retroflexion and adduction of the humerus and depression of the shoulder [3]. Indeed, evidence was found to support the clinically based assumption that the LD and the TPA are active in partially compensating function loss of the ES in seated thoracic SCI subjects, and especially in people with a high thoracic SCI. A correlation was demonstrated between the extent to which sitting posture was 
perturbed and the magnitude of altemative postural muscle use necessary to restore the initial sitting posture in thoracic SCI subjects. The fact that non-sensorimotor impaired subjects reached further, involving larger scapular and arm movement, may have caused more phasic muscle activity of the LD and TPA. Activity of the LD and TPA was less in non-sensorimotor impaired subjects in conditions in which absolute displacements of the CP were similar to those of SCI subjects. Also the increase of activity of these muscles as a function of relative reaching distance was larger in SCI subjects and especially in high thoracic SCI participants. Regarding their anatomical location the LD and TPA seem to have a mechanically favourable position to be active in keeping the spine erect. They are the only muscles whose origin is in the thoraco-llumbar region and whose fibre direction is cranio-lateral towards the shoulder girdle, like guy ropes relative to the spine. Additionally, because both the LD and the TPA are innervated from levels cranial to the thoracic spinall segments, i.e. by the thoracodorsal nerve (C6-C8) and the spinal accessory nerve (C2-C4) respectively, they are under voluntary control in thoracic SCI subjects. In contrast the position of the rhomboid muscles is too cranial to be active in direct support of the spine against gravity in thoracic SCl subjects. Moreover, the ES at levels cranial to T3 was still active in all thoracic SCI participants, further reducing the necessity for the rhomboid muscles to be active in stabilising the upper part of the spine.

A second question that needed to be answered concerned the stability of the lumbar-pelvic region and the shoulder girdle as prerequisites for the LD and the TPA to become active in control of sitting posture. The drive to actively control the low thoracic and lumbar part of the spine and the position of the pelvis using residual ES muscle function by low thoracic SCI subjects was substantiated by the surface EMG findings in our first series of experiments. In contrast, high thoracic SCI subjects relied on a strategy of passive support in the lumbar-pelvic region, because of the total function loss of the low thoracic and lumbar parts of the ES. This resulted in a larger, clinically obserwable backward tilt of the pelvis and passive thoraco-lumbar support against the backrest of the chair, consequently enlarging the base of support and fixating the pelvis. Pheasant [15], McClenaghan [13] and more recently Myhr [14] have suggested that in seated non-sensorimotor impaired subjects the ischial tuberosities serwe as a fulcrum rellative to which the pelvis rolls when the centre of mass (CM) of the upper part of the body, i.e. of the trunk, arms and head, moves in anteroposterior direction. This rolling movement consists of a rotation and a translation. In conditions where the projection of this $\mathrm{CM}$ lies anterior to the ischial fulcrum, forward flexion of the trunk has to be counteracted by back extensor activity in order to prevent loss of balance. This active stabilisation however, is only possible if the pelvis is stabilised by hip extensor activity preventing forward pelvic tilt during sitting. The aforementioned backward pelvic tilt in seated high thoracic SCI subjects causes the projection of the CM of the upper part of the body to shift towards a more posterior position relative to the ischial 
tuberosities, leading to a biomechanically more stable situation regarding anteroposterior body sway. The latter is further enhanced by the contact between the sacrum and the support surface, resulting from posterior pelvic tilt [14, 17]. In essence the strategy of passive backward tilt of the pelvis and the passive thoracolumbar support provides a rigid basis on top of which residual, actively controlled trunk movement may take place. The postural support function of the LD and TPA in high thoracic SCI people is facilitated through this passive fixation of the body region from which both muscles originate.

If the LD and TPA are to be used as stabilisers of the trunk, scapular movement generated by these muscles should be counteracted. This would imply that both the sternocostal head of the pectoralis major (PM) and the serratus anterior (SA) would be active in such a role during restoration of sitting posture in thoracic SCI subjects. Unfortunately, the role of the pectoralis minor could not be investigated since it is not accessible to surface EMG. On the other hand, both the sternocostal head of the PM and the SA were found to be more active during restoration of sitting posture in thoracic $\mathrm{SCl}$ subjects, and especially in those subjects with a high degree of function loss of the ES, in contrast to non-SCI subjects. As to other muscles that could potentially contribute to stabilisation of the scapulae, the rhomboideus major and minor, the levator scapulae and the trapezius pars descendens could be active to counteract the detraction component caused by the LD and TPA in thoracic SCI subjects. Until now, these muscles were not evaluated in our study because of the limited number of EMG data-acquisition channels. Furthermore, in our task setting trapezius muscle activity would most certainly have caused cross talk in the attempt to record rhomboid muscles activity using surface EMG. Our concept of alternative postural muscle use also postulates increased use of the rotator cuff muscles in stabilising the glenohumeral, also counteracting depression of the humerus caused by the combined action of the LD and sternocostal part of the PM as proposed by Basmajian and De Luca [3]. Also the endorotation of the humerus caused by increased postural activity of the LD and PM should be counteracted by exororatory muscle activity. More in-depth research will have to be performed to elucidate further the complex interaction between the different muscles stabilising the shoulder girdle in postural postural control in thoracic SCI subjects.

In view of the aforementioned changes in the use of muscles to control sitting posture in thoracic SCI subjects, a third question arose concerning how the necessary motor control mechanisms adapt within this frame of alternative postural muscle use, and whether programming such alternatives would be more difficult and would therefore take longer time than the programming of postural muscle responses in non-sensorimotor impaired subjects. In a previous study by Seelen and Vuurman [18], reaction time (RT) performance associated with conditions in which sitting posture was perturbed, was evaluated in a group of thoracic SCI subjects with a complete SCI at level T2-T12 and a group of matched non-SCI subjects. This 
study provided evidence for the assumption that (a) thoracic SCI subjects may be slower than non-SCI subjects in their ability to program movements in which maintaining sitting balance was of key importance and (b) that these subjects are less able to benefit from precued movement information associated with postural disturbance. Results from our transwersal study presented in chapter 5 provided a more differentiated and complex picture regarding the relationship between postural impairment, compensatory muscle function and central programming processes. Low thoracic SCI subjects seem to adopt a more complex postural control strategy when performing a reaching task, than high thoracic SCI subjects, as is reflected by longer RT's in the former group. Apparently the postural control strategy the high SCI subjects used was less complex. Indeed, our EMG and CP results support the idea that high thoracic SCI subjects adopt a postural strategy of passive stabilisation of the lumbar-pelvic region. It should be noted, however, that the maintenance of sitting posture in high thoracic SCI subjects included increased use of alternative postural muscles. The latter did not result in poorer motor progranming performance as might have been expected (chapter 2). With respect to the RT benefit as a result of precuing movement extent thoracic SCI subjects performed at least as good as non-SCI persons. The extent of postural perturbation was found to influence RT performance in both $\mathrm{SCl}$ and non-SCI subjects in conditions in which advance movement information was provided. Larger postural perturbations yielded longer RT's. In contrast to a previous study [18] no significant interaction between group and precue was found in our transversal study (chapter 5) which might have indicated that either high or low thoracic SCI subjects were less able to benefit from precued information regarding postural perturbation. To further investigate the existence of a possible change in this precue benefit in SCI patients during their rehabilitation, a longitudinal clinical study was carried out (chapter 6).

\section{Efficiency of alternative postural muscle use}

Although the LD and TPA were used by thoracic SCI subjects to keep the lumbar and thoracic part of the spine erect in order to maintain an upright posture, the muscle function loss of the ES in these subjects could not be fully compensated, indicating the biomechanical limitation of the postural strategies adopled. The reduced abilities to control posture were revealed prominently in the centre of pressure (CP) displacement parameters recorded simultaneously with lask performance, i.e. during bimanual reaching movements in the medio-sagittal plane. In line with the work of Winter [20] the CP was taken as an indicator of the neuromuscular response to the body's centre of gravity. The range in which the thoracic SCI people shifted their CP was strongly reduced compared to matched non-SCI subjects. Low thoracic SCI subjects, having less functional impairment of the ES, were able to cover larger reaching distances thereby shifting their CP further 
in anteroposterior direction than high thoracic SCI individuals. One reason for this limited ability to fully counteract postural ES function loss by SCI subjects could be that the torque generated by the LD and TPA becomes insufficient during forward flexion of the spine. If , however, this was the only cause then both the high and the low thoracic SCI participants should be able to change their CP to the same extent, since in both groups the LD and the TPA were fully functional. A second reason could be that passive stabilisation of the pelvis and the lumbar spine becomes insufficient, especially in high thoracic SCI subjects, during larger forward flexion of the spine. In effect the base of support for the LD and TPA to act from, becomes unstable. This latter concept would imply that, if the pelvic region would be externally stabilised using for example a hip belt, as used by e.g. Myhr [14] in her research on sitting stability in children with cerebral palsy, the range in which $\mathrm{SCI}$ subjects may change their $\mathrm{CP}$ without loosing sitting balance would increase. This, however, remains to be investigated further.

Similar to the maximal $\mathrm{CP}$ displacement values, the peak velocity of the $\mathrm{CP}$ displacement as well as the maximum anteroposterior acceleration of the centre of mass, caused by the resultant anteroposterior force generated by active muscle contraction during the initial stage of lorward reaching movements, were found to be significantly lower in seated low thoracic $\mathrm{SCl}$ subjects and were even marginal in some of the high thoracic SCI subjects in comparison to non-SCI subjects. An indication as to which muscles may have attributed to the active forward acceleration of the $\mathrm{CM}$ in non-sensorimotor impaired persons is given by the work of Reinders and Risamasu [16] of which EMG recordings, illustrative to the aforementioned problem, are displayed in figure 2.1 of chapter 2 . In the early stage of the forward reaching movement, before anterior pelvic rotation starts, the rectus femoris as well as the tensor fasciae latae, the obliqui abdominis and the rectus abdominis become more active. The abdominal muscles remain active during the whole phase in which the pelvis is tilted anteriorly. It should be noted however, that the contribution of the iliopsoas muscle to forward acceleration of the $\mathrm{CM}$ and to anterior pelvic rotation can not be investigated using surface EMG. In this initial phase of the movement posterior displacement of the $\mathrm{CP}$ as well as a slight posterior shift of the greater trochanters and the posterior superior iliac spines was reported in non-SCI subjects (chapter 3). Thoracic SCI subjects, having no voluntary control over leg or pelvic muscles and, depending on the lesion level, having only reduced control of abdominal muscles, are less able to generate a forceful forward movement during sitting without loosing control over sitting balance. They are also less able to decelerate any rapid displacement of the $\mathrm{CM}$ due to loss of muscle function in the lower limbs, the lumbar-pelvic region and especially of the lower part of the back extensor muscles. 


\section{Regaining of postural control during rehabilitation}

Having laid the basis for the understanding of some of the biomechanical and neurophysiological principles regarding alternative postural muscle use in thoracic $\mathrm{SCI}$ subjects, the next step has been to study the development of muscle patterns during the active rehabilitation period. Of special interest was the time course of the reorganisation of postural muscle use in both high and low thoracic $\mathrm{SCl}$ patients. Insight in this development could serve as a basis for future research concerning the efficacy of rehabilitation therapy interventions focused on reorganisation of motor control in general and of alternative postural control specifically, thus contributing to 'theory-based neurorehabilitation' as advocated by Bach-Y-Rita [2].

Based on the amount of therapy spent on regaining some form of postural control in SCI subjects in the early stages of the clinical rehabilitation program [4] it was assumed that the development of alternative postural muscle use would show a steep increase during the initial stage of rehabilitation period and that this process would gradually level off towards the end. For this reason the frequency of the experimental test sessions in the longitudinal studies (chapter 4 and 6) was higher during the first three months of the rehabilitation period than in the subsequent rehabilitation phase. However, in contrast to this assumption EMG results from the experiments performed. in the longitudinal study (chapter 4) show that the new patterns of muscle use develop more gradually in the total course of the rehabilitation phase. In low thoracic SCI patients some restoration of function of the low thoracic and lumbar ES was found, concomitant to slight increases in the use of the LD and TPA during restoration of sitting posture. Clear augmentation in postural activity in high thoracic SCI patients was observed in the LD, TPA and, to a lesser extent, in the PM in the course of their stay in the rehabilitation clinic. Such a gradual increase in performance was also seen in the posturographic data collected. A positive effect of spinal bracing on the ability to shift the CP was observed in high thoracic SCI patients. In the period shortly after removal of this spinal brace the ability to shift the $\mathrm{CP}$ was reduced in high thoracic $\mathrm{SCl}$ patients, indicating an increased level of difficulty in maintaining sitting posture in these patients. This deterioration in maintaining sitting baslance gradually disappeared during the remaining part of the rehabilitation period, simultaneously to the improvement in use non-postural muscles to restore and maintain sitting posture. Low thoracic SCI patients did not perform poorer regarding their control of posture when their spinal brace was removed. Their performance regarding $C P$ displacement systematically improved throughout the whole rehabilitation period.

Similar to the results from the transversal research, the data from the longitudinal study showed that patients with a low thoracic SCI were slower in programming bimanual reaching movements involving postural adjustments than high thoracic SCI patients. A possible explanation for this phenomenon is that, since 
sensorimotor function loss in high thoracic $\mathrm{SCl}$ patients is larger and consequently less possibilities are available to them to compensate postural muscle function loss, these patients have to resort to less active strategies to maintain posture, which may be simpler to program. This is in contrast to low thoracic SCI patients who are able to control a larger part of their muscles, making possible more complex postural strategies during task execution.

In general RT's decreased during the clinical rehabilitation phase in both high and low thoracic SCI patients concomitantly with their improvement of (alternative) postural muscle function. Similarly, differences in RT"s between conditions of various grades of postural perturbation decreased in the course of the rehabilitation phase. Both these phenomena indicate that postural motor programming performance improved. In contrast to our expectations, as mentioned earlier in this chapter, also improvement in motor programming developed gradually across the whole rehabilitation period rather than during the first few weeks. The absence of any significant improvement in precue benefit associated with control of posture in either SCI group during rehabilitation may indicate that the precuing technique addresses more general, central motor control mechanisms that are relatively independent of the level of sensory or muscle function loss due to the SCI.

\section{Post clinical period}

When comparing the biomechanical results from the transversal study to the results from the longitudinal clinical study it seems that the ability of both high and low thoracic SCI subjects to shift their CP in anteroposterior direction improves to a small extent in a period of at least one year after clinical discharge. Although the absolute value of this improvement in maximal CP displacement (CPmax) was low ( $\delta \mathrm{cpmax}=1.2 \mathrm{~cm}$ for the high thoracic SCI groups and $\delta \mathrm{cpmax}=3.8 \mathrm{~cm}$ for the low thoracic SCl groups) if compared to e.g. the range in which non-sensorimotor impaired subjects were able to shift their CP (mean CPmax $=23.1 \mathrm{~cm}$ ), the proportional increase over the aforementioned period was approximately $32 \%$ and $86 \%$ respectively. In contrast, the improvement in CPmax between the moment when spinal bracing was stopped during rehabilitation and clinical discharge amounted to $19 \%$ in the high thoracic SCI group and $34 \%$ in the low thoracic SCI group on average. It should be noted however, that some differences in group composition existed between the groups in the longitudinal study on the one hand and groups in the transversal study on the other hand. In the longitudinal study 12 SCI patients participated, whereas in the transversal study two (matched) groups of $15 \mathrm{SCl}$ participants participated. However, differences in average weight and height between patients who were about to be discharged from the rehabilitation clinic and SCI participants from the transversal study were both less than $3 \%$. It is unlikely that these small anthropometric variations between the aforementioned SCI groups 
could have caused such large relative CPmax differences. Regarding the EMG values of the SCI groups at the time of discharge and those recordled in SCI subjects at least one year after discharge less clear differences can be observed as opposed to the CP results.

\section{Some methodological issues}

\section{EMG normalisation}

In our evaluation of EMG activity associated with alternative postural muscle use no normalisation was used. In literature some discussion as to the use of such procedures for EMG analyses has been reported $[12,23]$. In a number of pilot studies prior to this thesis possible methods for normalisation of the EMG signal, as suggested in the literature by e.g. Knutson and co-workers [12], were tested, involving both SCI and non-SCI subjects. First the suitability of mean rectified EMG values recorded during maximum voluntary contractions (MVC) for normalisation of the EMG signals in postural muscles was investigated in a pilot study. However, results indicated that (a) MVC was highly non-reproducible in healthy subjects as well as in SCI subjects in the muscles under investigation in the present thesis, variations in MVC values of 150-200\% being common, (b) since in the populations of thoracic SCl patients some muscles are paretic or even paralytic, eliciting MVC's was very difficult in these muscles. Also the suitability of EMG normalisation procedures involving mean rectified EMG values recorded during several submaximal muscle function tests was investigated. However, these tests proved not to reduce variance, neither within one session nor between multiple sessions. Yang and Winter [23] concluded in their research on normalisation procedures for $\mathrm{EMG}$ signals recorded in gait analysis that neither normalisation using 50\% MVC nor using $100 \%$ MVC improved intersubject variability, but rather increased intersubject variability in the EMG signal. Furthermore, it is known that in SCI patients some recovery of muscle function (e.g. caused by resorption of oedema in the spinal canaly is possible in the course of the subacute phase $[7,11,24]$. If a standardisation procedure would hawe been used, such effects would have been completely concealed. A similar reasoning applies for any other possible progress in muscle function during rehabilitation of the patients. This would be especially dramatic since one of the aims of the present research was to investigate the course of reorganisation of postural muscle use in thoracic $\mathrm{SCl}$ patients during their clinical rehabilitation.

The general problem is that there is no absolute standard for normalising the EMG signal. If an absolute normalisation or standardisation procedure would be available, EMG variability could have been reduced. However, even with the actual variability in the EMG data it was already possible to identify specific trends in the data as discussed in chapter 3 and 4. 
Average EMG values and muscle synergies

One of the aims of this thesis was to evaluate how postural activity patterns across multiple muscles changed relative to (a) level of sensorimotor impairment, (b) extent of postural perturbation and (c) rehabilitation time. In the present research (chapter 3 and 4 ) changes in average EMG activity values, calculated over a relative short time period, were used to describe patterns of muscular activity and muscle synergies. Traditionally linear envelope profiles are used to describe patterns of individual muscle activity in time $[5,6,9,19,21-23]$. It is our view that synergies are not only identified by a temporal aspect in muscle activation (i.e. a possible sequential activation pattern or time pattern), but foremost by the fact that they involve multiple muscles working co-operatively in a given function at a given moment during task performance. It is this latter aspect, i.e. the function of restoring posture including extension and stabilisation of the spine after postural perturbation, which was of interest in the present research. More specifically the involvement of multiple muscles "normally" not used in the restoration of posture e.g. LD and TPA in (new) synergies to be developed during rehabilitation was investigated.

\section{General conclusions}

This research has presented evidence supporting the concept of alternative postural muscle use in thoracic SCI subjects. It has been shown that primarily the LD and TPA are used to partially compensate ES function loss. Furthermore, clear evidence was found indicating the augmented use of the PM and SA in stabilising the shoulder girdle as a prerequisite for the postural function of the LD and TPA. Also some restoration of function of the ES caudally to the lesion site was observed. However, considerable limitations in the ability to maintain posture during bimanual task performance remained evident in thoracic SCI subjects. Differences in postural strategies during task performance between (a) seated SCI and non-SCI subjects and (b) seated subjects with various levels of SCI were confirmed by our research. These strategies developed gradually during clinical rehabilitation rather than abruptly or within a short time span. Main changes in alternative postural muscle use appear during the rehabilitation phase, whereas improvement in the range of $C P$ displacement seems to occur both during and after the clinical rehabilitation period.

In rehabilitation there is a growing demand to study and evaluate the effects of specitic rehabilitation interventions and training programs on both the speed and quality with which new patterns of co-ordinated movement develop in sensorimotor impaired patients. The present study has provided a basis for the evaluation of the development of compensatory muscle function in these patients (a) by developing instruments and methods with which compensation of sensorimotor function loss can be assessed, (b) by showing the applicability of such instruments and techniques in rehabilitation practice, both in transversal and in longitudinal clinical studies and 
(c) by developing and experimentally verifying a theory-based concept of alternative (postural) muscle use in patients with impairments of the central nervons system. Theory-based neurorehabilitation requires insight in basic mechanisms that govern (impaired) sensorimotor control. From this insight models may be developed to predict rehabilitation outcome and guide efforts to evaluate and improve therapy.

\section{Future directions}

Apart from answering questions regarding alternative postural muscle use in thoracic SCI, the present research raised a number of new questions, necessitating further research.

One research domain which should be explored concerns the (mechanical) efficiency with which the LD, TPA and other muscles contribute to the control of posture in thoracic SCI patients. Little is known about the magnitudes of force and torque that can be generated by the e.g. the TPA and the LD in stabilising the trunk in these patients in both static and dynamic conditions. What is needed for this kind of investigation is a biomechanical (computer) model through which mechanical efficiency of alternative postural muscle use may be explained or predicted.

A second line of research should be focused on the influence of specific (wheel-)chair configurations on the support of impaired sitting posture and alternative postural control mechanisms both in static conditions, e.g. during quiet sitting and in dynamic conditions during (manual) task performance. This research should include investigations into the passive mechanical effect of the lower extremities in seated SCI subjects. The influence of passive, external pelvic stabilisation on the ability to control sitting posiure and to adequately perform activities of daily living in SCI subjects is another topic that remains to be investigated further.

In the present thesis EMG based evidence was presented as to the (partial) loss of ES function and the assignment of postural functions to muscles which in non-sensorimotor impaired persons are primarily involved in shoulder and arm movement. A third topic for future research concerns the effects of this alternative postural muscle use on shoulder and arm function, including the increased use of muscles involved in scapular elevation and of the rotator cuff muscles predicted in our concept to be active in stabilising the shoulder girdle. Whether the changes in muscle function in alternative postural muscle use also lead to physiological changes for example in muscle fibre composition or to pathological changes associated with excessive muscle load is another topic for further research.

Until now a main interest in our research concerned questions regarding restoration of perturbed posture. Therefore attention was mainly focused on a relatively short epoch in our experimental task sequence which was associated with restoration of sitting posture. Another field of interest in the investigation of 
alternative postural muscle activity in sitting SCI subjects concerns anticipatory postural adjustments (APA) and onset of muscle activity following external perturbations, in line with the work of Forssberg and Hirschfeld [10] who investigated $\mathrm{APA}$ in sitting non-SCI persons.

Another challenging fie]d of research, especially for rehabilitation, concerns the specific effects physical training programs may have on the quality and the speed of the development of alternative (postural) muscle co-ordination in patient suffering from central nervous deficits. The concept of functional compensation rather than restoration of function, and the consequences as to alternative movement co-ordination, as presented in this thesis, can also be applied to a wider range of movement control problems involving more phasic muscles, e.g. in arm function impairments like plexus brachialis lesions or tetraparesis in low cervical SCI patients.

\section{References}

1. Andersson BJG, Örtengren R: Lumbar disc pressure and myoelectric back muscle activiry during sitting: III. Studies on a wheelchair. Scand J Rehab Med 6:122-127, 1974.

2. Bach-Y-Rita P: Theory based neurorehabilitation. Arch Phys Med Rehabil 70(2):162, 1989

3. Basmajian JV, De Luca CJ: Muscles alive: Their function revealed by electromyography. Williams and Wilkins, Baltimore, 1985.

4. Beckers DML, Buck MJI, Pons C: (The rehabilitation of spinal cord injured patients). De revalidatie van dwarslaesiepatiènten. In Dutch. Uitgeversmatschappij de Tijdstroom, Lochem, 1992.

5. Chen JI, Shiavi $\mathrm{R}$ : Temporal feature extraction and clustering analysis of electromyographic linear envelopes in gait studies. IEEE Trans Biomed Eng 37:295-302, 1990.

6. Chen JJ, Shiavi RG, Zhang $L$ : A quantitative and qualitative description of electromyographic linear envelopes for synergy analysis. IEEE Trans Biomed Eng 39:9-18, 1992.

7. Dimitrijevic MR, Hsu CY, McKay WB: Neurophysiological Assessment of spinal cond and headi injury. J Newrotrauma 9, suppl 1:293-300, 1992.

8. Do MC, Bouisset $\mathrm{S}$, Moynot $\mathrm{C}$ : Are partiplegics handicapped in the execution of a manual task? Ergonomics 28:1363-1375, 1985.

9. Dubo HIC, Peat M, Winter DA, Quanbury AO, Hobson DA, Steinke T, Reimer G: Electromyographic temporal analysis of gait: normat htman locomotion. Arch Phys Med Rehabil 57:415-420, 1976.

10. Forssberg $\mathrm{H}$, Hirschfeld $\mathrm{H}$ : Postural adjustments in sitting humans following external perturbations: muscle activity and kinematics. Exp Brain Res 97:515 527, 1994.

11. Kakulas A: The applied neurobiology of human spinal cord injury: a review. Paraplegia $26: 371-379,1988$.

12. Knutson LM, Soderberg GL, Ballantyne BT, Clarke WR: A study of various normalization procedures for within day electromyographic data. J Electromyogr Kinesiol 4:47-59, 1994.

13. McClenaghan BA: Sitting stabillty of selected subjects with cerebral palsy. Clin Bionech 4:213-216, 1989.

14. Myhr U: On factors of importance for sitting in children with cerebral palsy. Thesis. Luleå, I-Tryck/Grafiska Huset, 1994. 
15. Pheasant S: Bodyspace, anthropometry ergonomics and design. Taylor \& Fancis, London, 1986.

16. Reinders $\mathbb{N}$, Risamasu A: (Postaral muscle activity and petwic position duming siring.) Posturale spieractiviteit en bekkerpositie in zit. In Dutch. MSc thesis. University Maastricht. Institute for Rehabilitation Research, Maastricht/Hoensbroek, 1995

17. Schoberth H: Orthopädie des Sitzens. Springer-Verlag, Berlin, 1989.

18. Seelen HAM, Vurman EFPM: Compensatory muscle activity for sitting posture during upper extremity task performance in paraplegic patients. Scand J' Rehab Med 23:89-96, 1991.

19. Winter DA: Pahologic giat diagnosis with computer-averaged electromyographic profiles. Arch Phys Med Rehabil 65:393-398, 1984.

20. Winter DA: Biomechanics and motor control of human movement. John Wiley \& Sons, Inc., New York, 1990.

21. Winter DA: Linear envelope EMG as a biomechanical variable in the assessment of human movement. In: Electromyographical kinesiology, ed by Andersson PA, Hobson DJ, Danoff JV. Elsevier Science Publishers BV, Amsterdam, 1991.

22. Winter DA, Yack $H J$ : EMG profiles during normal human walking: Stride-to-stride and inter-subject variability. Electroencephalogr Clin Neurophysiol 67:402-411, 1987.

23. Yang JF, Winter DA: Electromyographic amplitude normalization methods: improving their sensitivity as diagnostic tools in gait analysis. Arch Phys Med Rehabil 65:517.521, 1984.

24. Young W: Neurophysiology of spinal cord injury. In: Spinal trauma, ed by Errico TJ, Bawer RD, Waugh T, JB Lippincott Company, Philadelphia, pp 377-414, 1991. 
Summary 
This thesis deals with the reorganisation of postural control in thoracic spinal cord injured (SCI) subjects both during and after their rehabilitation. The main aims of our research have been (a) to investigate and describe the development of new postural muscle synergies in these $\mathrm{SCl}$ subjects, given their sensorimotor function loss, (b) to objectively quantify their ability to maintain sitting posture during manual task performance and (c) to investigate changes in central motor programming associated with the control of sitting posture. A biomechanical and neurophysiological concept of alternative postural muscle use in thoracic SCI subjects has been put forward.

The research has been carried out in three phases. In an instrumentation phase several instruments were developed and integrated. These instruments encompassed surface electromyography, force plate recordings, three dimensional movement analysis and recording of reaction time performance. A multi-adaptable chair was developed as was a set of standardised movement tasks with which sitting posture could be perturbed systematically. In the second research phase a transversal study into postural control in high and low thoracic SCI subjects, who had completed their rehabilitation program at least a year ago, and matched non-SCI subjects was carried out. The third research phase consisted of a longitudinal clinical study. The development of alternative postural muscle use, balance control during manual task performance and central motor programming in both patients with a high and a low thoracic SCl was evaluated at several point in time during their active rehabilitation period.

In chapter 1 a short description of SCI pathology is given, followed by estimates of incidence and prevalence figures concerning SCI. A general overview of the rehabilitation therapy these patients receive is also provided. This chapter finishes with an outline of the contents of the subsequent chapters.

Chapter 2 presents a literature review concerning research of control of posture and movement providing the context in which the present research is situated. The contribution of feedback and feedforward in postural control is explained briefly. Since most of the research into postural control is focused on stance, a number of studies in this domain are reviewed concerning key issues such as the existence of postural muscle synergies, central programming, anticipatory postural adjustments, the consequences of impaired feedback and the redundancy of feedback. Next an overview of research concerning ergonomics and seating, mainly focused on the influence of external support on the body, is presented. This is followed by a section in which research into impaired control of sitting posture is addressed. In chapter 2 a concept of alternative postural control in thoracic SCI subjects is presented. Several biomechanical and neuromuscular aspects as well as some motor control considerations regarding the aforementioned concept are put forward. The final part of chapter 2 addresses the main research aim and the research questions of this thesis, the overall research design and a description of the instruments used. 
In chapter 3 muscle activity patterns during restoration of perturbed sitting posture in high and low thoracic SCI subjects who had completed their active rehabilitation program are compared to those of non-SCI subjects. The assumption was that the $\mathrm{SCI}$ subjects would use non-postural muscles like the latissimus dorsi (LD) and the ascending part of the trapezius (TPA) in an effort to compensate the loss of function of the erector spinae (ES). Also increased activity of the sternocostal head of the pectoralis major (PM) and the serratus anterior (SA) to stabilise the shoulder and to counteract scapular depression was postulated. Graded postural perturbation was invoked using bimanual forward reaching movements towards targets at $15,30,75$ and $90 \%$ of each individual's maximum reach. Muscle activity of the ES at level L3, T9 and T3, the LD, the TPA, the PM, the SA and the oblique abdominal muscles (OA) was measured using surface electromyography (EMG). Changes in the position of the centre of pressure (CP), as an indication of postural perturbation, was also recorded. Pelvic movement was further investigated in non-SCI subjects. EMG data confirm that the LD and TPA are used to maintain and restore sitting posture in thoracic SCI subjects in contrast to non-SCl subjects. Higher PM, SA and ES-T3 activity during restoration of sitting posture was also found in high thoracic SCI subjects. Results indicate that the range in which subjects can actively vary the position of the $\mathrm{CP}$ diminishes as a function of $\mathrm{SCl}$ level, as does the forward acceleration of the body mass. Apparently, the alternative postural muscle use in $\mathrm{SCl}$ subjects cannot fully compensate the loss of postural ES function.

The study in chapter 4 deals with the course the development of alternative postural muscle use in thoracic SCI patients takes during their clinical rehabilitation program. In a longitudinal study five patients who were clinically diagnosed having a complete high thoracic SCI and seven patients with a complete low thoracic SCI were monitored on their ability to maintain and restore sitting posture. This was done at several stages during their stay in the rehabilitation clinic. The methods used in this study were identical to the ones used in the transversal study reported in chapter 3. The amount of restoration of postural function of the ES and compensation of ES function loss through the use of non-postural muscles, i.e. the LD and TPA, was investigated. Furthermore, the improvement of postural control, indicated by the ability to shift the $\mathrm{CP}$, during the rehabilitation phase was examined. The results show that the range in which the $\mathrm{CP}$ can be shifted gradually increases in low thoracic SCI patients. In high thoracic SCI patients the CP-range decreased when spinal bracing was stopped, but increased again subsequently. During the rehabilitation phase some restoration of function of the lumbar and low thoracic ES was observed in low thoracic SCI patients. High SCI patients started to use their high thoracic ES more in their efforts to maintain sitting posture approximately one month after spinal bracing was stopped. A clear increase in postural use of the LD and TPA during clinical rehabilitation was found in high thoracic $\mathrm{SCl}$ patients. Such effects were less prominent in low thoracic SCI patients. 
Although a relation between the SA activity and the necessity to restore sitting posture existed in both thigh and low thoracic SCI patients, no significant changes occurred during the rehabilitation phase. High thoracic SCI gradually started to use their PM more during restoration of posture. Towards the end of the rehabilitation period an inverse relation between extent of postural perturbation and the level of PM activity was detected.

In chapter 5 motor programming in postural control in SCI and non-SCI subjects is reported. A task, in which sitting posture was systematically perturbed through forward reaching movements covering four different reaching distances, was presented using a visual precue choice reaction time paradigm. Reaction time (RT) was used as an index for response complexity. Three groups of either high thoracic SCI, low thoracic SCI or non-SCI subjects participated in the experiment. The SCI subjects had completed their active rehabilitation at least one year earlier. One assumption was that, in view of the alternative postural muscle use in thoracic $\mathrm{SCI}$ subjects, these subjects would need longer time to program postural perturbing reaching movements, in contrast to non-SCI subjects. A second assumption was that subjects would use precued information regarding the extent of the ensuing postural perturbation in preparation of this perturbation. Results indicate that low thoracic SCI subjects are slower in programming balance perturbing reaching movements than non-SCI and high SCI subjects. The precue benefit in the SCI groups was at least as high as in the non-SCI group. Evidence for the occurrence of different movement preparation strategies regarding cued and uncued conditions was found. RT results support the hypothesis that low thoracic SCI subjects use more complex movement strategies in their control of sitting posture, whereas low thoracic SCI subjects rely on simpler strategies. These RT results corroborate EMG and CP findings indicating that high SCI subjects have to rely on more passive support in e.g. the lumbar and low thoracic region. Precue benefit was similar in all groups. Apparently precuing involves only central control processes which are relatively independent of the state of the peripheral sensorimotor system.

Chapter 6 deals with the development of postural motor programming in thoracic SCI patients during their clinical rehabilitation. Generally, the time to program bimanual reaching movements leading to perturbation of sitting posture became shorter in the course of the rehabilitation period in both high and low thoracic SCI patients. This improvement in RT performance proved to be a gradual process rather than an abrupt one. Also differences in RT's as a function of postural perturbation, found in the initial stages of the rehabilitation process, disappeared in high and low SCI patients in the course of their clinical stay. RT differences between SCI groups in the longitudinal clinical study were similar to the RT differences found between the SCI groups in the transversal study. High thoracic SCI patients generally reacted faster than low thoracic SCI patients, a phenomenon which did not change in the course of the rehabilitation. Precuing led to shorter 
RT's in both SCI patient groups. This precue benefit did not change over time in the SCI patients.

In chapter 7 the experimental studies that have been carried out are reviewed. The proposed concept of alternative postural control is discussed, as is the efficiency of alternative postural muscle use. The regaining of postural control in thoracic SCI patients during and after rehabilitation is addressed. Two methodological issues concerning (a) EMG normalisation and (b) the description of muscle synergies using averaged EMG values are discussed. Finally, general conclusions are drawn and several recommendations for future research are made. 
Samenvatting 


\section{Doel en vraagstelling}

Bij een dwarslaesie is het normale samenspel van houdingsspieren, gestuurd door propriocepsis en exterocepsis, verstoord. Gedurende de revalidatie moeten nieuwe houdings- en bewegingspatronen aangeleerd worden. Nieuwe spiersynergieèn en clus ook nieuwe centrale sturingsprocessen zullen ontwikkeld moeten worden waarbij slechts gebruik gemaakt kan worden yan de nog intacte senso-motoriek. Dit is veelal een langdurig proces. Hierbij is geen sprake van herstel van functie maar van compensatie van functieverlies en reductie van beperkingen in termen van activiteiten van het dagelijks leven (ADL). Ofschoon een grote mate van klinische expertise t.a.v. de (eind-)resultaten van bewegingstherapie is ontwikkeld, zijn de mechanismen waarlangs bewegingstherapie reorganisatie van houdingscontrole kan beïnvloeden en verbeteren nog verregaand onbekend. Houdingscontrole is in dit onderzoek gedefinieerd als het vermogen van een individu om met behulp van (nog) aanwezige senso-motoriek zijn balans te handhaven in rust en tijdens taakuitvoering. Balans is hier gedefinieerd als de dynamisch wisselende toestand waarbij de projectie van het lichaamszwaartepunt binnen het steunvlak valt, zonder dat dit ten koste gaat van de uitvoering van ADL. In hoofdstuk 1 is in het kort het algemene (klinische) beeld van een dwarslaesie beschreven.

Het hoofddoel van het onderhavige onderzoek is geweest inzicht te krijgen in de manier waarop en de mate waarin mensen met een complete thoracale dwarslaesie in staat zijn hun zithouding te handhaven tijdens taakuitvoering. De posturale coördinatie- en zitbalansproblemen bij dwarslaesiepatiënten en de consequenties hiervan zijn geëvalueerd gedurende en na hun revalidatieproces. Een biomechanisch en neurofysiologisch concept van alternatief posturaal spiergebruik bij mensen met een thoracale dwarslaesie is opgesteld (Hoofdstuk 2) en geverifieerd. Om de huidige studie te kunnen plaatsen binnen het grotere domein van houdings- en bewegingsonderzoek is een overzicht wan de literatuur met betrekking tot houdingscontrole gegeven in hoofdstuk 2 .

De vragistellingen in dit onderzoek \uidden als volgt:

1. Hoe en in welke mate kunnen mensen met een complete thoracale dwarslaesie de functie-uitval van de erector spinae actief compenseren in zit? (Hoofdstuk 3)

2. Welke veranderingen treden op het niveau van centrale bewegingssturing op bij mensen met een complete thoracale dwarslaesie, gegeven het feit dat bij alternatjeve posturale controle spieren betrokken zijn die bij mensen zonder een dwarslaesie geen houdingsfunctie hebben? (Hoofdstuk 5)

3. Hoe en in welke mate ontwikkelt zich een patroon van alternatief posturaal spiergebruik gedurende het revalidatie-proces bij patiënten met een complete thoracale dwarslaesie? (Hoofdstuk 4) 
4. Hoe passen de noodzakelijke centrale bewegingssturingsprocessen zich aan in patiënten met een complete thoracale dwarslaesie gedurende het revalidatie-proces? (Hoofdstuk 6)

\section{Gehanteerd werkplan en onderzoeksdesign}

Het onderzoek is uitgevoerd in 3 fasen. In fase 1 zijn enkele meetinstrumenten ontwikkeld waarmee de kwaliteit van houdingscontrole in zit geobjectiveerd kan worden. Tevens is een veelzijdig instelbare stoel ontwikkeld ten behoeve van dit project (Hoofdstuk 2).

In de tweede, transversale onderzoeksfase (Hoofdstuk 3 en 5) namen 15 oudrevalidanten met een complete lage thoracale dwarslaesie (spinaal niveau T9- T12) (L-groep), 15 oud-revalidanten met een complete hoge thoracale dwarslaesie (spinaal niveau T2-T8) (H-groep) en 15 personen zonder sensomotorische aandoeningen $(\mathrm{N}$ groep) deel aan het onderzoek. De groepen waren 'gematched' voor leeftijd, geslacht, gewicht, lichaamslengte, hand-dominantie en opleidingsniveau. De verwachting was dat de deelnemers met een dwarslaesie, die reeds meer dan een jaar uit het revalidatieproces ontslagen waren, een min of meer stabiel en ontwikkeld patroon van alternatief posturaal spiergebruik zich eigen gemaakt hadden. Dit in tegenstelling tot patiënten die nog therapie kregen in het revalidatiecentrum. De $\mathrm{N}$-groep fungeerde in deze transversale onderzoeksfase als referentie-groep voor de H- en L-groep.

De zitbalans is verstoord door de deelnemers een bimanuele reiktaak in voorwaartse richting te laten uitvoeren. De reikbeweging werd vanuit de bovengenoemde meetstoel uitgevoerd naar een aantal knoppenparen die op een tafel voor hen geplaatst waren. De positie van de knoppen kwam overeen met een bepaald percentage van de individuele maximale reikafstand in anterieure richting. Zodoende konden systematisch graduele houdingsweranderingen uitgelokt worden, waarbij in verschillende mate een beroep gedaan moest worden op spieractiviteit ter handhaving van zitbalans. Visuele informatie t.a.v. het knoppenpaar waarnaar gereikt diende te

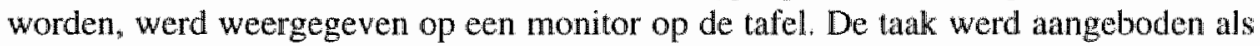
een visuele 'precue' keuze reactietijdtaak. Na een waarschuwingssignaal, dat in $50 \%$ van de gevallen voor-informatie bevatte over de reikafstand, verscheen een actiesignaal dat aangaf naar welk knoppenpaar de deelnemer moest reiken. De reactietijd werd geregistreerd. De eerste veronderstelling was dat mensen met een thoracale dwarslaesile meer moeite zouden hebben om een houdingsverstorende beweging te programmeren dan mensen zonder een dwarslaesie, gezien het feit dat ze daarbij cen beroep zouden moeten doen op spieren die normaal niet voor het handhaven of herstellen van zitbalans gebruikt worden. De tweede veronderstelling was dat personen zouden proberen optimaal gebruik te maken wan de voorinformatie teneinde zich te prepareren op de daarop volgende balansverstorende beweging. 
Als indicator van de mate van balansverandering werd de verplaatsing van het "centre of pressure ${ }^{*}$ (CP) geregistreerd wia het krachtenplatform onder de stoel. De veronderstelling hierbij was dat het bereik waarin het $\mathrm{CP}$ gevarieerd kan worden afgenomen zou zijn bij mensen met een verminderd vermogen tot het handhaven van zitbalans. Tijdens taakuitwoering werd tevens met behulp van oppervlakte elektromyografie (EMG) bilateraal spieractiviteit geregistreerd van de erector spinae (ES) ter hoogte van processus spinosus L3, T9 en T3, alsmede bilateraal van de $\mathrm{m}$. latissimus dorsi (LD), $m$. trapezius pars ascendens (TPA), m. pectoralis major pars sternocostalis (PM), m. serratus anterior (SA), en de mm. obliqui abdominis (OA). De activiteit van deze spieren werd m.n. beoordeeld in situaties waarin het handhaven van zitbalans moeilijk was, i.e. in de verre reikpositie tijdens de taak. De veronderstelling was dat mensen met een thoracale dwarslaesie het gemis aan ES activiteit zouden proberen te compenseren door gebruik te maken van niet-posturalle spieren zoals de LD en TPA. Zowel de LD als de TPA lijken een mechanisch relatief gunstige ligging te hebben ten opzichte van de wervelkolom, te vergelijken met tuidraden. Daarbij worden beide spieren geïnnerveerd vanuit niveaus die craniaal van het thoracale (letsel-)niveau liggen. Een dergelijke posturale functie van de LD en de TPA werd slechts mogelijk geacht indlien de schoudergordel gestabiliseerd/gefixeerd zou worden door ondermeer de PM en SA. Met behulp van de EMG registraties kon een indruk verkregen worden ten aanzien van de (rest-) capaciteit van de ES voor houdingshandhaving tijdens taakuitvoering, alsmede over verhoogd spiergebruik van de overige spieren bij herstel van de zithouding. Alternatief posturaal spiergebruik bij mensen met een thoracale dwarslaesie zou hieruit kunnen afgeleid worden.

Om uitsluitsel te kunnen geven over de oorzaak van enkele specifieke verschillen in CP resultaten tussen mensen met en zonder een dwarslaesie is de anteroposterieure kanteling van het bekken en de positieverandering van de lumbale en laag thoracale wervelkolom tijdens het witvoeren van een bimanuele reiktaak gemeten. Hierbij is gebruik gemaakt van een 3D bewegingsanalyse-systeem met 4 infra-rood camera's. Dit aparte deelonderzoek is in eerste instantie uitgewoerd bij mensen zonder een dwarslaesie.

In de derde, longitudinale fase (Hoofdstuk 4 en 6 ) is onderzoek verricht naar de ontwikkeling van alternatief posturaal spiergebruik bij patiënten gedurende hun actieve klinische revalidatie periode. Hiertoe zijn 5 patiënten met een gediagnostiseerde complete hoog thoracale dwarslaesie en 7 patiènten met een complete laag thoracale dwarslaesie gedurende hun verblijf in het revalidatiecentrum onderzocht op hun vermogen tot het handhaven van zithouding tijdens taakuitwoering. Dit is gebeurd op een aantal vooraf bepaalde tijdstippen gedurende hun revalidatie in een longitudinaal quasi-experimenteel design. Op ieder van deze tijdstippen is een onderzoek uitgevoerd dat identiek was aan het eerste experiment/onderzoek dat bij de deelnemers uit de transversale fase (fase 2) is uilgevoerd. Onderzocht is in welke mate herstel van functie van de ES c.q. compensatie van ES functieverlies door niet-posturale spieren zoals de LD en TPA 
optrad gedurende het revalidatieproces van mensen met een thoracale dwarslaesie. Tevens is onderzocht in welke mate alternatief posturaal spiergebruik in deze periode leidde tot verbetering in houding-en balanshandhaving in zit, uitgedrukt in het vermogen tot verplaatsing van het CP. Naast deze kinematische gegevens is onderzocht in welke mate veranderingen op het niveau van centrale motorische sturing geassocieerd met houdingshandhaving optraden gedurende het revalidatieproces. Hiervoor zijn reactietijdgegevens geregistreerd, analoog aan het onderzoek in de transversale onderzoeksfase. De assumptie was dat gedurende het revalidatieproces nieuwe (alternatieve) en goed gecoördineerde patronen van houdingshandhaving zouden ontstaan bij thoracale dwarslaesiepatiënten. De verwachting was dat re-automatisering van posturale controle gedurende de revalidatieperiode zou leiden tot verkorting van de reactietijd tijdens taakuitvoering in zit bij patiënten.

\section{Resultaten en discussie}

\section{Transversale onderzoeksfase}

De data van de experimenten in fase 2 daten zien dat het bereik waarin mensen met een thoracale dwarslaesie hun $\mathrm{CP}$ kunnen verplaatsen, zowel in dynamische als semi-statische condities, aanzienlijk kleiner is t.o.v. personen zonder dwarslaesie. Ook is gebleken dat de maximale $C P$ verplaatsing bij personen uit de H-groep gemiddeld kleiner was dan bij personen uit de L-groep. Deze verschillen konden niet toegeschreven worden aan anthropometrische verschillen tussen groepen daar groepen gematched waren voor geslacht, lengte en gewicht. De verschillen in maximale $\mathrm{CP}$ verplaatsingen zijn een indicatie dat het posturale functieverlies van onder andere de ES bij mensen met een dwarslaesie niet geheel gecompenseerd kon worden door spieren die wel nog onder cerebrale controle stonden. De typische achterwaartse verplaatsing van het $\mathrm{CP}$ aan het begin van een voorwaartse reikbeweging die werd waargenomen bij de deelnemers zonder een dwarslaesie, was geringer bij mensen met een dwarslaesie. Deze vermindering was proportioneel met de (spier-) functie-uitval. Op basis van $3 \mathrm{D}$ registraties van de verandering van de positie van het bekken en de thoracolumbale wervelkolom kon worden uitgesloten dat deze initiële posterieure verplaatsing van het $\mathrm{CP}$ een gevolg was van een achterwaartse verplaatsing van het massamiddelpunt van het lichaam veroorzaakt door hetzij strekking van de wervelkolom, hetzij achterwaartse kanteling van het bekken. Verdere analyse van de horizontale krachtcomponenten, geregistreerd met behulp van het krachtenplatform, bevestigde dat de eerder genoemde initiële CP verplaatsing geassocieerd was met (krachtige) voorwatise acceleratie van de lichaamsmassa aan het begin van de reikbeweging. Blijkbaar zijn mensen met een thoracale dwarslaesie minder in staat een krachtige voorwaartse acceleratie te genereren bij gebrek aan spierkracht in de buikspieren, iliopsoas, 
rectus femoris en tensor fasciae latae waardoor ook de initiële CP verplaatsing minder was. Bovendien zullen zij, omdat ze ook minder in staat zijn een voorwaartse snelheid af te remmen met behulp van spierkracht van onder andere de ES en de heup-extensoren, minder geneigd zijn een krachtige voorwaartse bewegingsinzet te geven om zo het gevaar voor verlies van zitbalans te minimaliseren.

Ofschoon mensen zonder een dwarslaesie verder konden reiken en daardoor meer fasische spieractiviteit genereerden, kon met behulp van EMG aangetoond worden dat, bij gelijke absolute verplaatsing van het CP, voor houdingshandhaving aanzienlijk meer gebruik gemaakt werd van de LD en TPA door mensen met een thoracale dwarslaesie. De LD en TPA hebben geen posturale functie bij mensen zonder sensomotorische stoornissen. Door inzet van de LD en TPA probeerden mensen met een thoracale laesie het functieverlies van de lumbale en laag thoracale ES, zoals geverifieerd met behulp van EMG registraties, te compenseren. Tevens kon aangetoond worden dat met name mensen uit de H-groep sterker gebruik maakten van het hoog thoracale deel van de ES bij herstel van de zithouding tijdens taakuitvoering dan de deelnemers uit beide andere groepen.

Wanneer de LD en TPA een posturale functie zouden gaan vervullen, zou dit betekenen dat (1) de schouder gestabiliseerd moet worden om retractie en depressie te voorkomen bij aanspanning van deze spieren en (2) het bekken en de thoracolumbale regio gefixeerd moeten zijn. Geconstateerd werd dat personen met een dwarslaesie het bekken passief meer achterover kantelden tegen de rugleuning van de stoel naar mate de spierfunctie-uitval groter was in een poging bekken en lumbale regio te stabiliseren. Deze observatie was in overeenstemming met de CP gegevens die simultaan geregistreerd waren. Tevens werd geconstateerd dat in condities waarin de absolute CP verplaatsing voor alle groepen vergelijkbaar was en houdingshandhaving op de proef gesteld werd, personen met m.n. een hoog thoracale dwarslaesie meer gebruik maakten van de PM en de SA. Deze bevinding ondersteunt het concept van alternatief posturaal spiergebruik dat schouderstabilisatie door o.a. de protactoren van de scapulae postuleerde.

Bij mensen met een thoracale dwarslaesie werd, ondanks het laesieniveau, relatief meer spieractiviteit van de schuine buikspieren (OA) geregistreerd bij balans-herstel dan bij mensen uit de $\mathrm{N}$-groep. Twee mogelijke verklaringen kunnen hiervoor gegeven worden. Ten eerste zouden mensen met paretische OA's de nietparetische delen van deze spieren sterker ingezet kunnen hebben in een synergie met de PM en SA en in een antagonistisch patroon met de LD-TPA-ES synergie in een poging de romp en de wervelkolom stabiliseren. Een tweede mogelijkheid zou kunnen zijn dat mechanische rek van de paralytische OA, veroorzaakt door PM en SA activiteit, spinale reflexactiviteit teweeg zou brengen, waardoor onwillekeurige OA activiteit zou gegenereerd worden. Uit het huidige onderzoek kan echter geen definitieve conclusie getrokken worden t.a.v. de oorzaak van de geconstateerde OA activiteit. 
Mensen met een lage thoracale dwarslaesie lijken complexere strategieèn te gebruiken in hun pogingen om zithouding en zitbalans te handhaven, in tegenstelling tot mensen zonder een dwarslaesie, blijkende uit tragere reactiepatronen c.q. langere RT"s. Mensen uit de H-groep reageerden sneller dan mensen uit de L-groep. Blijkbaar gebruiken zij posturale strategieën die minder complex zijn. Verdere ondersteuning hiervoor werd gevonden in de EMG en CP data, die erop duidden dat mensen met een hoge thoracale dwarslaesie een posturale strategie volgen waarbij passief steun gezocht wordt in de lumbale regio. Het alternatief posturaal spiergebruik bij de deelnemers uit de $\mathrm{H}$-groep leidde niet tot vertraagde centrale programmering zoals eerder verwacht. 'Precuing', i.e. het aanbieden van voorinformatie ten aanzien van bewegingsparameters die gespecificeerd moeten worden in het motor programma, leidde in alle groepen tot een vergelijkbare verkorting van de RT. Blijkbaar beïnvloedt precuing alleen zuiver centrale sturingsmechanismen die onafhankelijk zijn van de toestand van het perifere sensomotorische systeem. Wel bleek dat tijdens de precue condities de mate van zithoudingverandering van invloed was op de RT. Wanneer personen verder moesten reiken en dus meer zithoudingverandering zou optreden, bleken de RT"s toe te nemen. Dit gebeurde in alle groepen.

\section{Longitudinale onderzoeksfase}

De resultaten van de longitudinale, klinische studie laten zien dat de mate waarin patiënten met een lage thoracale laesie in staat waren hun zithouding te veranderen toenam. Het bereik waarin het $\mathrm{CP}$ gevarieerd kon worden, nam geleidelijk aan toe gedurende het revalidatieproces. Bij patiènten met een hoge dwarslaesie nam aanwankelijk het CP-bereik af, nadat het thoracale korset, dat zij droegen ter stabilisering van de wervelkolom, verwijderd was. Gedurende de verdere revalidatieperiode nam het CP-bereik toe tot een niveau dat gelijk was aan het beginniveau toen de patiënt nog een korset droeg. Een dergelijk gevolg van het verwijderen van het korset op het vermogen tot handhaving van zitbalans was niet aanwezig bij patiënten met een lage thoracale dwarslaesie.

Gedurende het revalidatieproces werd enig functieherstel in de lumbale en laag-thoracale ES waargenomen in patienten met een lage thoracale laesie. Een mogelijke oorzaak hiervoor zou o.a. kunnen zijn (a) vermindering van de spinale pathologie als gevolg van b.v. oedeem-resorptie rond het laesie-niveau of (b) hypertrofie van de polysegmentale spiervezels van de ES die geïnnerveerd worden vanuit ruggemergsegmenten craniaal van de laesie. Patiënten met een hoge thoracale laesie bleken al vanaf een maand na verwijdering van het korset meer gebruik te maken van het hoog-thoracale deel van de ES bij het handhaven en herstellen van zithouding tijdens bimanuele taakuitvoering, in tegenstelling tot patiënten met een lage thoracale laesie. Dit verschil tussen beide groepen bleef bestaan gedurende de rest van de revalidatieperiode. 
Een effect dat duidelijk aangetoond kon worden in deze studie was de ontwikkeling c.q. toename van LD en TPA activiteit bij houdingshandhaving bij patiènten met een hoge thoracale laesie gedurende hun verblijf in het revalidatiecentrum. Bij patiénten met een lage laesie nam de activiteit van de TPA toe gedurende het revalidatieproces tot enkele weken voor de ontslag datum, waarna deze activiteit enigszins verminderde. De SA werd door de deelnemers uit beide groepen meer ingezet bij het herstel wan de zithouding naar mate deze verder verstoord was. Deze reactie veranderde niet verder gedurende het revalidatieproces. De OA bleken in beide patièntengroepen marginaal actief te blijven. Het gebruik van de PM veranderde bij mensen met een lage thoracale dwarslaesie niet, in tegenstelling tot patiënten met een hoge dwarslaesie die meer gebruik gingen maken van deze spier tijdens handhaving van zithouding. Echter een inverse relatie tussen reikafstand en PM gebruik ontwikkelde zich tegen het einde van het revalidatieproces bij de laatstgenoemde groep. Een mogelijke verklaring zou kunnen zijn dat patiënten met een hoge thoracale dwarslaesie hun zithouding proberen te stabiliseren door adductie van de humerus tegen de borstkas. Deze strategie is echter alleen mogelijk bij korte reikafstanden, wanneer de humerus parallel aan de borstkas gehouden kan worden. Verder ondlerzoek ter verheldering van dit fenomeen is echter noodzakelijk.

Met betrekking tot centrale programmering bleek dat voor beide groepen de snelheid waarmee houding- en balanswerstorende bewegingen geprogrammeerd konden worden, verbeterde gedurende het revalidatieproces. Dit bleek een geleidelijk proces te zijn. Zowel de reactietijden in het algemeen als de verschillen in reactietijden tussen condities waarin zithouding meer c.q. minder verstoord werd, namen af. De reactietijdverschillen tussen beide groepen in de longitudinale onderzoeksfase waren vergelijkbaar met de reactietijdresultaten uit fase 2 . Patiënten met een hoge laesie reageerden sneller dan patiënten met een lage laesie. Ook deze verschillen varieerden niet als functie wan revalidatietijd. Ofschoon "precuing' leidde tot lagere reactietijden in beide patiëntengroepen, veranderden deze effecten van 'precue' niet gedurende het revalidatie-proces.

\section{Algemene conclusies}

Met dit onderzoek is ondersteuning gevonden voor de ontwikkeling van alternatief posturaal spiergebruik bij mensen met een thoracale dwarslaesie. Aangetoond kon worden dat primair de LD en TPA gebruikt worden om het verlies aan ES functie gedeeltelijk te compenseren. Voorts is duidelijk gevonden dat de PM en SA ingezet worden ter stabilisering van de schoudergordel als voorwaarde voor de posturale functie van de LD en TPA. Ook werd enig functieherstel van de ES enigszins caudaal van de dwarslaesie-locatie waargenomen. Forse beperkingen in het vermogen tot houdingshandhaving tijdens bimanuele taakuitvoering bleven 
echter bestaan bij mensen met een thoracale dwarslaesie. Het bestaan van verschillen in strategieën voor houdingshandhaving tijdens bimanuele taakuitwoering in zit tussen zowel mensen met en zonder een dwarslaesie als ook tussen mensen met een thoracale dwarslaesie op verschillende niveaus werd bevestigd.

Het huidige onderzoek heeft een basis gelegd voor de evaluatie van bewegingscoördinatie, (a) door het ontwikkelen van instrumenten en methoden waarmee bewegingssturing geobjectiveerd kan worden, (b) door aan te tonen dat toepassing van een dergelijk instrumentarium in de revalidatiepraktijk mogelijk is in zowel transversale als longitudinale, klinische studies en (c) door een kwalitatief model voor alternatief spiergebruik te formuleren en experimenteel te toetsen. 


\section{List of abbreviations}


ADL activities of daily living

Ag silver

AgCl silver chloride

ANOVA analysis of variance

APA anticipatory postural adjustments

ASIA American Spinal Injury Association

ASIS anterior superior iliac spine

A/D analog to digital

C.. cervical

CB central button

$\mathrm{CG} \quad$ centre of gravity

$\mathrm{CG}_{\mathrm{pr}} \quad$ projection of the centre of gravity

$\mathrm{CI}_{99} \quad 99 \%$ confidence interval of the mean

CM centre of mass

CMRR common mode rejection ratio

$\mathrm{CP} \quad$ centre of pressure

DF degrees of freedom

DMA direct memory access

edn edition

ed(s) editor(s)

EMG electromyography

ES erector spinae

F female

FIM functional independence measure

FNy normalised anteroposterior directed force

GT greater trochanter

HCUP-3 Healthcare Cost and Utilization Project

$\mathrm{Hz} \quad$ hertz

H-group high spinal cord injured group

ICC intraclass correlation coefficient

ICE Institute for Consumer Ergonomics

ISCSC1-92 International Standards for Neurological and Functional Classification of Spinal Cord Injury (revised in 1992)

ISt imperative stimulus

ITI inter-trial interval

$\mathrm{KHz} \quad$ kilo hertz

L.. lumbar

LD latissimus dorsi

LFE lateral femoral epicondyle

L-group low spinal cord injured group

M male

m. muscle / musculus 
MANCOVA multivariate analysis of co-variance

MANOVA multivariate analysis of variance

MRC Medical Research Council

MS mean square

MT movement time

MVC maximum voluntary contraction

$\mathrm{M} \Omega$ mega ohm

$\mathrm{N} \quad$ newton

n number

n. nerve/ nervus

$\mathrm{N}$-group non-spinal cord injured group

$\mathrm{OA}$ obliquus abdominis

PB peripheral button

PM pectoralis major

pp pages

PSIS posterior superior iliac spine

$\mathrm{R} \quad$ response

RMS root mean square

RT reaction time

$\mathrm{S} \quad$ stimulus

S.. sacral

SA serratus anterior

SAS sitting assessment scale

SB start button

SC spinal cord

SCI spinal cord injury

sd standard deviation

SS sum of squares

T.. thoracic

T time

1 time

TB target button

TPA ascending part of the trapezius

UVc unit vector

Vcp velocity of centre of pressure displacement

VGA video graphics adapter

WS warning signal

$\delta \mathrm{RT}_{\mathrm{fn}} \quad$ reaction time difference between "near" and "far" conditions

$\mu \mathrm{V} \quad$ micro volt

$\Sigma \mathrm{F} \quad$ summation of forces

$\Sigma \mathrm{M}$ summation of torques

3D three dimensional 


\section{Dankwoord}


Ik zou graag iedereen die aan de totstandkoming van dit proefschrift heeft meegewerkt willen bedanken. Een bijzonder woord van dank wil ik richten aan mijn beide promotores, Prof. dr. A. Huson en Prof. dr. F. Spaans, alsmede aan Prof. dr. J. Drukker voor de bijzondere wijze waarop zij de uitvoering van het onderzoek gestimuleerd hebben, voor hun inhoudelijke suggesties tijdens de vele projectbesprekingen en hun kritische beoordeling van het manuscript.

Dr. Jos Adam wil ik bedanken voor de talloze, voor mij verhelderende, discussies ten aanzien van motor control paradigma's, de gerichte commentaren en de vele suggesties voor relevante literatuur, die mede de basis gevormd hebben van het onderzoek.

Dr. Jos Reulen ben ik dlankbaar voor de snelle en adequate beoordelingen van de talloze (concept)versies van dit proefschrift en de artikelen. Van zijn suggesties voor heldere en beknopte representatie van de soms toch forse hoeveelheden data heb ik overvloedig gebruik kunnen maken.

Voor de samenwerking en hulp bij de vele klinische aspecten van het onderzoek wil ik drs. C. Pons bedanken. Zijn niet aflatende inzet en zijn enthousiasme voor het onderzoek vormden een grote bijdrage in het succes van deze studie.

Yvonne Potten wil ik heel speciaal bedanken voor alle hulp bij de opzet en uitvoering van het onderzoek en de vele inhoudelijke discussies die we gevoerd hebben. Jouw heldere en nuchtere opmerkingen bij de besprekingen van de resultaten, de snelle en adequate commentaren tijdens het schrijven van artikelen en jouw niet aflatende werklust zijn essentieel geweest voor het slagen van het onderzoek. Je was altijd weer bereid je eigen werk stil te leggen wanneer ik je weer eens onderbrak om je mening te vragen ten aanzien van een acuut probleem. Naast alle serieuze werkzaamheden heb je ook altijd kans gezien een vrolijke dimensie in het werk te brengen. Yvonne, nogmaals bedankt!

Met groot respect en dankbaarheid kijk ik terug op de bijdrage van de deelnemers aan het onderzoek die zonder uitzondering bereid waren de ongemakken die aan de deelneming verbonden waren op zich te nemen. Mijn waardering is groot voor het geduld en cle bereidwilligheid van de klinisch residente dwarslaesie-patiënten die herhaalde malen onderzocht zijn gedurende hun verblijf in het revalidatiecentrum.

Ben Noorloos wil ik bedanken voor zijn hulp bij het oplossen van (meestal zeer acute) electronica-problemen tijdens de diverse experimenten.

Alle stagiaires die geholpen hebben bij de pilot-studies die vooraf gingen aan het onderzoek ben ik zeer erkentelijk voor hun bijdrage.

Tenslotte wil ik de collega's binnen het thema "Effectiviteit van revalidatieprocessen" van het Instituut voor Revalidatievraagstukken bedanken voor de prettige samenwerking. 
About the author 
The author was born on New Year's Eve of 1959 in Heerlen as the youngest of five children. After he passed the final exam at the St. Bernardinuscollege (Atheneum B) al the age of 18 , he started his study at the Limburgse Opleiding voor Fysiotherapie. In those years of becoming a physical therapist he often posed the question: 'Why?'. Not always satisfied with the received answer, he started his study at the University Maastricht, Faculty of Health Sciences, after graduating as a physical therapist in 1984. Together with fellow students he was the first to be specialised in Movement Sciences. Being one of the pioneers he was a member of the group involved in planning the curriculum. After graduation in 1988, he started his scientific career at the Institute for Rehabilitation Research (iRv) where he worked as a research associate until 1990. In 1990 he became projectleader and for the next seven years he was involved in several research projects concerning impairments of the musculo-skeletal system and neurological disorders. For the purpose of this research he set up a movement lab focused on surface electromyography, posturography, three dimensional movement analysis and task performance. Since then, colleagues knew where to find him for his technical and computer knowledge! Besides being a great help to others, he is also a great support. He supervised many students and rehabilitation physician trainees during their first steps of research, with a catching enthusiasm for patient related topics. It is that same enthusiasm that made him start the experiments in 1993, that provided the basis for this thesis. With these experiments he proved the applicability of the developed instruments and techniques, for the assessment of compensation of sensorimotor loss in spinal cord injured people, in clinical practice and verified a theory-based concept of alternative postural muscle use in these people. The author is an advocate of theory-based neurorehabilitation which requires insight in basic mechanisms. It is his opinion that from this insight, models may be developed to predict rehabilitation outcome and to guide efforts to evaluate and improve therapy. At the moment the author is a member of the senior staff at the iRv and will continue his work in the field of reorganisation and co-ordination of movement, therapy evaluation and modelling.

A 'paranimf'. 